\author{
Universidade DE SÃo PAUlo \\ Faculdade de Filosofia, Ciências e Letras de Ribeirão Preto \\ Programa de Pós-Graduação em Psicobiologia
}

\title{
Influência do enriquecimento ambiental físico na ocupação de espaços por gatos domésticos (Felis silvestris catus) mantidos em cativeiro
}

\section{Stella da Fonseca}

Dissertação apresentada ao Programa de Pós-Graduação em Psicobiologia da Faculdade de Filosofia, Ciências e Letras de Ribeirão Preto da Universidade de São Paulo como parte das exigências para a obtenção do título de Mestre em Ciências, Área: Psicobiologia.

Orientador: Prof. Dr. Gelson Genaro 
AUTORIZO A REPRODUÇÃO TOTAL OU PARCIAL DESTE DOCUMENTO, POR MEIO CONVENCIONAL OU ELETRÔNICO PARA FINS DE ESTUDO E PESQUISA, DESDE QUE CITADA A FONTE.

\section{Fonseca, S.}

Influência do enriquecimento ambiental físico na ocupação de espaços por gatos domésticos (Felis silvestris catus) mantidos em cativeiro/ Stella da Fonseca; orientador Prof. Dr. Gelson Genaro.

- Riberão Preto/SP, 2013.

$80 \mathrm{f}$.

Dissertação (Mestrado - Programa de Pós-Graduação em Psicobiologia) - Faculdade de Filosofia, Ciências e Letras de Ribeirão Preto da Universidade de São Paulo.

Palavras Chaves: ocupação de espaços, bem-estar, enriquecimento ambiental, abrigos, gatos domésticos. 
Fonseca, S. Influência do enriquecimento ambiental físico na ocupação de espaços por gatos domésticos (Felis silvestris catus) mantidos em cativeiro. Dissertação apresentada à Faculdade de Filosofia, Ciências e Letras de Ribeirão Preto da Universidade de São Paulo para a obtenção do título de Mestre em Ciências, Área: Psicobiologia.

Aprovado em:

\section{Banca examinadora}

Prof. Dr.

Instituição: Assinatura:

Prof. Dr.

Instituição: Assinatura:

Prof. Dr

Instituição: Assinatura: 

À toda minha família, pelo amor e incentivo em mais essa fase da minha vida e à todos os animais, em especial, aos que fizeram parte desse estudo, por transmitirem diariamente a alegria e a paz, essenciais, para a conclusão desse trabalho. 



\section{Agradecimentos}

À Deus, por toda a proteção e sabedoria, ao longo de mais essa fase da minha vida.

À minha família, por todo o apoio, compreensão e amor, fundamentais para a conclusão de mais essa etapa.

Ao Thiago Raymundo Rosa, meu amor, meu porto-seguro, por estar sempre ao meu lado, me aconselhando e me dando forças em todos os momentos.

Ao meu orientador, Prof. Dr. Gelson Genaro, por toda confiança e incentivo depositados em mim e no meu trabalho, por todos os exemplos e ensinamentos, que vão além da vida acadêmica e que com certeza, levarei comigo para sempre.

À Prof ${ }^{\mathrm{a}}$. Mildre Loraine Pinto, por todo carinho e prontidão nos cuidados com os animais e pelas palavras sábias ditas sempre no momento certo.

Ao Sr. José Artur Berti e a Sra. Maria Imaculada Cárnio Berti, por permitirem o desenvolvimento desse trabalho, e aos funcionários Odamir, Alcides, Orozimbo e Conceição, por toda ajuda, amizade e respeito, ao longo dessa jornada.

Às queridas "Gatilzetes": Juliana Damasceno, Adriana Sicuto de Oliveira e Carolina Mazzei Kroll, por compartilharem comigo os momentos de alegria e me confortarem em meio às preocupações. E à "nova geração do gatil" Carolina Albuquerque e Inajara Fiusa, por todo carinho, empenho e dedicação demonstrados para comigo e com os animais.

Ao Prof. Dr. César Augusto Sangaletti Terçariol, pela grandiosa colaboração nas análises estatísticas desse trabalho.

À Renata Vicentini Del Moro, por toda orientação e auxílio prestados frente aos assuntos da pós-graduação.

À CAPES/PROEX pelo apoio financeiro durante a realização deste trabalho. 

"Quando o homem aprender a respeitar até o menor ser da criação, seja animal ou vegetal, ninguém precisará ensiná-lo a amar seu semelhante."

(Albert Schweitzer) 



\section{Resumo}

O estudo da ocupação do espaço, bem como o modo de utilização dos itens de enriquecimento ambiental são ferramentas fundamentais para medir a adequação do ambiente e dos níveis de bem-estar de gatos domésticos (Felis silvestris catus) mantidos em cativeiro. Este trabalho teve como objetivo avaliar o padrão de ocupação dos animais no recinto, antes do enriquecimento, na condição Controle e após a introdução de itens de enriquecimento ambientais físicos: Permanente de uso Coletivo, Temporário de uso Coletivo e Temporário de uso Restrito, que atuaram subdividindo as áreas do ambiente e renovando os locais já conhecidos pelos animais. Foram utilizados 31 gatos domésticos, que passaram pelos testes comportamentais, registrando-se, por meio de filmagens, ao longo dos 10 dias de observações/por teste: o local de ocupação (área de piso ou elevada) e os comportamentos realizados pelos animais. Os resultados mostraram que o padrão de ocupação dos animais no recinto se deu com uma maior utilização das áreas elevadas em relação às áreas de piso, tanto na condição Controle, como após a introdução dos itens de enriquecimento ambiental. Dentre os itens utilizados, e suas diferentes formas de aplicação, houve uma maior frequência de interação por parte dos indivíduos com o item temporário de uso coletivo, que atuou como barreira visual, promovendo a subdivisão das áreas do recinto e uma ocupação mais homogênea dos animais no espaço disponível. O tempo de permanência dos animais na área interna ao item temporário de uso restrito, foi significativamente maior em relação à permanência dos mesmos na área externa ao item, que além de enriquecer o ambiente, foi utilizado como refúgio pelos indivíduos. Os dados também revelaram que a colônia estudada possui uma organização social para a interação, bem como para a realização de compartilhamentos dos itens de enriquecimento com os outros animais. Concluímos que por meio de observações da ocupação do espaço, assim como, através do modo de utilização dos itens de enriquecimento ambiental pelos indivíduos, podemos acessar informações sobre as preferências e as necessidades biológicas dos animais, adequando o seu habitat e aumentando os níveis de bem-estar da espécie em questão.

Palavras Chaves: ocupação de espaços, bem-estar, enriquecimento ambiental, abrigos, gatos domésticos. 



\section{Abstract}

The study of space occupation, as well as how to use the items of environmental enrichment are fundamental tools to measure the suitability of the environment and the level of welfare of domestic cats (Felis silvestris catus) kept in captivity. This study aimed to evaluate the pattern of occupation of the animals in the enclosure, before enrichment, in control condition and after the introduction of physical environmental enrichment items: Permanent Collective use, Temporary Collective use and Temporary Restricted use who acted subdividing areas environment and renewing the places already known by the animals. We used 31 domestic cats, which passed by behavioral tests, registering through filming, over the 10 days of observations / per test: the place of occupation (floor or elevated areas) and behaviors performed by animals. The results showed that the pattern of occupation of the animals in the enclosure occurred with greater use of elevated areas in relation to floor areas, both in the control condition, and after the introduction of environmental enrichment items. Among the items used, and different forms of application, there was a higher frequency of interaction by individuals with temporary collective use item, which acted as a visual barrier, promoting the breakdown of the areas of the enclosure and a more homogeneous occupation of animals the available space. The time spent in the inner area of the animals to temporary restricted use item, was significantly higher in relation to the permanence in the outdoor area of the same item, which besides enriching the environment, was used as a refuge by individuals. The data also show that colony has a social interaction, as well as to perform the enrichment items shares with the other animals. We conclude that through observations of space occupation, as well as, through the mode of use of environmental enrichment items by individuals can access information about the preferences and biological needs of the animals, adapting their habitat and increasing levels of welfare the species in question.

Keywords: space occupation, welfare, environmental enrichment, shelters, domestic cats. 



\section{Sumário}

1 Introdução $\quad$ p. 17

1.1 Bem-Estar de animais confinados . . . . . . . . . . . p. 17

1.2 Uso do espaço e Comportamento Exploratório . . . . . . . . . . . . p. 20

1.3 Enriquecimento Ambiental . . . . . . . . . . . . . . . p. 23

1.4 O gato doméstico como modelo experimental . . . . . . . . . . p. 25

2 Objetivos $\quad$ p. 27

2.1 Objetivos gerais . . . . . . . . . . . . p. 27

2.2 Objetivos específicos . . . . . . . . . . . . p. 27

3 Material e Métodos $\quad$ p. 29

3.1 Animais . . . . . . . . . . . . . . . . . . . . p. 29

3.2 Local de Estudo . . . . . . . . . . . . . . . . . . . . p. 30

3.3 Manutenção dos animais . . . . . . . . . . . . . . . . . p. 32

3.4 Registros dos comportamentos . . . . . . . . . . . . . p. 32

3.5 Testes Comportamentais . . . . . . . . . . . . . p. 33

3.5.1 Condição Controle . . . . . . . . . . . . . . . p. 33

3.5.2 Teste I - Enriquecimento Ambiental Físico Permanente de uso Coletivo . . . . . . . . . . . . . . . . . p. 33

3.5.3 Teste II - Enriquecimento Ambiental Físico Temporário de uso Coletivo ........................... p. 34

3.5.4 Teste III - Enriquecimento Ambiental Físico Temporário de uso Restrito . . . . . . . . . . . . . . p. 35 
3.6 Análises Estatísticas . . . . . . . . . . . . . . p. 36

4 Resultados $\quad$ p. 37

4.1 Condição Controle . . . . . . . . . . . . . . . . . . . . . . . p. 37

4.2 Condição Controle $\times$ Enriquecimento Ambiental Físico Permanente de uso Coletivo . . . . . . . . . . . . . . . . . . . . p. 38

4.3 Condição Controle $\times$ Enriquecimento Ambiental Temporário de uso Coletivo . . . . . . . . . . . . . . . . . . . p. 45

4.4 Condição Controle $\times$ Enriquecimento Ambiental Temporário de uso Res-

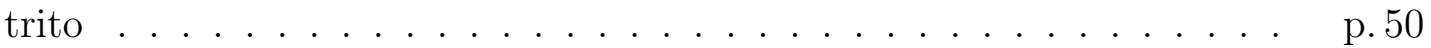

5 Discussão $\quad$ p. 59

6 Conclusão $\quad$ p. 69

$\begin{array}{ll}\text { Referências } & \text { p. } 71\end{array}$ 


\section{Introdução}

\subsection{Bem-Estar de animais confinados}

O conceito de Bem-Estar Animal envolve uma ampla análise de contextos, sobre as questões do universo que envolve os animais, de modo geral, pode ser definido como o estado de um animal durante suas tentativas de se ajustar ao meio ambiente em que está inserido [1]. Sendo uma característica mensurável dos indivíduos, no que diz respeito a sua capacidade de lidar com o próprio ambiente e não algo oferecido a ele [2].

Em vida-livre os animais são expostos a um ambiente, em constante mudança, onde exigências físicas e cognitivas são continuamente impostas, como: encontrar e obter alimentação, defender o território de outros animais e/ou co-específicos, socializar, acasalar, entre outros estímulos. No entanto o contraste com o ambiente de cativeiro e seu espaço restrito, a falta de complexidade e rotinas de manejo, torna o ambiente previsível e sem opções para que haja o controle das variáveis fundamentais para o seu conforto e elevação nos níveis de bem-estar [3, 4].

Diversos agentes estressores, como: as relações individuais dentro do grupo, a estabilidade social, o espaço disponível, a densidade populacional e as interações com humanos, podem afetar o bem-estar de felinos confinados em grupo [5], além de culminar em distúrbios comportamentais graves, como a inatividade, redução na alimentação e aumento de encontros aversivos entre os indivíduos do grupo [6].

Tais condições provenientes do ambiente cativo, e a ausência de estímulos apropriados, podem afetar os padrões normais de comportamento [7]. Em cativeiro, os animais não apresentam a motivação e a oportunidade de exibir alguns comportamentos considerados normais da espécie $[8,9,4]$. Por conta dessas condições, muitos indivíduos acabam desenvolvendo comportamentos estereotipados como manifestação do estresse em cativeiro [10], sendo comportamentos que diferem na forma, na frequência, e no contexto daqueles apresentados pela maioria dos membros de uma espécie em vida livre [11]. Den- 
tre esses comportamentos, estão: coprofagia, letargia, hiperagressividade, automutilação, entre outros $[12,7]$.

Segundo Rochlitz (1999) [13], gatos domésticos (Felis silvestris catus) respondem a baixa condição de bem-estar com a inibição de grande parte dos seus comportamentos normais e essenciais à sua manutenção, ao invés de apresentarem comportamentos anormais, o que também é verdadeiro para indivíduos com algum processo patológico. Portanto, mantê-los em ambientes enriquecidos irá facilitar a percepção de problemas de saúde [14], além de favorecer a adequada manutenção desses animais, utilizados muitas vezes como modelo de estudo, seja para análises comportamentais, fisiológicas, ou outras quaisquer.

Especificamente, para os gatos utilizados em experimentos, a qualidade da criação e da manutenção tem um grande impacto sobre a saúde desses animais. Onde o bem-estar e a qualidade de vida [15], estão relacionados com a amplitude do repertório comportamental que são permitidos aos indivíduos executarem, o que requer o conhecimento desses comportamentos e das necessidades espécie-específicas [16]. Um ambiente que não atenda as necessidades dos animais, pode ser muito estressante, especialmente para os gatos. Este estresse pode causar mudanças na fisiologia, na sua capacidade de se adaptar ao seu ambiente, além de alterações no comportamento [17]. Assim, um animal em alto nível de estresse, e privado de condições satisfatórias de manutenção e bem-estar, pode não ser um modelo adequado para estudos e pesquisas, já que estas condições de manutenção podem proporcionar resultados duvidosos.

Outro fator crítico para a manutenção de animais em cativeiro, de acordo com as recomendações da revista Animal Behaviour (2002) [18], é o espaço físico disponível nos recintos, que deve ser grande o suficiente, permitindo aos animais, a realização de comportamentos típicos da espécie, como: os atos de explorar, brincar, e esconder-se. A qualidade do recinto onde o animal está sendo mantido e que muitas vezes passa a ser mais importante que seu tamanho, também deve ser considerada [19].

Broom e Fraser (2007) [2] afirmam que gatos confinados por um longo período de tempo precisam de um ambiente complexo, que satisfaça a maioria das necessidades do animal, como a capacidade de interagir socialmente com outros parceiros do grupo e que possam explorar o ambiente.

A exploração do espaço vertical é de extrema importância para os felinos, portanto é necessário que exista, nos recintos, locais elevados como mesas, prateleiras proporcionando locais para esconderijos, promovendo efeito positivo sobre o nível de agressão, diminuindo interações aversivas, etc. [20]. Subdivisões das áreas do recinto, bem como a verticalização 
do espaço, são opções que potencializam a complexidade das áreas disponibilizadas aos animais [21](Fig. 1).

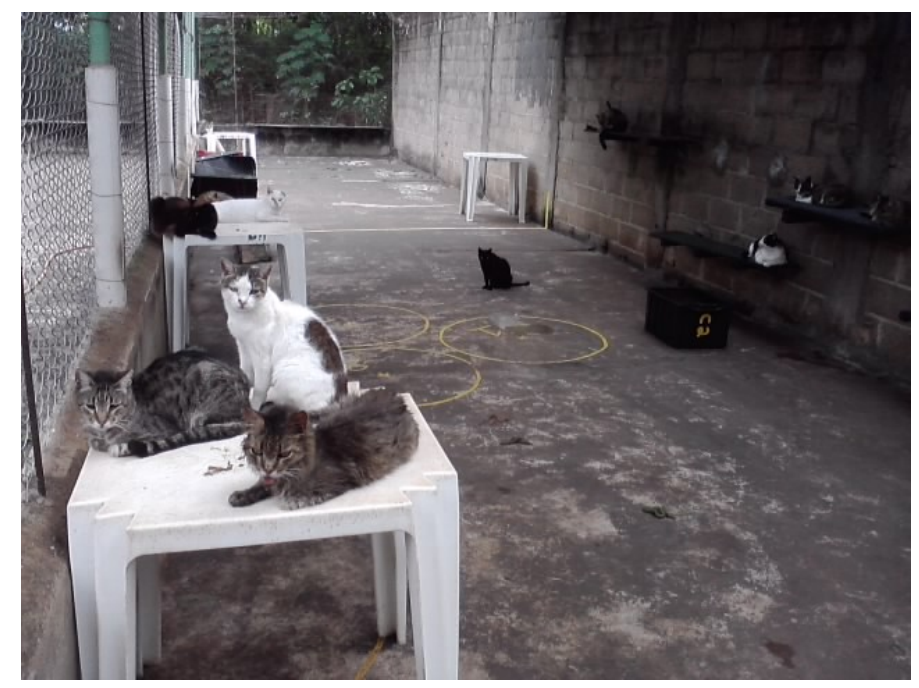

Figura 1: Animais ocupando as áreas elevadas do recinto, representadas por mesas plásticas e plataformas de madeira.

Além do espaço ideal, o cuidado por parte dos funcionários, e tratadores, são fatores essenciais para o bem-estar dos animais em qualquer condição de manutenção [22]. E, por fim, a saúde e o bem-estar animal devem ser os principais objetivos de instituições que mantenham animais em cativeiro.

Para garantir um estado ótimo de saúde para estes animais é necessário esclarecer os impactos biológicos e psicológicos causados pelo ambiente de confinamento, assim como oferecer requisitos básicos que garantam o mínimo de segurança e conforto para os mesmos [23]. Alguns estudos vêm destacando as condições necessárias para o alojamento de gatos em situações de ambientes restritos [24, 25, 26, 27], englobando aspectos como: estrutura física do alojamento, relações sociais entre membros da mesma espécie, e com os seres humanos (tratadores, bioteristas, veterinários, biólogos, zootecnistas, proprietários, cuidadores, etc.).

Outro requisito fundamental para a garantia e manutenção do bem-estar dos animais de cativeiro, é a estimulação de comportamentos naturais, apresentados em vida livre como: atividades locomotoras e sensoriais [28]. Quanto mais pobre o ambiente, com impossibilidade de exploração e fuga, ausência de esconderijos e de itens que estimulem a atividade, maior será o desenvolvimento de estereotipias e/ou inatividade destes animais [29]. Por outro lado, a presença de um ambiente complexo resultará em um elevado desempenho exploratório [30] afastando todas as condições patológicas anteriormente citadas. 
Neste sentido é imprescindível a execução de manobras que criem situações inovadoras que estimulem a exploração e a cognição dos indivíduos. O enriquecimento ambiental vem se destacando como uma técnica efetiva em prover estímulos de caráter inovador e dinâmico, com a finalidade de aumentar os comportamentos, como por exemplo, o comportamento exploratório [31].

\subsection{Uso do espaço e Comportamento Exploratório}

Animais em confinamento sofrem restrições comportamentais devido às limitações na circulação e no uso de espaço dos recintos, cujas: variações no tamanho do grupo, características estruturais do ambiente, alta densidade da população, e outros fatores sociais podem também exacerbar esses efeitos [5].

Apesar das importantes conseqüências que a disponibilidade de espaço tem sobre o comportamento e bem-estar dos animais em cativeiro, existe um número limitado de estudos relatando a análise espacial em espécies domesticadas [32, 33, 34].

Sabe-se que a utilização do espaço em animais confinados é afetada não só pelo tamanho do recinto, mas também pelas características estruturais do ambiente [34]. Por exemplo, a presença de obstáculos, tais como as paredes de um recinto, pode ter grande impacto na forma como os animais se movem dentro de um espaço fechado [35]. Tamanho de grupo e densidade de animais também podem ter efeitos relevantes. Quando a densidade de animais está aumentada, estes tendem a movimentar-se menos, o que resulta na diminuição da utilização do espaço [33].

A restrição do espaço em confinamento, que atinge animais de laboratório, de zoológicos, de programas de conservação, e até mesmo os animais de companhia, pode desencadear estresse, redução da qualidade de vida [36] e do repertório comportamental desses indivíduos [37]. Observar o comportamento de um animal em confinamento pode resultar em dados enviesados se as necessidades do mesmo não estiverem supridas.

O entendimento do uso do espaço pelos animais, em cativeiro, permitirá desenvolver instalações que melhor se ajustem às suas necessidades biológicas, maximizando assim, o bem-estar da espécie em questão [38].

Benson (2006) [39] e Leone et al. (2007) [40] afirmam que a regulação do uso do espaço pode refletir interações intraespecíficas e organização social.

Em estudos com bovinos, a redução do espaço no recinto, acarretou em uma queda no 
tempo de descanso e aumentou a quantidade de interações agressivas entre os animais [41, 42]. Resultados semelhantes foram encontrados em grupos sociais de ovelhas, quando há diminuição no espaço do recinto, são os indivíduos submissos que tendem a sofrer mais, apresentando uma redução no comportamento de "Descansar" [43].

Vários parâmetros são utilizados para analisar animais mantidos em isolamento ou em grupos, como: comportamento exploratório, interação social, comportamento de vigília, vocalização, dentre outros. Sendo o comportamento exploratório um dos parâmetros mais utilizados [30].

O comportamento exploratório é definido como um conjunto de padrões motores direcionados a um ambiente ou objeto desconhecido através do qual, informações sobre tais itens são obtidas [44]. Por meio deste comportamento, os animais podem se familiarizar com uma situação de novidade, aprendendo, por exemplo, onde encontrar água, alimento ou esconderijo, influenciando ainda nas suas habilidades sociais e competitivas [45].

De acordo com Boissy e colaboradores (2007) [46], a exibição do comportamento exploratório está associada a sensações positivas visto que os animais tipicamente exibem alta motivação para explorar. Compreende-se como motivação, mudanças comportamentais e fisiológicas induzidas pelo sistema neural, a fim de determinar quais ações vão ser executadas e quando [11]. Nesta perspectiva, segundo Berlyne (1966) [44], a exploração é motivada pela curiosidade e envolve a investigação de uma novidade em particular (Fig. 2).

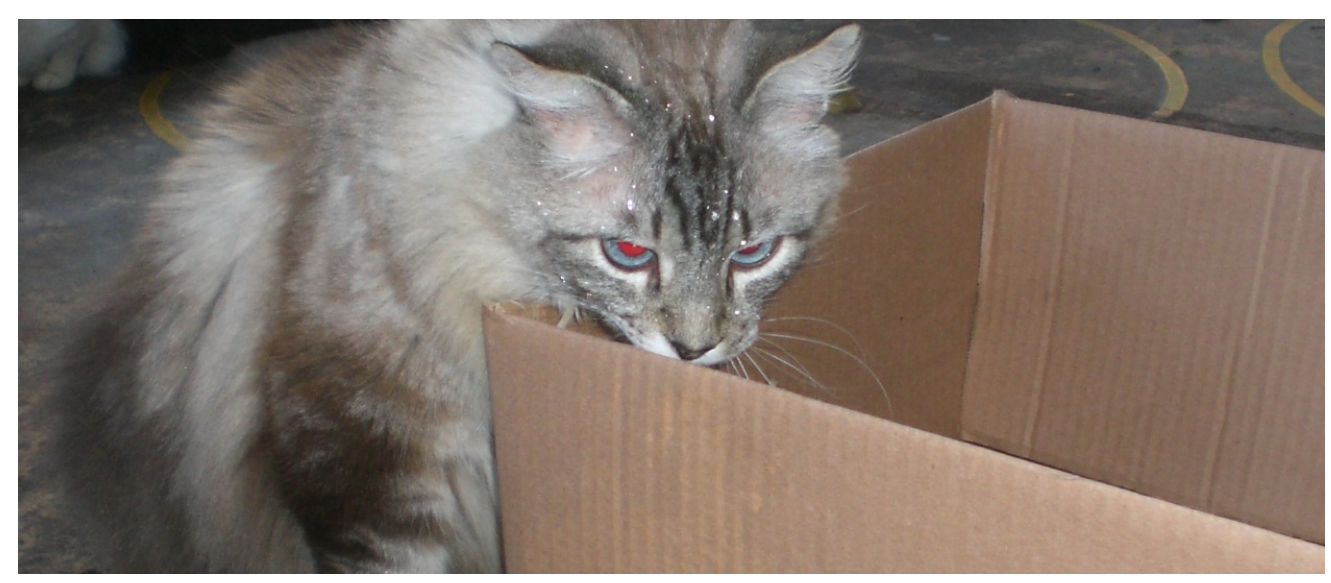

Figura 2: Animal realizando o comportamento exploratório frente ao item de enriquecimento ambiental introduzido no recinto.

Sabendo-se que neofilia é a tendência de um indivíduo se lançar em direção à novidade explorando-a, baseado na curiosidade e que neofobia é a aversão do indivíduo frente a um ambiente ou objeto novo, com base no medo [47, 45]; verifica-se que ao se deparar com a novidade, o animal experimenta um conflito entre neofobia e neofilia, onde o que vai 
determinar a sua aproximação ou não ao estímulo serão suas experiências prévias em relação ao mesmo.

Em trabalhos realizados com roedores, por exemplo, demonstram que a exploração solitária, na ausência dos outros membros do grupo social do qual o animal faz parte, mostra-se como uma situação muito mais neofóbica que neofílica [48], o mesmo sendo percebido para a exploração em labirintos abertos [30] e ambiente novos [49, 50]. Estudos que avaliam o comportamento exploratório baseando-se em ambientes novos ou exposição solitária devem estar atentos, visto que a aversão a novidade pode estar gerando a movimentação intensa do animal na busca por uma oportunidade de fuga e não por interesse ou curiosidade [51].

Hugues (1997) [45] relatou que indivíduos aprendem a interagir com situações distintas impostas pelo seu ambiente a fim de obter como recompensa a simples opção de explorálo. Assim, nota-se que explorar por si só, já pode ser considerado um comportamento recompensador e que a falta desta oportunidade exploratória está geralmente associada ao aumento na previsibilidade do ambiente [52], acarretando em elevados níveis de estresse, comportamentos anormais, diminuição na motivação em explorar e consequentemente queda nos níveis de bem-estar dos animais [53].

Experimentos têm demonstrado que animais preferem ambientes complexos a ambientes pobres em estímulos. Sendo importante destacar que estudos sobre preferências ambientais podem ajudar no delineamento dos recintos, oferecendo a possibilidade de conhecimento das escolhas do animal [54].

Assim, observando o modo de utilização e exploração do espaço, podemos acessar informações sobre a biologia e bem-estar do animal em questão. Medidas de como os animais utilizam seu espaço, bem como exploram e interagem frente a diferentes itens, vem se tornando um método comum para determinar aspectos positivos e negativos de cativeiros, medir a sua adequação e maximizar o bem-estar dos indivíduos mantidos nesses recintos [37].

Broom (2010) [55] foi assertivo ao dizer que quando as necessidades de um animal não são atendidas, o grau de bem-estar deste, pode estar prejudicado. Dessa maneira, após o estudo das necessidades da espécie, torna-se então, imprescindível, o delineamento de um sistema viável de enriquecimento, que vá ao encontro das necessidades e exigências dos animais [56]. 


\subsection{Enriquecimento Ambiental}

O termo enriquecimento ambiental é frequentemente aplicado a diferentes tipos de mudanças, seja no conteúdo ou na estrutura dos recintos [57], por meio de abordagens físicas, sociais, sensoriais e nutricionais, proporcionando um aumento na complexidade do ambiente e no bem-estar dos animais [58].

Trata-se de uma estratégia para minimizar o potencial de estresse, quando animais são mantidos em cativeiro, podendo ser realizado de várias formas, com a sistemática alteração do meio ambiente, através de deslocamento de objetos já conhecidos, ou ainda, por meio da introdução de novos itens, garantindo desse modo à manutenção da novidade dentro de um ambiente já conhecido pelos indivíduos. Abrange também o delineamento da infraestrutura dos recintos, tamanho e composição dos grupos sociais, através da inserção de outros fatores/ estímulos que possam influenciar a maneira pela qual um animal cativo percebe seu ambiente.

Tais estímulos devem mimetizar aos animais, oportunidades que resultem em atos comportamentais semelhantes aos que estes, realizariam em vida-livre. As atividades devem, por exemplo, promover comportamentos como o forrageio, permitindo a esses animais obterem seu alimento; o deslocamento através de estruturas que necessitem de esforços físicos, ainda que para isso, aprendam novos comportamentos e realizem tarefas com exigências cognitivas mais refinadas [59]. Funciona também como uma forma de aperfeiçoar o espaço disponível para os animais mantidos em cativeiro, promovendo maior interação destes, com o ambiente.

A utilização de métodos de enriquecimento ambiental tem como propósitos: a manutenção da atividade exploratória, evitar ou eliminar comportamentos atípicos, maximizando assim, a qualidade de vida dos animais [60].

Muitos autores tais como Holm e Ladewig (2007) [58], pontuam o enriquecimento ambiental como sendo uma estratégia que já potencializa as condições de manutenção apenas por oferecer novas oportunidades comportamentais [57], resultando no aumento dos níveis de bem-estar e das habilidades do animal em participar dos desafios e experimentações em cativeiro, além da manter a integridade fisiológica e reduzir a execução de comportamentos anormais pelos indivíduos [56].

Comportamentos estes, também denominados estereotipias, que geralmente aparecem quando não há a possibilidade do animal exercer atividades naturais da espécie, sendo o enriquecimento ambiental, uma das formas mais eficientes na redução desses comporta- 
mentos $[57,61]$.

Efeitos neurológicos positivos também foram relatados em ratos idosos cujo ambiente foi enriquecido, como a redução dos prejuízos na memória de curto prazo, renovação e prevenção da morte de células hipocampais, além da atenuação de distúrbios psiquiátricos $[62,63]$.

O enriquecimento ambiental é também um modo de estimular o comportamento exploratório através de modificações do espaço físico disponível que, muitas vezes, não conta com a possibilidade de ser ampliado estruturalmente [35].

Enriquecimento ambiental físico consiste em aumentar a complexidade de ambientes de cativeiro por meio da introdução de túneis, plataformas, brinquedos [64], ou outras estruturas como: vegetações, diferentes substratos (areia, terra, folhas secas, etc.), estruturas para se pendurar ou se balançar (cordas, troncos) entre outros itens apropriados para a manutenção da espécies e seus comportamentos naturais.

O ato de escalar ou subir em objetos é uma parte importante do comportamento locomotor do gato, sendo que estes animais passam menos tempo no solo de seus ambientes do que em superfícies elevadas, o que lembra suas origens evolutivas [65]. Assim, o uso de mesas, prateleiras como itens de enriquecimento, podem oferecer ao mesmo tempo, possibilidade de exercícios físicos, esconderijos e pontos vantajosos de observação do ambiente para esses animais.

Assim como outros felinos, os gatos domésticos utilizam um padrão territorial ativo e têm dificuldades em aceitar a inclusão de novos indivíduos no grupo; o enriquecimento ambiental físico irá diminuir a probabilidade de encontros agressivos além de fornecer aos animais, novas oportunidades de abrigo [66].

Cornetto e Estevez (2001) [34] ressaltam a importância em inserir abrigos/refúgios nos recintos de cativeiro, já que em ambientes naturais, as vegetações, rochas e barreiras naturais são utilizadas para esse propósito.

A segmentação do recinto em diferentes áreas, através da implementação de barreiras físicas ou visuais, também pode ser uma forma de enriquecimento do ambiente, levando a uma utilização mais eficaz do espaço, além de diminuir o contato visual indesejado entre os animais [67].

Barreiras visuais podem permitir que os animais se ajustem melhor em relação a distância percebida entre co-específicos ou outras fontes de estimulação social. Com o aumento do número de barreiras visuais houve uma diminuição do tempo gasto realizando 
o comportamento de Pacing em pequenos felinos [68, 23, 69].

Para gatos domésticos a aplicação de técnicas de enriquecimento ambiental tem sido uma das formas mais bem sucedidas para a modificação comportamental e aumento nos níveis de bem-estar [70].

Porém, se faz necessário que os itens de enriquecimento ambiental sejam bem elaborados, avaliados [71] e que haja a seleção de uma ampla variedade de brinquedos, como: bolas, caixas de papelão, túneis, balanços, e outros itens [72].

O conceito de novidade é importante, sendo que os itens devem ser regularmente alterados para evitar a habituação. Criatividade na elaboração e na exposição dos itens são necessárias para manter os gatos interessados no ambiente enriquecido [27].

A combinação de enriquecimento físico e ocupacional também pode promover o enriquecimento social, uma das necessidades mais negligenciadas aos gatos mantidos em confinamento. O enriquecimento social, fornece uma fonte constante de estimulação mental que nenhum outro item de enriquecimento ambiental, pode substituir [73].

Um item estimulante que possa ser utilizado e compartilhado por todos os indivíduos do grupo, pode desempenhar um papel importante na promoção de interação social entre os gatos, aumentando assim, o bem-estar desses animais [74].

De fato, a escolha da técnica a ser utilizada deve priorizar o entendimento do comportamento natural do animal, assim como o padrão comportamental do mesmo em um ambiente cativo [57], além do conhecimento sobre as necessidades biológicas da espécie em questão.

\subsection{O gato doméstico como modelo experimental}

O gato doméstico foi escolhido como nosso modelo de estudo, pois pouco se encontra sobre comportamentos característicos desta espécie na literatura, embora sua população mundial, como animais de companhia, esteja aumentando consideravelmente, chegando a superar a de cães (Canis familiaris) em alguns países ocidentais como: Estados Unidos, e no continente Europeu [22]. Este fato decorre de sua capacidade em viver em ambientes restritos e também pelo fato de possuir caráter mais independente, suportando períodos prolongados na ausência do proprietário, apresentando-se, portanto, como animais mais fáceis de cuidar [75].

Devido às facilidades em manusear e agrupar grandes quantidades de indivíduos em 
áreas reduzidas, além de apresentarem características fisiológicas e comportamentais semelhantes, o gato doméstico também está sendo utilizado em diversos estudos da família Felidae [76], tornando-se modelo em trabalhos sobre a biologia reprodutiva de felinos selvagens [77], marcações odoríferas [78], socialidade, domesticação [79] e territorialidade [80].

O número desses animais em confinamento vem aumentando nas últimas décadas, em todo o mundo, como em abrigos, Centro de Controle de Zoonoses e/ou instituições de pesquisa, onde são de suma importância e passam a ser utilizados como modelos experimentais para estudos da sua própria espécie, de outras espécies domésticas, ou ainda em outros estudos científicos abordando assuntos como: fisiologia [81, 82], ecologia [83], cardiomiopatias [84], neuroanatomia [85], psicologia [86, 87], e microbiologia [88].

Até o momento, mais de 200 patologias hereditárias felinas têm sido descritas, e muitas delas, são modelos para o estudo de doenças humanas. Isso vale também para doenças infecciosas, como por exemplo a infecção pelo vírus da imunodeficiência felina (FIV), que é o único modelo que ocorre naturalmente para o vírus da imunodeficiência humana (HIV) [89, 90].

Declínios da função cognitiva, associados com a idade, a reduzida capacidade de aprendizagem, de memória e atenção têm sido relatados em uma variedade de espécies, incluindo os seres humanos [91], cães [92], primatas e roedores [93]. Da mesma forma, Gunn-Moore et al. (2006) [94] relataram que mudanças histopatológicas de cérebros humanos em idade senil, também foram observadas no cérebro de gatos idosos, fazendo com que esses animais, se tornem modelos importantes, para futuras pesquisas sobre esses e outros temas.

Havendo assim, uma crescente preocupação a respeito do conhecimento sobre esta espécie, a fim de proporcionar condições adequadas para a sobrevivência e bem-estar da mesma [95] em espaços reduzidos, típica condição de biotérios, CCZs, etc. 


\section{Objetivos}

\subsection{Objetivos gerais}

- Avaliar o padrão de ocupação dos animais no recinto, antes (condição Controle) e após a introdução de itens de Enriquecimento Ambiental Físico:

- Permanente de uso Coletivo,

- Temporário de uso Coletivo, e

- Temporário de uso Restrito,

que irão subdividir o ambiente e renovar os locais já conhecidos pelos animais.

- Analisar as possíveis diferenças na ocupação de espaços e realização de comportamentos pelos animais frente aos Testes:

- Enriquecimento Ambiental Físico Permanente de uso Coletivo,

- Temporário de uso Coletivo, e

- Temporário de uso Restrito,

em relação aos eventos registrados na condição Controle.

\subsection{Objetivos específicos}

- Avaliar a ocupação de espaço realizada pelos animais, comparando o uso geral (em número médio), entre as áreas de Piso e áreas Elevadas, antes (condição Controle) e após a introdução dos itens de Enriquecimento Ambiental Físico (Permanente de uso Coletivo, Temporário de uso Coletivo e Temporário de uso Restrito).

- Avaliar a ocupação de espaço realizada pelos animais, ao longo dos dias e entre as horas de observações (em frequência), e a possível Habituação aos itens de En- 
riquecimento Ambiental Físico (Temporário de uso Coletivo e Temporário de uso Restrito).

- Avaliar os comportamentos executados pelos animais (em frequência), nas áreas de Piso e áreas Elevadas, antes (condição Controle) e após a introdução dos itens de Enriquecimento Ambiental Físico (Permanente de uso Coletivo, Temporário de uso Coletivo e Temporário de uso Restrito).

- Avaliar as interações realizadas pelos indivíduos (em latência, frequência e compartilhamentos), frente aos itens de Enriquecimento Ambiental Físico (Permanente de uso Coletivo, Temporário de uso Coletivo e Temporário de uso Restrito). 


\section{$3 \quad$ Material e Métodos}

O presente estudo foi avaliado pela Comissão de Ética no Uso de Animais (CEUA) do Campus da USP- Ribeirão Preto/SP, apresentando-se de acordo com os princípios éticos para a experimentação animal (Protocolo $\mathrm{n}^{\mathrm{O}}$ 12.1.119.53.2).

\subsection{Animais}

A colônia estudada constituiu-se de 31 gatos domésticos (sendo 11 machos e 20 fêmeas) todos castrados e não pertencentes a nenhuma raça em particular (sem raça definida). O plantel (mantido no "Abrigo B") teve sua origem na doação de vários animais de uma Organização Não Governamental já extinta, da cidade de Ribeirão Preto/ SP. O grupo permanece estável, sem introdução de indivíduos novos.

Os indivíduos da colônia possuem um histórico (Fig. 3) com o nome, número de identificação (referente a pigmentação da pelagem e ao sexo), e duas fotos (sendo uma de face e outra de perfil-corporal direito). Neste histórico, são relatados os principais eventos da vida do animal, data de chegada, idade aproximada, patologias adquiridas, tratamentos veterinários realizados, e outros. A partir deste registro e de padrões de marcas, os animais foram identificados ao longo do estudo.

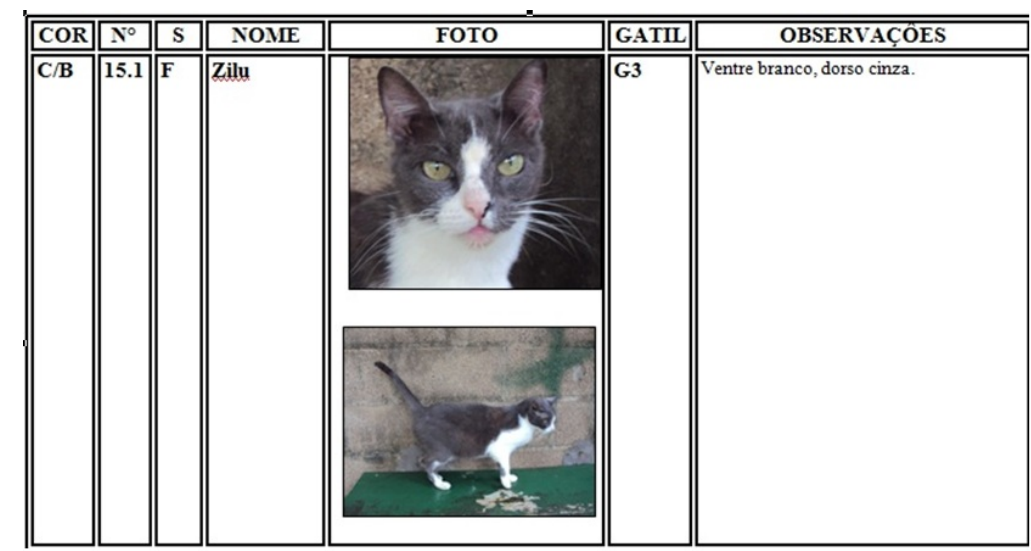

Figura 3: Exemplo do histórico dos indivíduos utilizados no estudo, contendo as informações necessárias para a correta identificação dos animais. 
No decorrer do presente estudo, os animais foram representados pelo número de identificação, que possui como referência a pigmentação da pelagem e o sexo do animal (Tabela 1).

Tabela 1: Identificação dos animais da colônia, com as informações do $\mathrm{n}^{\underline{0}}$ de registro, nome e cor da pelagem dos indivíduos utilizados no estudo.

\begin{tabular}{cllclc}
\hline \hline $\mathrm{N}^{\mathbf{0}}$ & Indivíduo & Cor & $\mathrm{N}^{\mathbf{0}}$ & Indivíduo & $\mathrm{Cor}$ \\
\hline 1.3 & Manhoso & $\mathrm{PP}$ & 4.25 & Quadradinha & $\mathrm{RL}$ \\
1.7 & Peluda & $\mathrm{PL}$ & 4.38 & Cuca & $\mathrm{RL}$ \\
2.10 & Cotoco & $\mathrm{PL}$ & 4.7 & Lolita & $\mathrm{RL}$ \\
2.13 & Capitão G. & $\mathrm{PL}$ & 8.23 & Metralha & $\mathrm{P} / \mathrm{B}$ \\
2.19 & Everest & $\mathrm{PL}$ & 8.24 & Joaninha & $\mathrm{P} / \mathrm{B}$ \\
2.2 & Linguinha & $\mathrm{PL}$ & 8.5 & Rabicó & $\mathrm{P} / \mathrm{B}$ \\
2.20 & Chatinha & $\mathrm{PL}$ & 8.7 & Unespo & $\mathrm{P} / \mathrm{B}$ \\
2.22 & Pretinha & $\mathrm{PL}$ & 9.1 & Rosa & $\mathrm{B} / \mathrm{R}$ \\
2.3 & Faiado & $\mathrm{PL}$ & 10.4 & Felícia & $\mathrm{R} / \mathrm{B}$ \\
2.44 & Preta & $\mathrm{PL}$ & 15.1 & Zilu & $\mathrm{C} / \mathrm{B}$ \\
2.6 & Dorinha & $\mathrm{PL}$ & 17.2 & Tita & $\mathrm{T}$ \\
3.2 & Peninha & $\mathrm{RP}$ & 20.2 & Branquinha & $\mathrm{B}$ \\
3.4 & Zé & $\mathrm{RP}$ & 23.2 & Carmela & $\mathrm{T}$ \\
3.6 & Ralinha & $\mathrm{RP}$ & 27.1 & Porquinha & $\mathrm{T}$ \\
4.15 & Gostosa & $\mathrm{RL}$ & 29.1 & Wisk & $\mathrm{S}$ \\
4.2 & Quadrado & $\mathrm{RL}$ & & & \\
\hline \hline
\end{tabular}

Cor da pelagem denominada por (PP: preto peludo, PL: preto liso, RP: rajado peludo, $\mathrm{RL}$ : rajado liso, $\mathrm{P} / \mathrm{B}$ : preto e branco, $\mathrm{B} / \mathrm{R}$ : branco e rajado, $\mathrm{R} / \mathrm{B}$ : rajado e branco, $\mathrm{C} / \mathrm{B}$ : cinza e branco, T: tricolor, B: branco e S: siamês).

\subsection{Local de Estudo}

No "Abrigo B" os animais dispõem de uma área total de aproximadamente $1250 \mathrm{~m}^{2}$, inteiramente fechada por grades e telas, com áreas de alvenaria e outras com terra, existindo vegetação dispersa pelo local, como árvores e grama. Os testes experimentais do presente trabalho foram realizados especificamente em um dos 3 gatis do Abrigo. Utilizamos especificamente o Gatil III, para tais atividades, cuja área total é de 112,41 $\mathrm{m}^{2}$, com 3,63 $\mathrm{m}^{2}$ /animal, área acima do recomendado por ROCHLITZ, (2000) [24], apresentando 100,32 $\mathrm{m}^{2}$ de área externa (Fig. 4) e 12,09 $\mathrm{m}^{2}$ de área interna coberta, utilizada como dormitório e local de alimentação, possuindo 20 cestas-camas, 2 comedouros, além de 2 bebedouros, sendo um deles com água corrente (Fig. 5). 


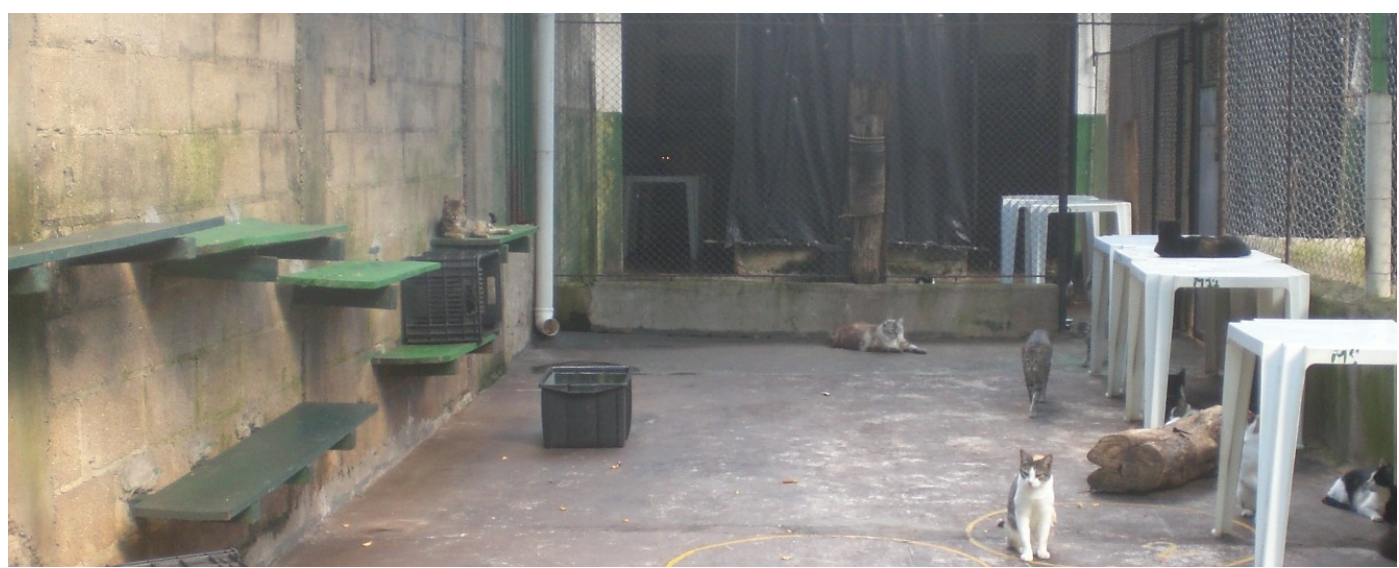

Figura 4: Área externa do gatil, com a presença dos itens de enriquecimento ambiental como: plataformas de madeira, mesas plásticas, troncos de madeira etc.

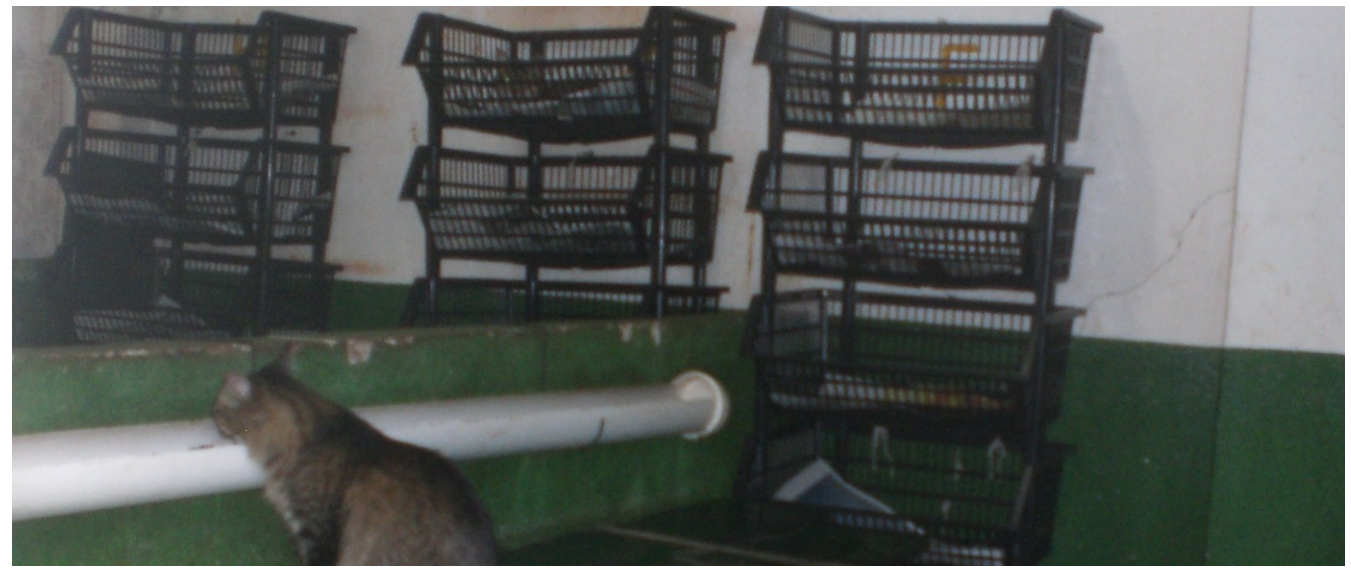

Figura 5: Área interna do gatil, onde estão localizados os comedouros e as camas plásticas que servem de dormitório para os animais.

As observações foram executadas em uma área de teste pré-definida, dentro do recinto, que correspondeu a uma área de Piso (p) de 35,81 $\mathrm{m}^{2}$ (1,16 $\mathrm{m}^{2} /$ animal), onde foram acrescentados mais $3,15 \mathrm{~m}^{2}\left(0,10 \mathrm{~m}^{2}\right.$ /animal) de área Elevada representada por duas mesas plásticas (m1 e m2), seis plataformas de madeira e um balanço de madeira (f1 à f7) sendo que para obtermos uma representação mais fidedigna do uso desses locais, utilizamos a densidade de animais $/ \mathrm{m}^{2}$ (dividindo o número de animais pela área disponível)(Fig. 6). 


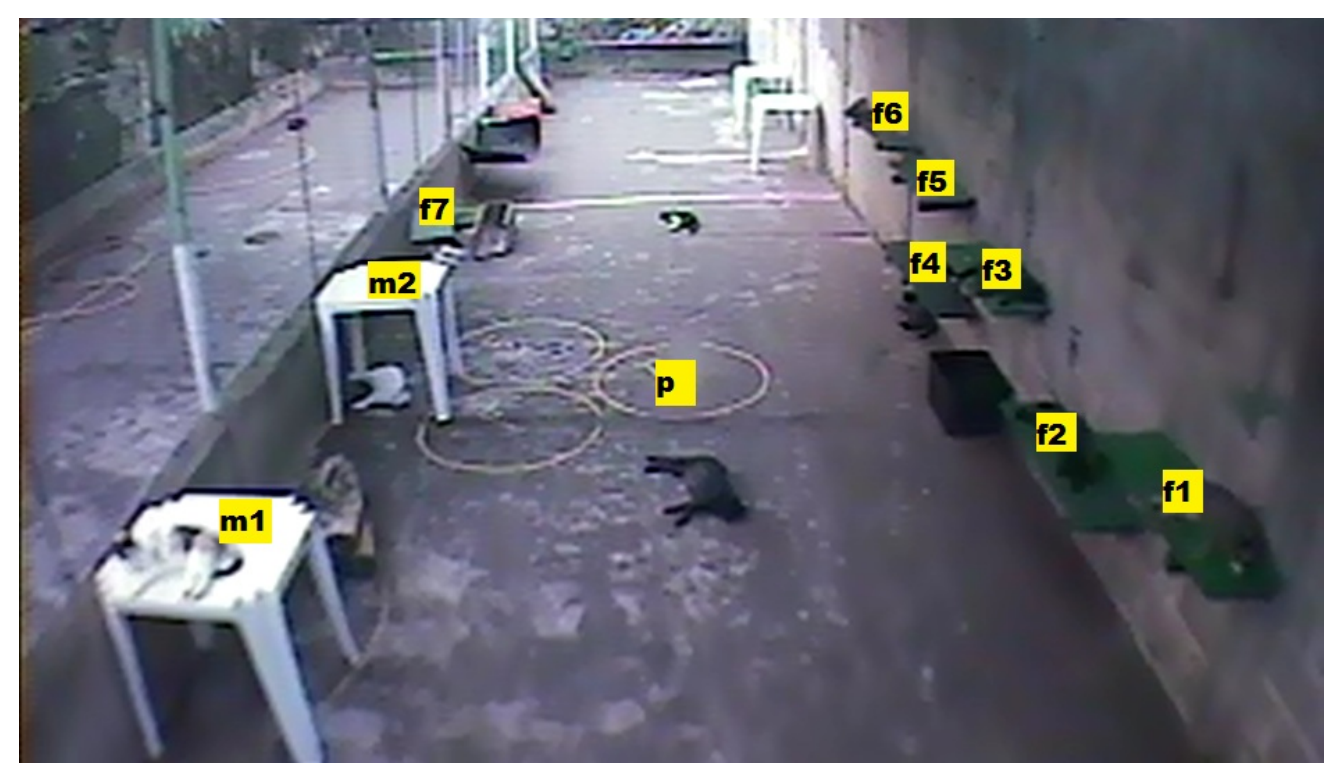

Figura 6: Área de teste, onde foram realizados os experimentos, representada pela área de piso (p) e pelas áreas elevadas (m1 e m2, f1 à f7).

\subsection{Manutenção dos animais}

A área é supervisionada diariamente pelos proprietários, e funcionários, que mantêm o controle da população. Sendo que esta área é higienizada, uma vez ao dia. O abrigo possui comedouros, onde os animais se alimentam com ração comercial seca (Fit 32- Royal Canin), e há 2 recipientes com água (ad libitum).

O controle sanitário é realizado com regularidade, vacinando-se os animais contra raiva e doenças específicas felinas, bem como, os controles antiparasitários são também efetuados sob supervisão de médica veterinária.

\subsection{Registros dos comportamentos}

Os comportamentos realizados pelos animais foram registrados por duas câmeras modelo Intelbras Vm 300 e Cftv Ccd, cujas imagens foram lançadas em um monitor de TV Broksonic, sendo simultaneamente gravadas em mídias de DVD por dois aparelhos (DVD) das marcas Samsung e Philips. É de fundamental importância o uso desta metodologia, já que a simples presença da experimentadora poderia interferir na distribuição espacial dos animais. 


\subsection{Testes Comportamentais}

\subsubsection{Condição Controle}

As observações Controle, foram realizadas em "Scan" (varredura) [96], através de um circuito interno de câmeras, de segunda à sexta-feira, por 10 dias, durante o período claro do dia (6:00h às 18:00h), evitando-se a inclusão de luz artificial, no intuito de não interferirmos nos comportamentos. Utilizamos intervalos de registros de 10 minutos (a cada hora), totalizando 6 observações/por hora, em uma bateria de 10 observações por horário, num total de 120 h de filmagem.

Foi registrado em tabelas previamente preparadas: o local onde o animal se encontrava (Área de Piso ou Área Elevada) e os comportamentos realizados (Andar, Descansar e "Autogrooming"), a fim de verificar a organização e a distribuição dos animais frente aos locais de ocupação disponíveis no recinto (Fig. 7)

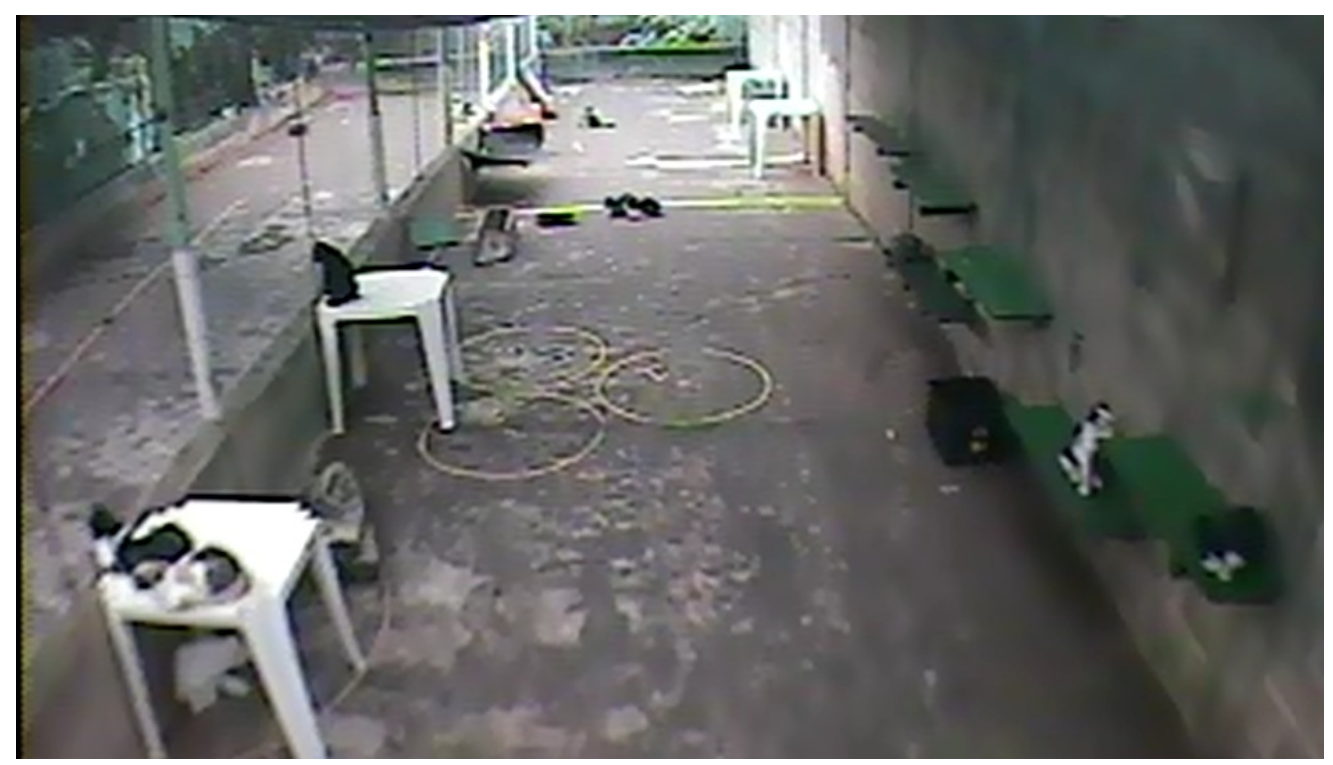

Figura 7: Ocupação de espaços e distribuição dos animais no recinto na condição Controle.

\subsubsection{Teste I - Enriquecimento Ambiental Físico Permanente de uso Coletivo}

O Teste I foi realizado de forma semelhante à metodologia descrita a cima, de segunda à sexta-feira das $06: 00 \mathrm{~h}$ às $18: 00 \mathrm{~h}$, durante 10 dias, porém foi introduzido no recinto o item permanente de uso coletivo: Carpete (constituído por fibras de Polietileno e resina sintética, no tamanho de $1,00 \mathrm{~cm} \times 0,30 \mathrm{~cm}$ ) revestindo a superfície da área Elevada, em duas disposições diferentes, denominadas "Disposição 1" (presença do item permanente 
de enriquecimento nas plataformas f1- superior e f4- inferior) (Fig. 8a) e "Disposição 2" (presença do item permanente de enriquecimento nas plataformas f2- inferior e f3- superior) (Fig. 8b), sendo que as plataformas superiores localizavam-se a $(0,80 \mathrm{~cm})$ e as inferiores $(0,44 \mathrm{~cm})$ do solo. Foi registrado a interação dos animais frente ao item de enriquecimento ambiental, bem como os comportamentos realizados.

Sendo também avaliada a disposição dos animais e a sua ocupação nos demais locais do recinto (Área de Piso ou Área Elevada), através de observações em "Scan", com intervalos a cada 10 minutos, após a introdução do item permanente de uso coletivo

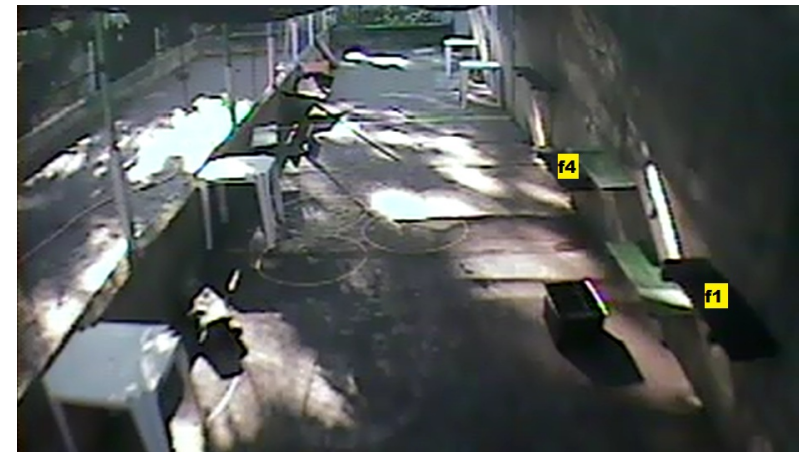

(A)

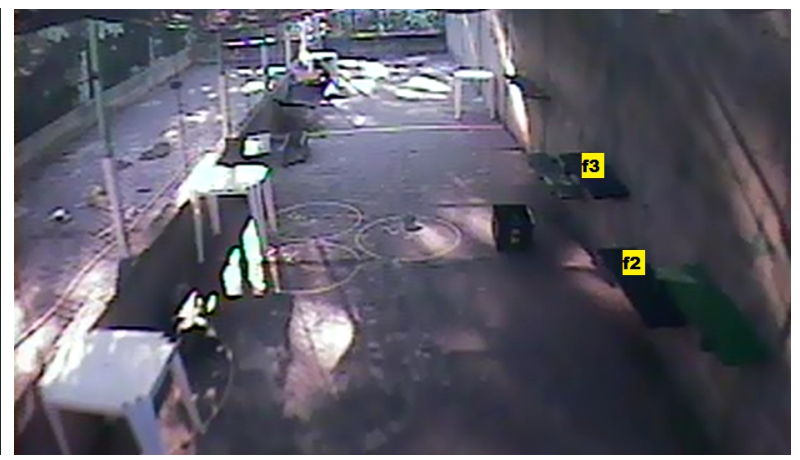

(B)

Figura 8: Recinto após a inclusão do item permanente de enriquecimento na (A) "Disposição 1" (presença do item permanente de enriquecimento nas plataformas f1superior e f4-inferior) e na (B) "Disposição 2" (presença do item permanente de enriquecimento nas plataformas f2- inferior e f3-superior).

\subsubsection{Teste II - Enriquecimento Ambiental Físico Temporário de uso Coletivo}

No Teste II, as filmagens foram realizadas no período das 13:30 às 16:30h, de segunda a sexta-feira, durante 10 dias, onde foi introduzido o item temporário de uso coletivo: Pano (tecido de Oxford, constituído por fibras de Poliéster), disposto em zigue-zague (formando triângulos de lados $6 \mathrm{~m} \mathrm{x} 5 \mathrm{~m}$ x $5 \mathrm{~m}$ ) ao longo da área de piso do recinto (área de teste) e ao final das três horas do experimento, o mesmo era retirado. Foram 14,40 m de Pano, cuja altura era de $0,70 \mathrm{~cm}$, impossibilitando assim a visão dos animais acima deste. Foi registrado de forma contínua: a interação dos animais frente ao item de enriquecimento ambiental, a latência de contato com o item, bem como os comportamentos realizados.

Além de ser avaliada a ocupação dos animais nos demais locais do recinto (Área de Piso ou Área Elevada), através de observações em "Scan", com intervalos a cada 10 minutos, após a introdução do item temporário de uso coletivo (Fig. 9). 


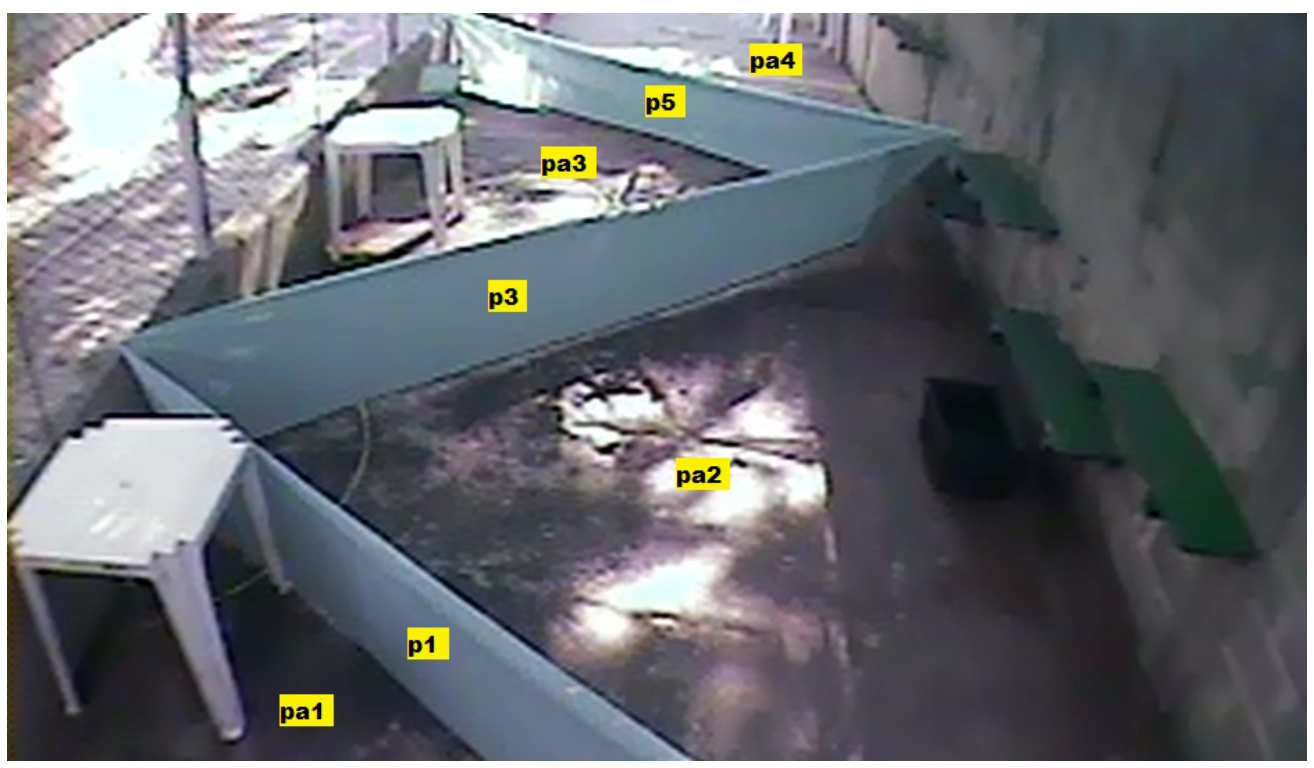

Figura 9: Recinto com a presença do item temporário de uso coletivo,disposto em ziguezague ao longo da área de teste.

\subsubsection{Teste III - Enriquecimento Ambiental Físico Temporário de uso Restrito}

No Teste III, as filmagens foram realizadas de segunda à sexta-feira no período das 14:00 às 17:00h, durante 10 dias, onde a cada dia, era introduzido no centro do recinto o item temporário de uso restrito: Caixa de Papelão (papel pardo CR2, gramatura 411, $0,50 \mathrm{~cm} \times 0,35 \mathrm{~cm} \times 0,20 \mathrm{~cm})$, e ao final das três horas do teste a mesma era retirada. A fim de verificar a interação dos animais frente ao item de enriquecimento ambiental registrou-se: o indivíduo, o tempo de permanência interagindo com o item e seus comportamentos realizados, estando na área interna (ocupando o espaço interior ao item), na área externa (interagindo externamente em contato com o item) ou na área próxima ao item(interagindo nas proximidades ao item, em uma distância de até $0,50 \mathrm{~cm}$ ). Com os registros sendo feitos de forma contínua, durante as três horas de filmagens.

Avaliou-se concomitantemente a disposição dos animais e a sua ocupação nos demais locais do recinto (Área de Piso ou Área Elevada), através de observações em "Scan" a cada 10 minutos, após a introdução do item temporário de uso restrito (Fig. 10). 


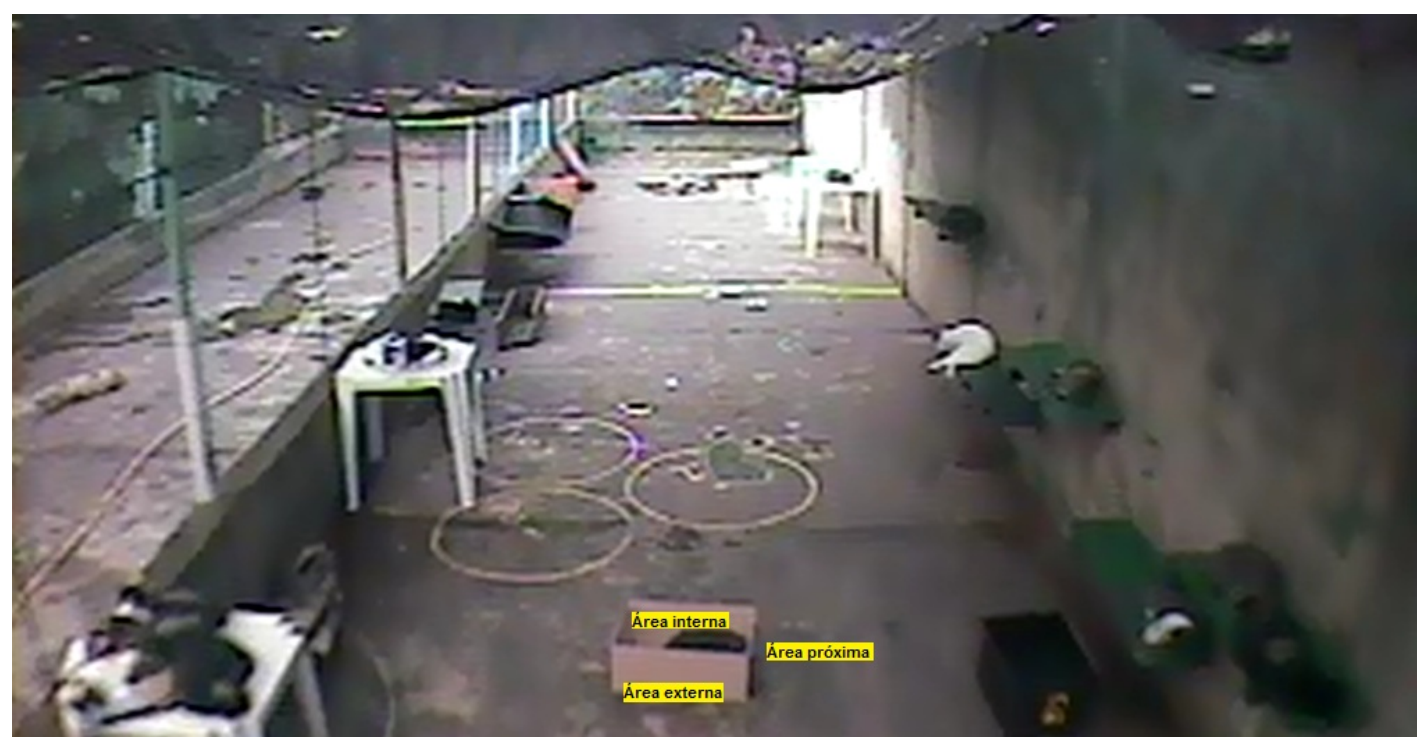

Figura 10: Distribuição dos animais e uso do espaço frente à apresentação do item temporário de uso restrito.

\subsection{Análises Estatísticas}

Todos os conjuntos de dados passaram pelo teste de normalidade de KolmogorovSmirnov, para verificar se os dados têm distribuição gaussiana (normal).

O teste paramétrico $t$-Student e seu correspondente não paramétrico Wilcoxon foram utilizados para comparações entre médias de duas condições, como por exemplo, ocupação de espaço na condição controle versus frente aos itens de enriquecimento ambiental (grupos não pareados), ocupação de espaço entre os locais do recinto e entre as horas de observações dos testes comportamentais (grupos pareados). Já para o confronto de médias referentes a mais de duas condições, tais como a frequência diária de interação dos animais frente aos itens de enriquecimento ambiental durante as três horas de observações ou para verificar a latência de interação entre os 31 indivíduos frente aos itens de enriquecimento, adotamos o teste não paramétrico de Kruskal-Wallis. O nível de significância estipulado em todos os testes foi de $p<0,05\left(^{*}\right), p<0,01(* *)$ e $p<0,001(* * *)$. 


\section{Resultados}

Todos os dados apresentados correspondem à média dos valores $(\bar{x})$ e ao erro padrão da média.

\subsection{Ocupação de espaços na condição Controle}

Os resultados obtidos através das observações na condição Controle mostraram que ao longo das 12 horas de observações/dia, durante os 10 dias de filmagens, o número médio de indivíduos $(\bar{x}=6,19 \pm 0,13)$ por "Scan", ocupando as áreas elevadas, foi significativamente maior se comparado ao número médio de indivíduos $(\bar{x}=3,07 \pm 0,07)$ em áreas de piso $(p<0,001)$ (Fig. 11).

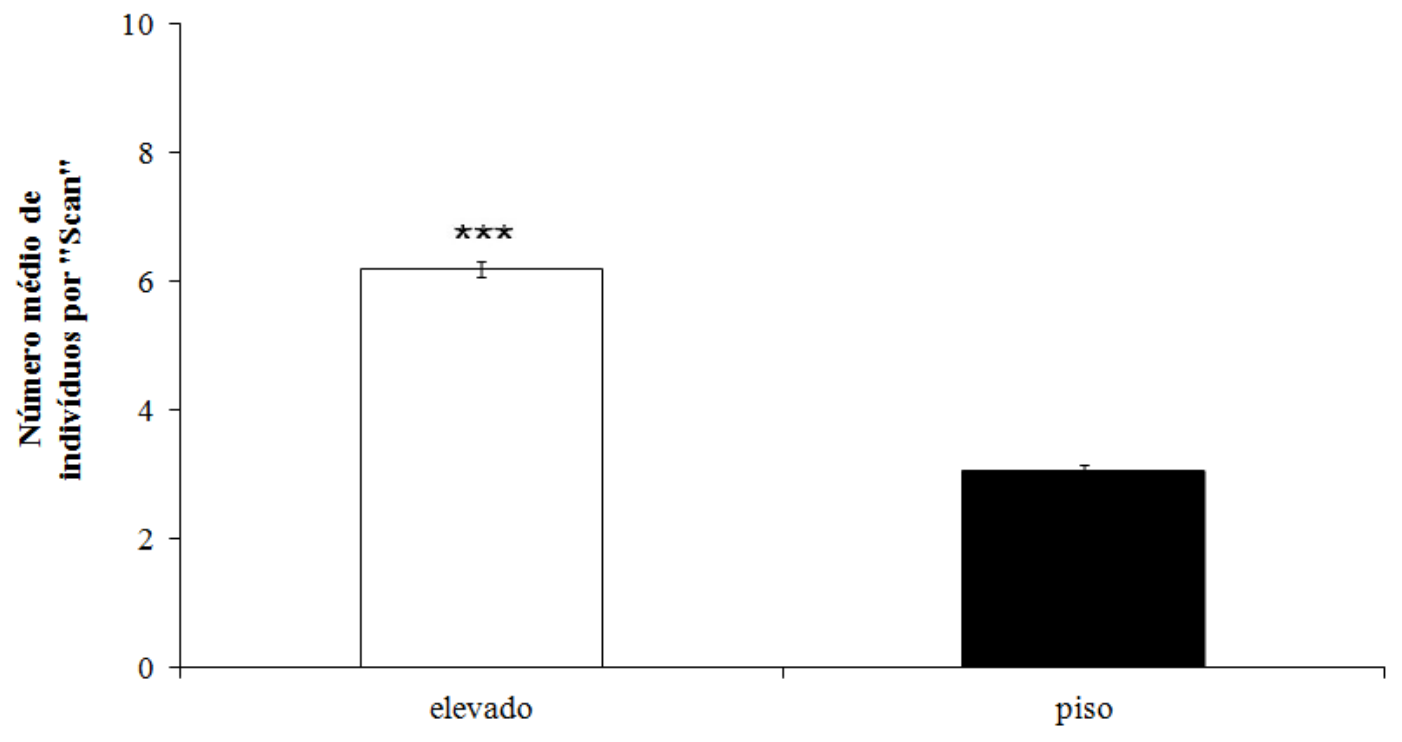

Local

Figura 11: Número médio de indivíduos por "Scan", ocupando as áreas elevadas e de piso, durante as 12 horas de observações na condição Controle. 
Em relação ao turno de ocupação, os resultados revelam que o número médio de indivíduos por "Scan", ocupando as áreas elevadas, foi significativamente maior em ambos os períodos do dia, sendo a média observada de 8,19 \pm 0,14 animais nas áreas elevadas, contra 2,94 $\pm 0,10$ indivíduos em áreas de piso, no período da manhã ( $p<0,001)$, e $\bar{x}=4,30 \pm 0,14$ indivíduos em áreas elevadas contra $\bar{x}=3,19 \pm 0,11$ em áreas de piso, no período da tarde $(p<0,001)$. Havendo uma preferência significativa no uso das áreas elevadas, no período da manhã $(\bar{x}=8,19 \pm 0,14)$ quando comparado à ocupação destas, no período da tarde $(\bar{x}=4,30 \pm 0,14)(p<0,001)$. Já para as áreas de piso, não houve diferença significativa na ocupação das mesmas, entre os turnos do dia (Fig. 12).

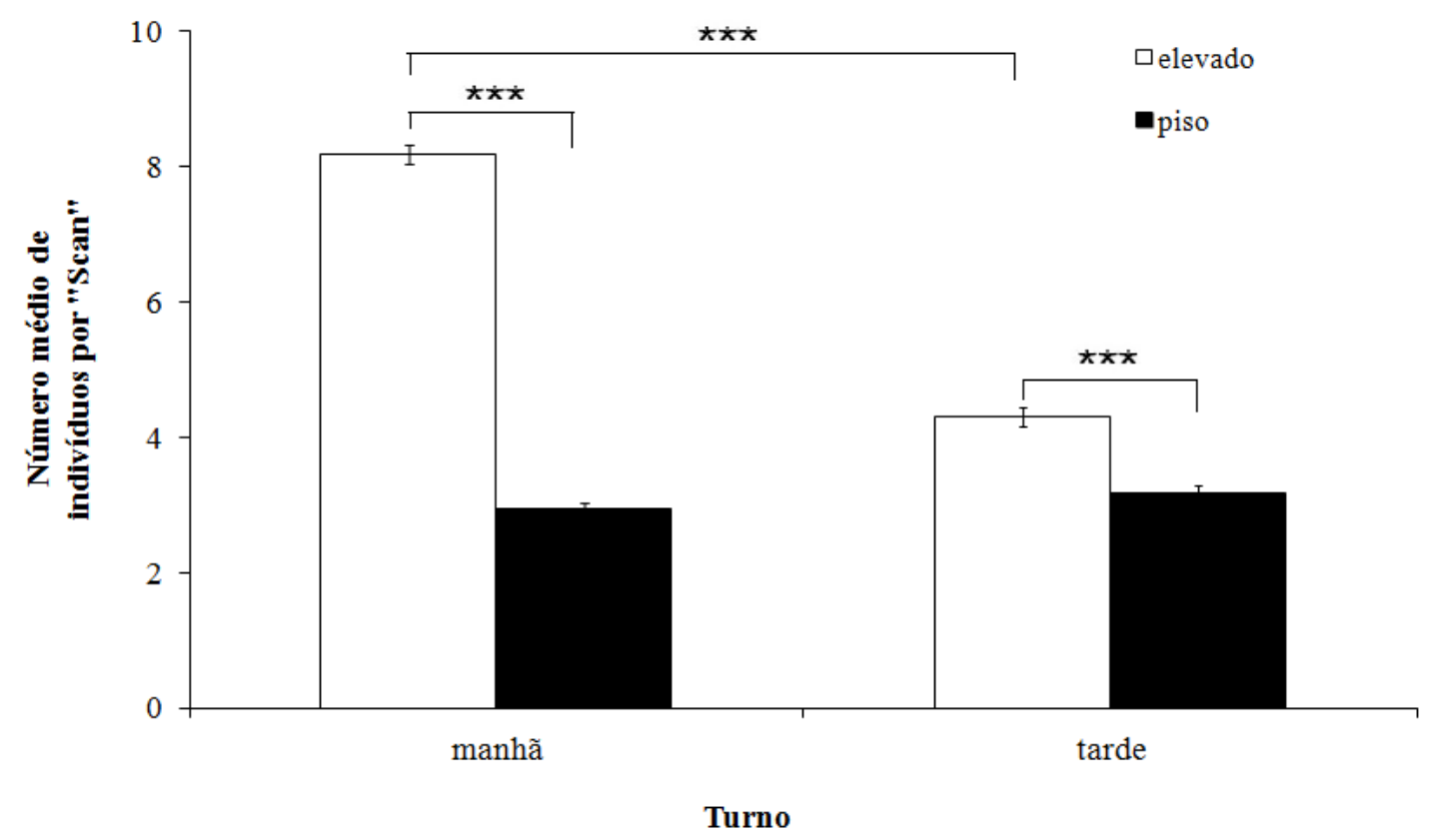

Figura 12: Número médio de indivíduos por "Scan", ocupando as áreas elevadas e de piso, durante o período da manhã (06:00-12:00h) e no período da tarde (12:00-18:00h), ao longo dos 10 dias de observações na condição Controle.

\subsection{Ocupação de espaços na condição Controle e no Teste Enriquecimento Ambiental Físico Perma- nente de uso Coletivo}

Comparando-se à ocupação de espaços realizada pelos animais, na condição Controle e no Teste Enriquecimento Ambiental Físico Permanente de uso Coletivo, após a apresentação do item de enriquecimento, foi revelado que o número médio de indivíduos por "Scan" ( $\bar{x}=7,85 \pm 0,09)$, ocupando as áreas elevadas foi significativamente maior no 
Teste Enriquecimento Ambiental Físico Permanente de uso Coletivo, se comparado ao número médio de indivíduos $(\bar{x}=6,19 \pm 0,13)$ nessa mesma área na condição Controle, sem a introdução do item no recinto $(p<0,001)$. Já em relação ao uso da área de piso, no Teste Enriquecimento Ambiental Físico Permanente de uso Coletivo, houve uma diminuição significativa na ocupação dessa área pelos animais, cujo número médio de indivíduos por "Scan" foi de $\bar{x}=1,39 \pm 0,04$, quando comparado a condição Controle, onde o número médio de indivíduos por "Scan" nessa mesma área, foi de $\bar{x}=3,07 \pm 0,07$ $(p<0,001)$ (Fig. 13).

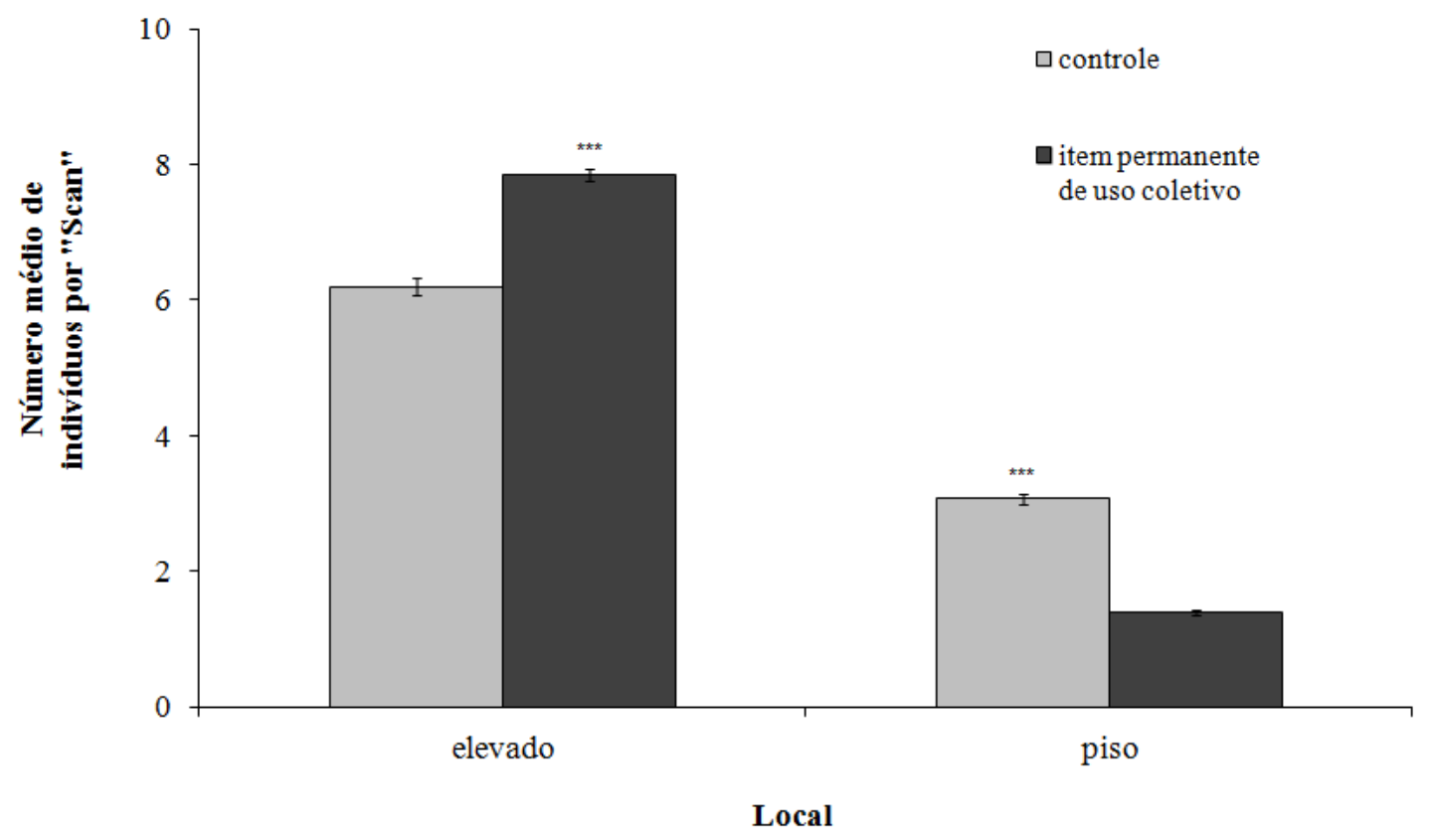

Figura 13: Número médio de indivíduos por "Scan", ocupando as áreas elevadas e de piso, durante os 10 dias de observações na condição Controle e após a introdução do item no Teste Enriquecimento Ambiental Físico Permanente de uso Coletivo.

Dentre os locais de ocupação disponíveis no recinto, os dados obtidos entre as observações na condição Controle, sem enriquecimento ambiental e no Teste Enriquecimento Ambiental Físico Permanente de uso Coletivo, os resultados nos revelaram que na "Disposição 1" (item permanente de enriquecimento em "f1" e "f4"), a densidade média de indivíduos, ocupando o elevado "f1" foi de $\bar{x}=5,23 \pm 0,12$, significativamente maior, em relação ao mesmo local, na condição Controle, onde a densidade média de indivíduos por "Scan" foi de $\bar{x}=3,13 \pm 0,10(p<0,001)$. O mesmo aconteceu com o elevado "f4", cuja densidade média de indivíduos por "Scan" foi de $\bar{x}=3,01 \pm 0,08$ contra $\bar{x}=0,80 \pm 0,06$ indivíduos ocupando este mesmo local, na condição Controle $(p<0,001)$. Os resultados na "Disposição 2" (item permanente de enriquecimento em "f2" e "f3"), mostraram que houve uma maior utilização do elevado "f3", quando enriquecido, cuja densidade 
média de indivíduos foi de $\bar{x}=3,99 \pm 0,14$, em relação ao mesmo local, na condição Controle, que apresentou a densidade média de $\bar{x}=1,59 \pm 0,08$ indivíduos por "Scan" $(p<0,001)$ (Fig. 14).

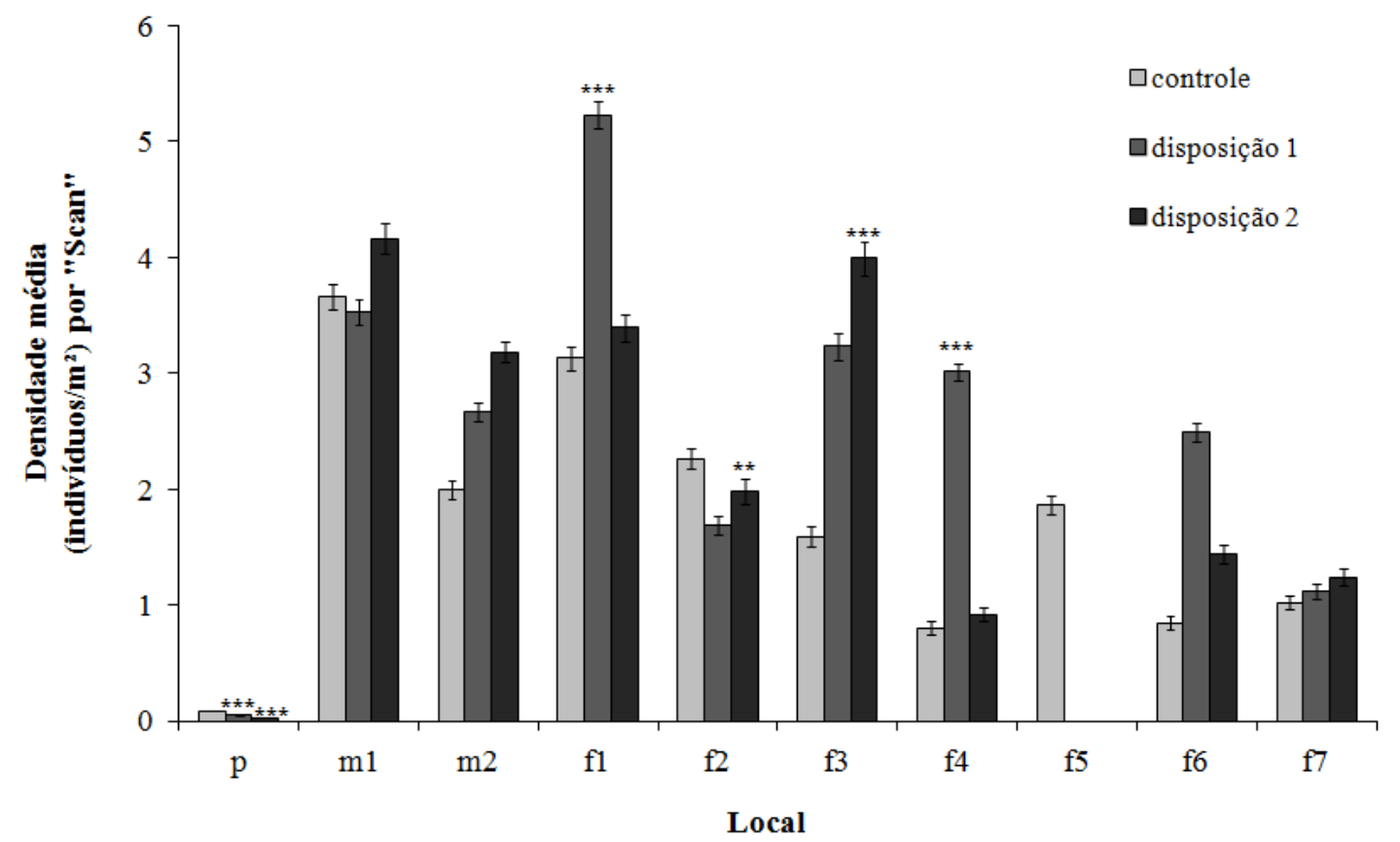

Figura 14: Densidade média de indivíduos por "Scan", ocupando a área de piso (p) e as áreas elevadas (m1 à f7), ao longo das 12 horas de observações na condição Controle e no Teste Enriquecimento Ambiental Físico Permanente de uso Coletivo ("Disposição 1" e "Disposição 2").

Em relação à ocupação na área de piso, os resultados nos revelaram que na condição Controle, houve uma maior densidade de indivíduos por "Scan" $(\bar{x}=0,09 \pm 0,01)$, ao compararmos com o Teste Enriquecimento Ambiental Físico Permanente de uso Coletivo ("Disposição 1"), onde a densidade média de indivíduos por "Scan" em área de piso, foi de $\bar{x}=0,05 \pm 0,01(p<0,001)$, assim como na "Disposição 2", cuja densidade média de indivíduos foi de $\bar{x}=0,03 \pm 0,01(p<0,001)$ (Fig. 15). 


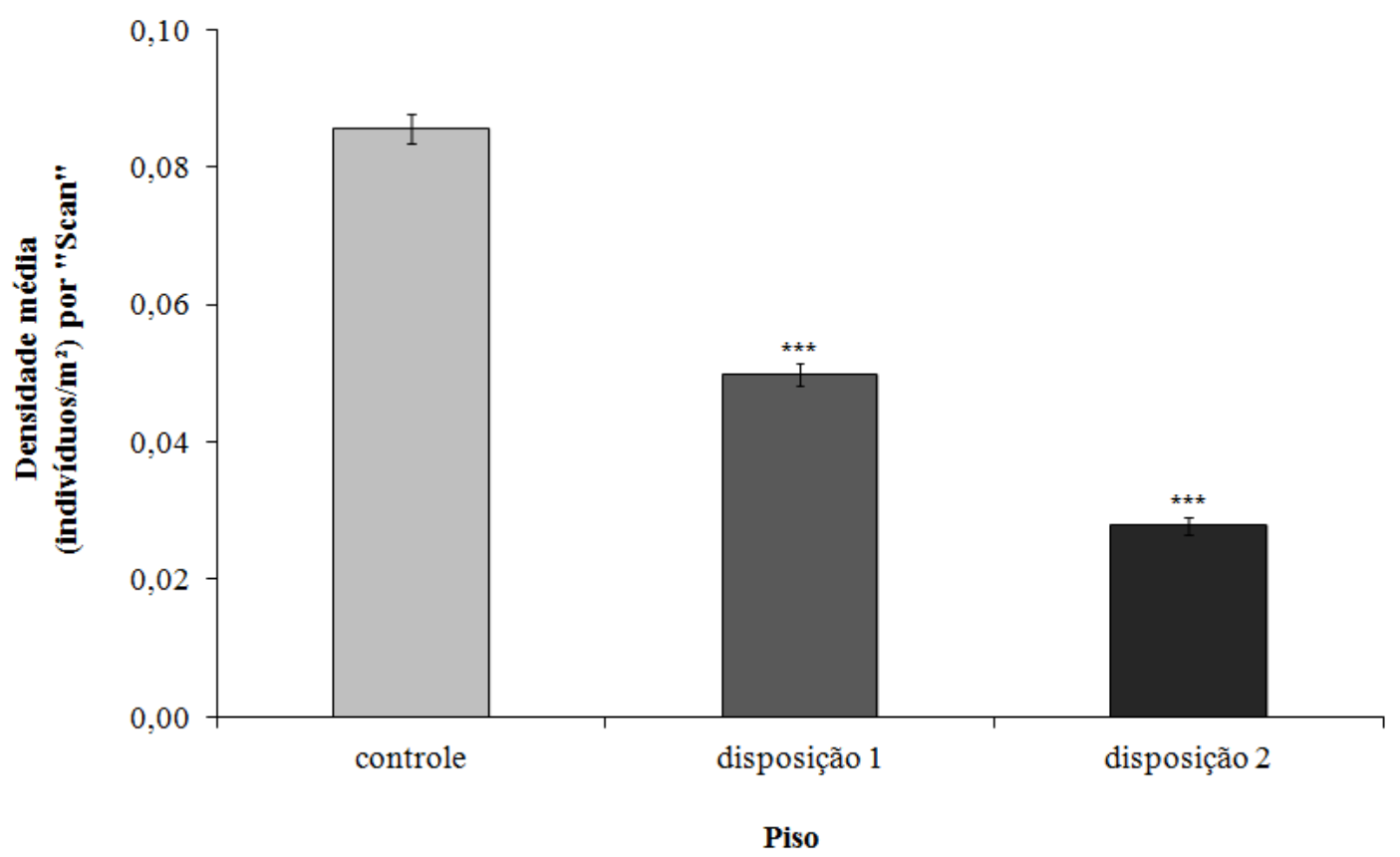

Figura 15: Densidade média de indivíduos por "Scan", ocupando a área de piso (p), ao longo das 12 horas de observações na condição Controle e no Teste Enriquecimento Ambiental Físico Permanente de uso Coletivo nas Disposições "1" e "2".

Em relação ao uso das plataformas com a introdução do item, dispostas em uma posição superior ou inferior no Teste Enriquecimento Ambiental Físico Permanente de uso Coletivo ("Disposição 1"), os resultados nos indicaram que o número médio de indivíduos por "Scan", utilizando as plataformas superiores com o item permanente de enriquecimento, foi de 1,57 $\pm 0,03$, seguidas de 1,08 $\pm 0,03$ indivíduos utilizando as plataformas inferiores com o item $(p<0,001)$. Contra $\bar{x}=0,97 \pm 0,03$ indivíduos por "Scan", ocupando as plataformas superiores sem o item, seguidas de $\bar{x}=0,54 \pm 0,02$ indivíduos por "Scan" ocupando as plataformas inferiores sem o item permanente de enriquecimento $(p<0,001)$ (Fig. 16a). No Teste Enriquecimento Ambiental Físico Permanente de uso Coletivo ( "Disposição 2"), os resultados nos mostraram que 1, 20 \pm 0,04 indivíduos por "Scan", ocuparam as plataformas superiores com o item e 1,02 $\pm 0,03$ indivíduos optaram em ocupar as plataformas superiores sem o item $(p<0,001)$. Seguidos de 0,63 $\pm 0,03$ indivíduos utilizando as plataformas inferiores com o item e por fim, 0,33 0,02 indivíduos por "Scan", utilizaram as plataformas inferiores sem o item permanente de enriquecimento $(p<0,001)$ (Fig. 16b). 


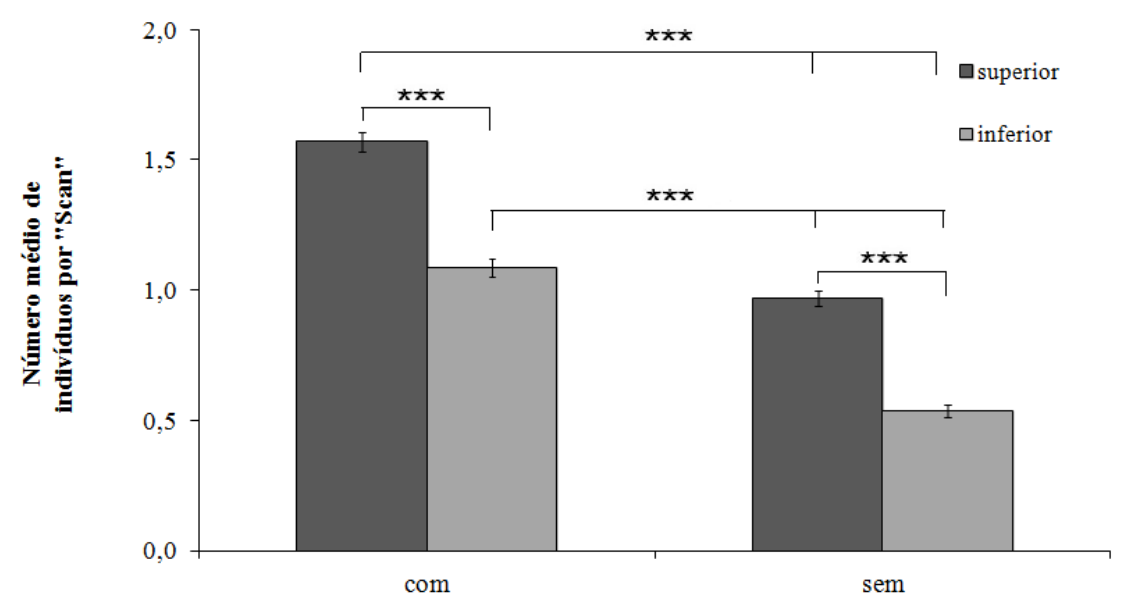

(A)

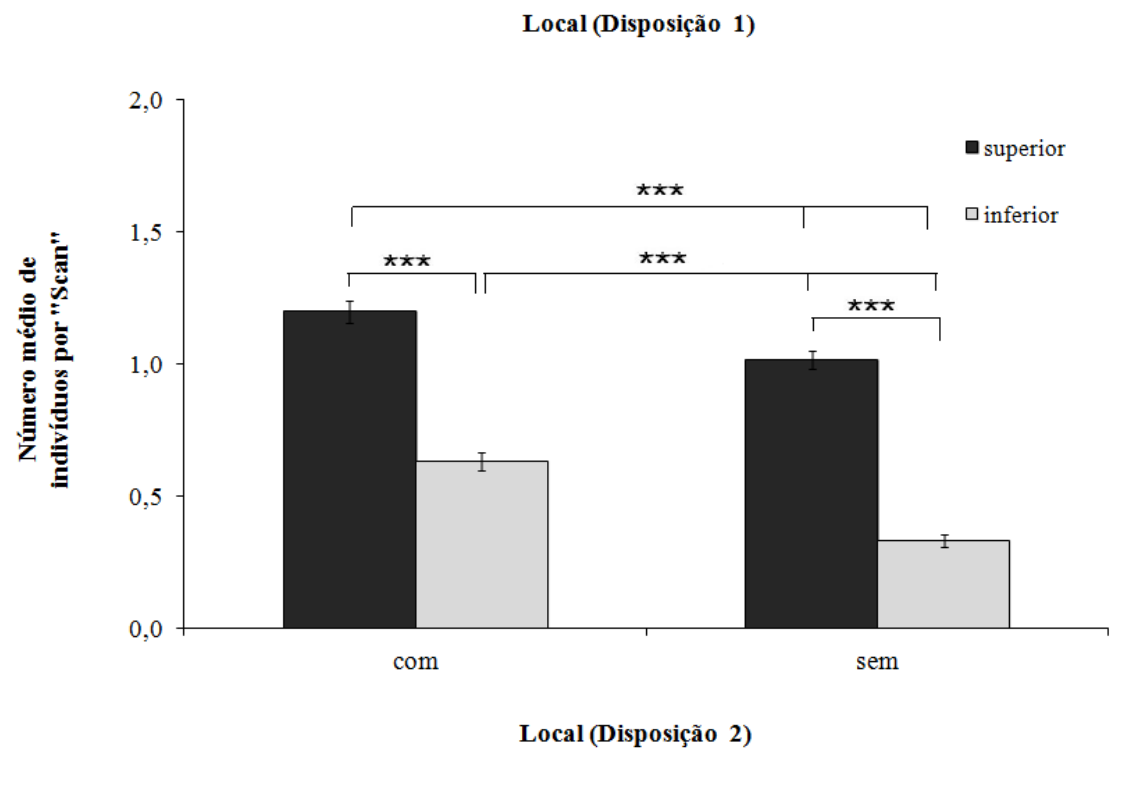

Figura 16: Número médio de indivíduos por "Scan", ocupando as áreas elevadas (superiores ou inferiores / com ou sem o item), ao longo das 12 horas de observações, durante os 10 dias do Teste Enriquecimento Ambiental Físico Permanente de uso Coletivo ("Disposição 1"e "Disposição 2").

Ao longo das 12 horas de observações, durante os 10 dias do Teste Enriquecimento Ambiental Físico Permanente de uso Coletivo, os resultados nos revelaram que no período das 6:00h às 7:00h, houve na média, um maior número de indivíduos por "Scan" ocupando as áreas elevadas em relação as áreas de piso $(p<0,001)$. Já entre 8:00h e 9:00h ocorreu a inversão na distribuição dos animais no recinto, com um menor número de indivíduos por "Scan" nas áreas elevadas, se comparado às áreas de piso $(p<0,001)$. A partir das 11:00h até o final do período de observação, foi visto novamente um maior número de indivíduos em áreas elevadas, em relação à ocupação destes, em áreas de piso $(p<0,001)$ (Fig. 17). 


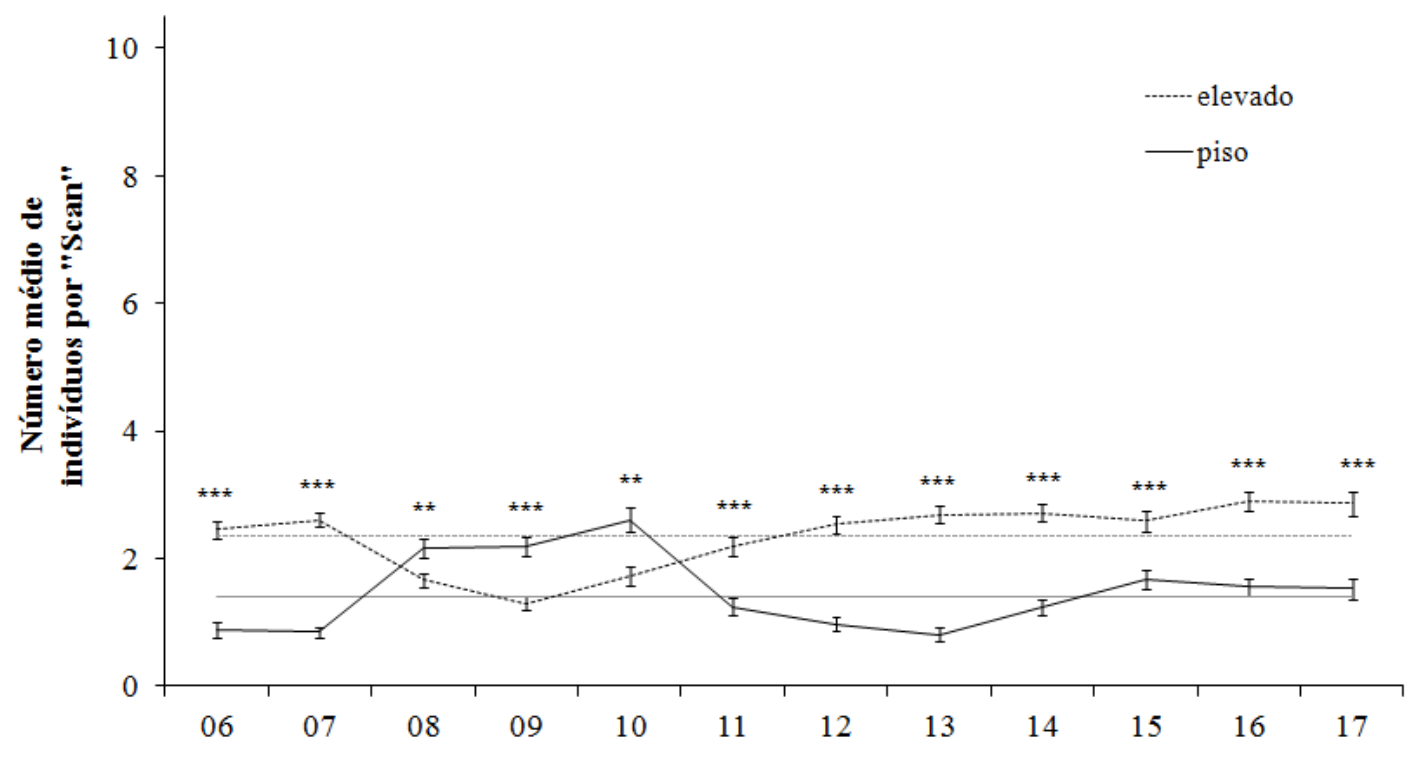

Hora de observação

Figura 17: Número médio de indivíduos por "Scan", ocupando as áreas elevadas e de piso, em relação à média geral (representa na figura, pelas linhas pontilhada e contínua), durante os 10 dias do Teste Enriquecimento Ambiental Físico Permanente de uso Coletivo, ao longo das 12 horas de observações.

Em relação aos comportamentos realizados frente aos locais do recinto, na condição Controle, podemos verificar que houve significativamente um maior número de animais $(\bar{x}=5,78 \pm 0,12)$, executando o comportamento "Descansar" em áreas elevadas, quando comparados ao número médio de animais $(\bar{x}=2,23 \pm 0,07)$, descansando em áreas de piso $(p<0,001)$ (Fig. 18a). O mesmo ocorreu no Teste Enriquecimento Ambiental Físico Permanente de uso Coletivo, onde os resultados nos revelam que houve significativamente um maior número de animais $(\bar{x}=2,27 \pm 0,04)$ executando o comportamento "Descansar" em áreas elevadas, quando comparados ao número médio de indivíduos $(\bar{x}=0,77 \pm 0,03)$ por "Scan", descansando em áreas de piso $(p<0,001)$ (Fig. 18b). 


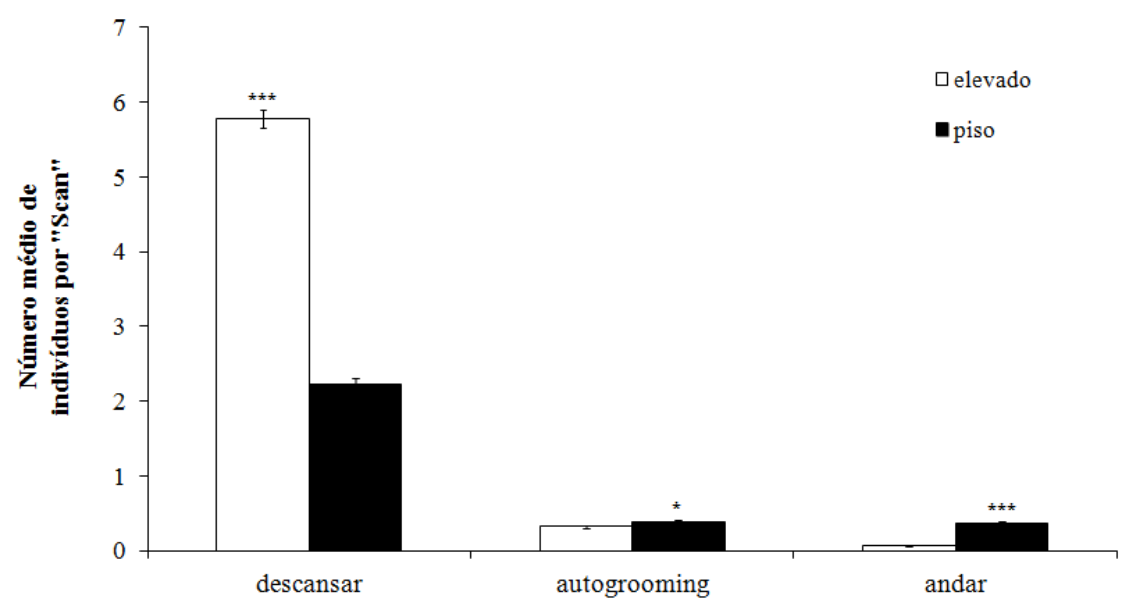

(A)

Comportamento

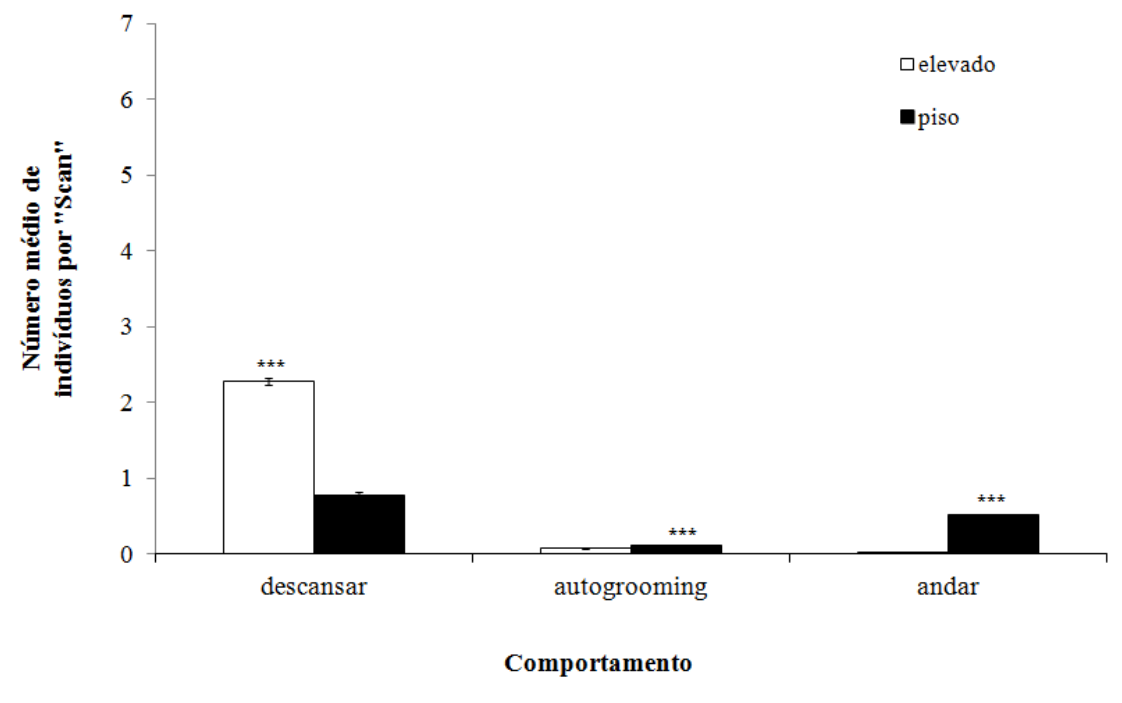

Figura 18: Número médio de indivíduos por "Scan", realizando os comportamentos "Descansar", "Autogrooming" e "Andar" nas áreas elevadas e de piso, durante os 10 dias de observações na condição Controle (A) e frente ao item permanente de uso coletivo (B).

Os resultados referentes à interação por indivíduo com o item permanente de enriquecimento, nas áreas elevadas "f1 à f4", nos mostraram que dentre os 31 animais observados no Teste Enriquecimento Ambiental Físico Permanente de uso Coletivo, os indivíduos que interagiram acima da média geral $(4,49)$ foram as fêmeas 29.1, 4.7, 1.3 e 3.6, assim como o macho 20.2. Dentre os animais que interagiram abaixo da média, estão as fêmeas 15.1, $4.25,2.13,3.4,10.4,4.38,2.10,2.20$ e o macho 2.19 . Já as fêmeas $2.2,8.23,8.24,17.2$ e os machos 2.22, 4.15, 23.2 foram os indivíduos que não interagiram com o item permanente de uso coletivo (Fig. 19). 


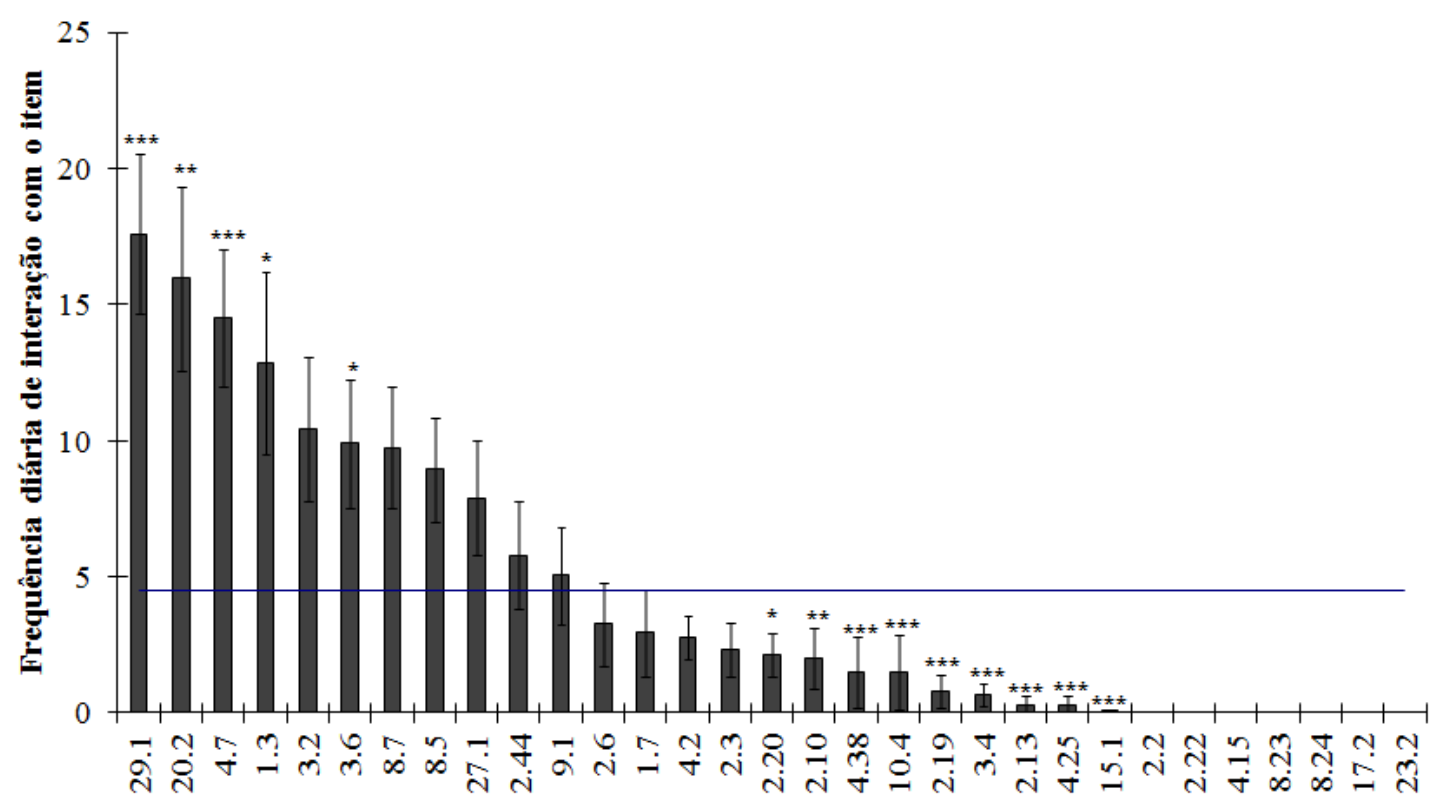

Indivíduo

Figura 19: Frequência diária de interação por indivíduo com o item permanente de uso coletivo, durante os 10 dias de observações no Teste de Enriquecimento Ambiental Físico Permanente de uso Coletivo.

\subsection{Ocupação de espaços na condição Controle e no Teste Enriquecimento Ambiental Físico Temporá- rio de uso Coletivo}

Com relação à ocupação de espaços realizada pelos animais, na condição Controle e após ser inserido no recinto o item temporário de uso coletivo, os resultados obtidos mostraram que o número médio de indivíduos por "Scan" ocupando $(\bar{x}=7,01 \pm 0,17)$, as áreas elevadas foi significativamente maior na presença do item, se comparado ao número médio de indivíduos $(\bar{x}=3,61 \pm 0,18)$ nessa mesma área na condição Controle $(p<0,001)$. Já em relação ao uso do piso, houve uma diminuição significativa no Teste Enriquecimento Ambiental Físico Temporário de uso Coletivo, apresentando o número médio de $(\bar{x}=1,38 \pm 0,10)$ indivíduos por "Scan", quando comparado à condição Controle, onde o número médio de indivíduos por "Scan" foi de $\bar{x}=3,10 \pm 0,13(p<0,001)$ (Fig. 20). 


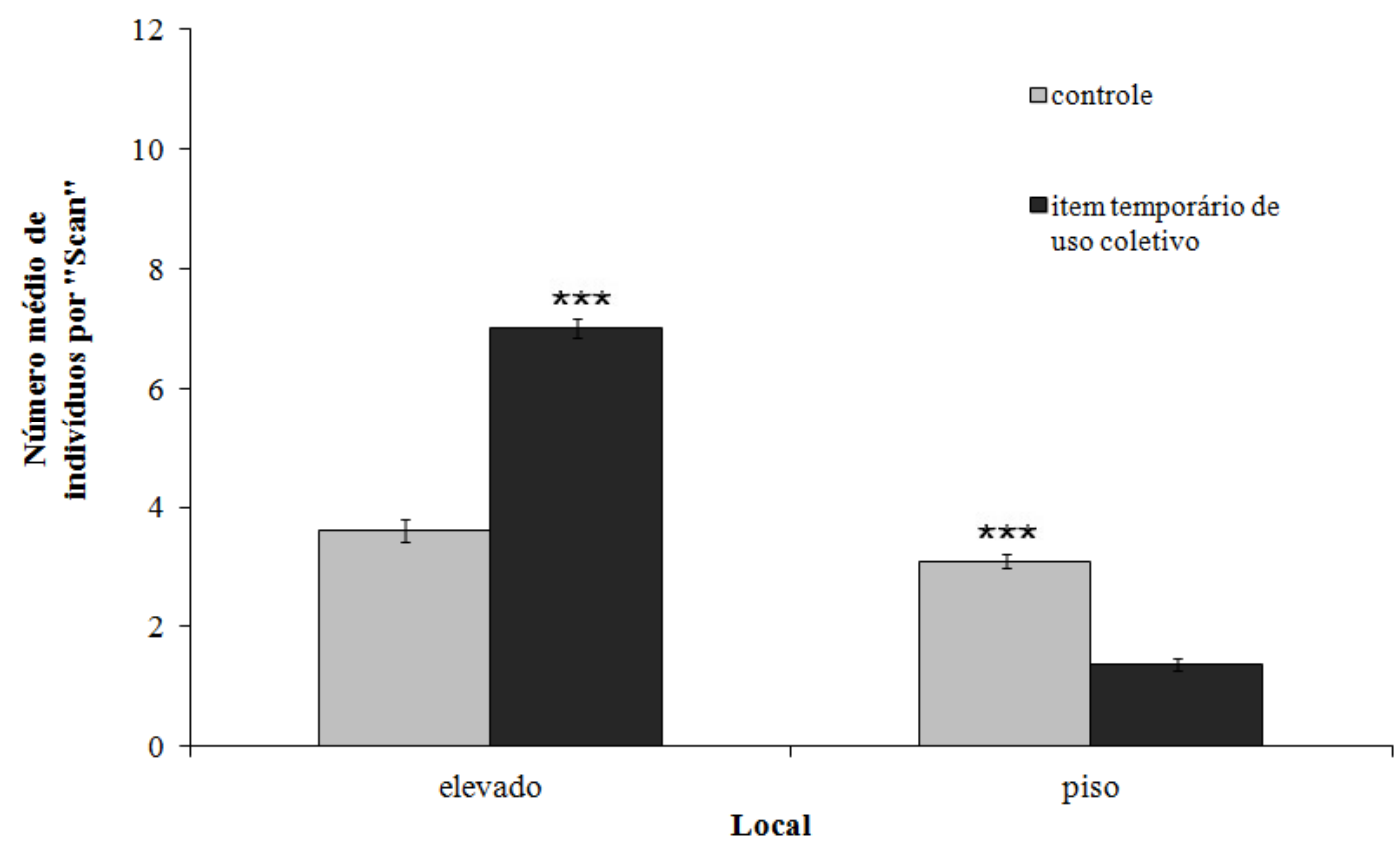

Figura 20: Número médio de indivíduos por "Scan", ocupando as áreas elevadas e de piso, durante os 10 dias de observações na condição Controle e após a introdução do item no Teste Enriquecimento Ambiental Físico Temporário de uso Coletivo.

Conforme representado na Figura 21, os resultados obtidos em relação à frequência diária de interação do grupo, por comportamentos, frente ao item temporário de uso coletivo, nos mostraram que o comportamento "Cheirar" foi o mais executado, na frequência diária de $(\bar{x}=57,50 \pm 3,94)$ interações, significativamente acima da média geral de $(14,03)$ interanños $(n-n$ n1)

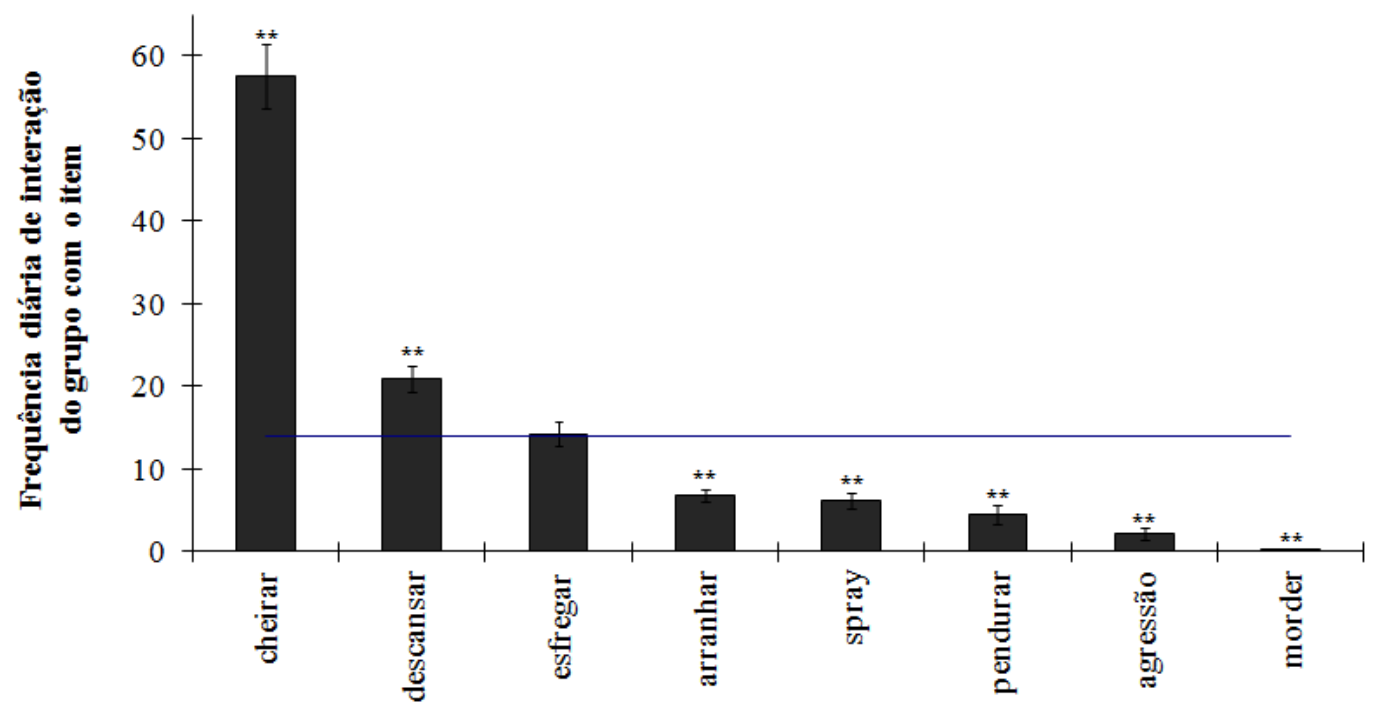

Comportamento

Figura 21: Frequência diária de interação do grupo de animais por comportamentos realizados frente ao item no Teste Enriquecimento Ambiental Físico Temporário de uso Coletivo, ao longo dos 10 dias de observações. 
Ao longo das 3 horas de filmagens no Teste Enriquecimento Ambiental Físico Temporário de uso Coletivo, os resultados nos revelaram que na primeira hora, à frequência diária de contato com o item, foi de $\bar{x}=64,70 \pm 6,89$ contra $\bar{x}=24,90 \pm 3,85$ na segunda hora $(p<0,01)$, chegando à terceira hora com uma frequência diária de $\bar{x}=22,60 \pm 3,53$ interações realizadas pelos indivíduos para com o item temporário de uso coletivo, significativamente menores em relação à primeira hora $(p<0,001)$ (Fig. 22).

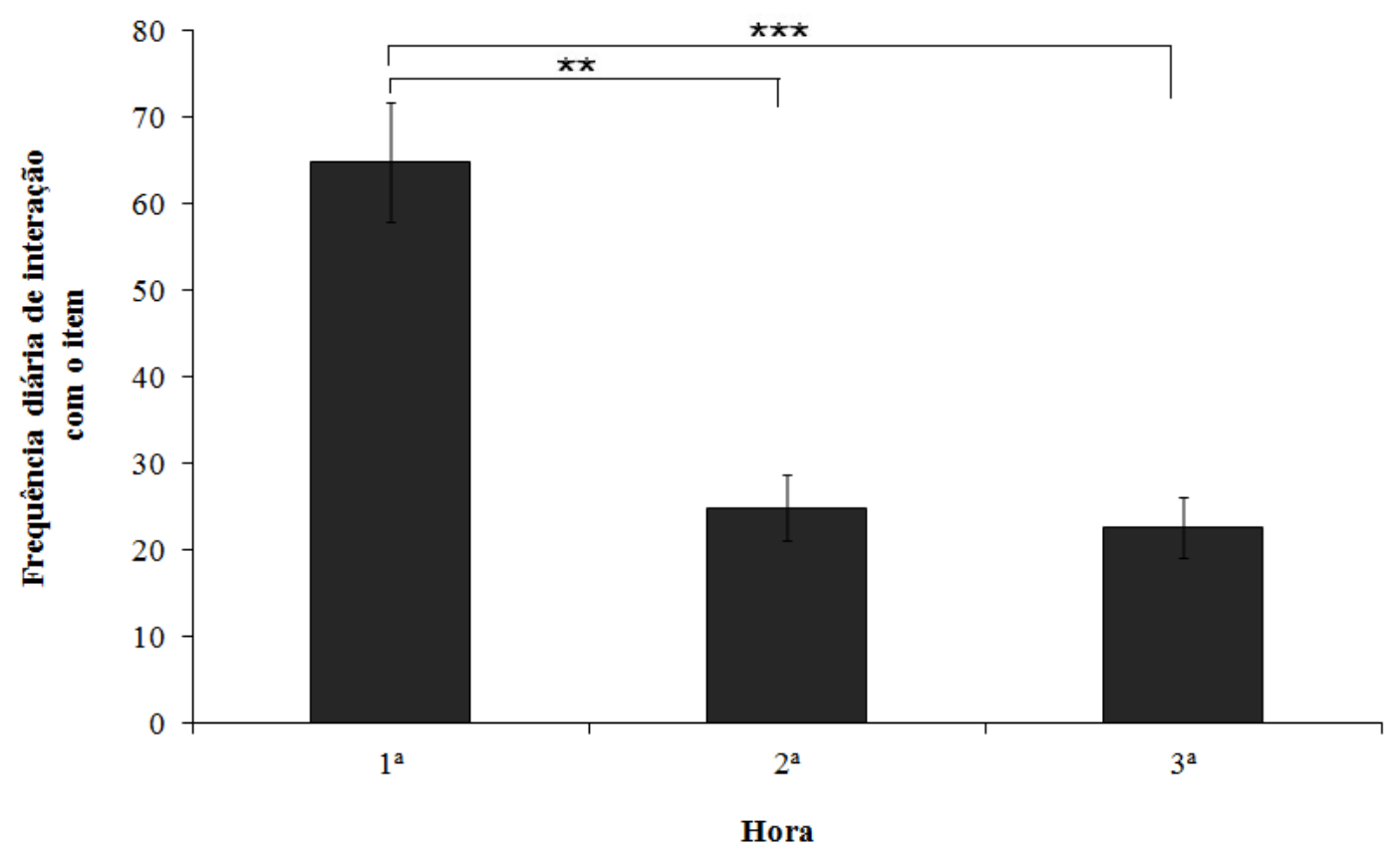

Figura 22: Frequência diária de interação por indivíduo com o item, ao longo das 3 horas de observações, durante os 10 dias do Teste Enriquecimento Ambiental Físico Temporário de uso Coletivo. 
Os resultados obtidos durante os 10 dias de observações do Teste Enriquecimento Ambiental Físico Agudo de uso Coletivo, revelaram que não houve diferença significativa na frequência de interação dos indivíduos com o item temporário de uso coletivo e a média geral de $(3,87)$ interações $(p>0,05)$ (Fig. 23).

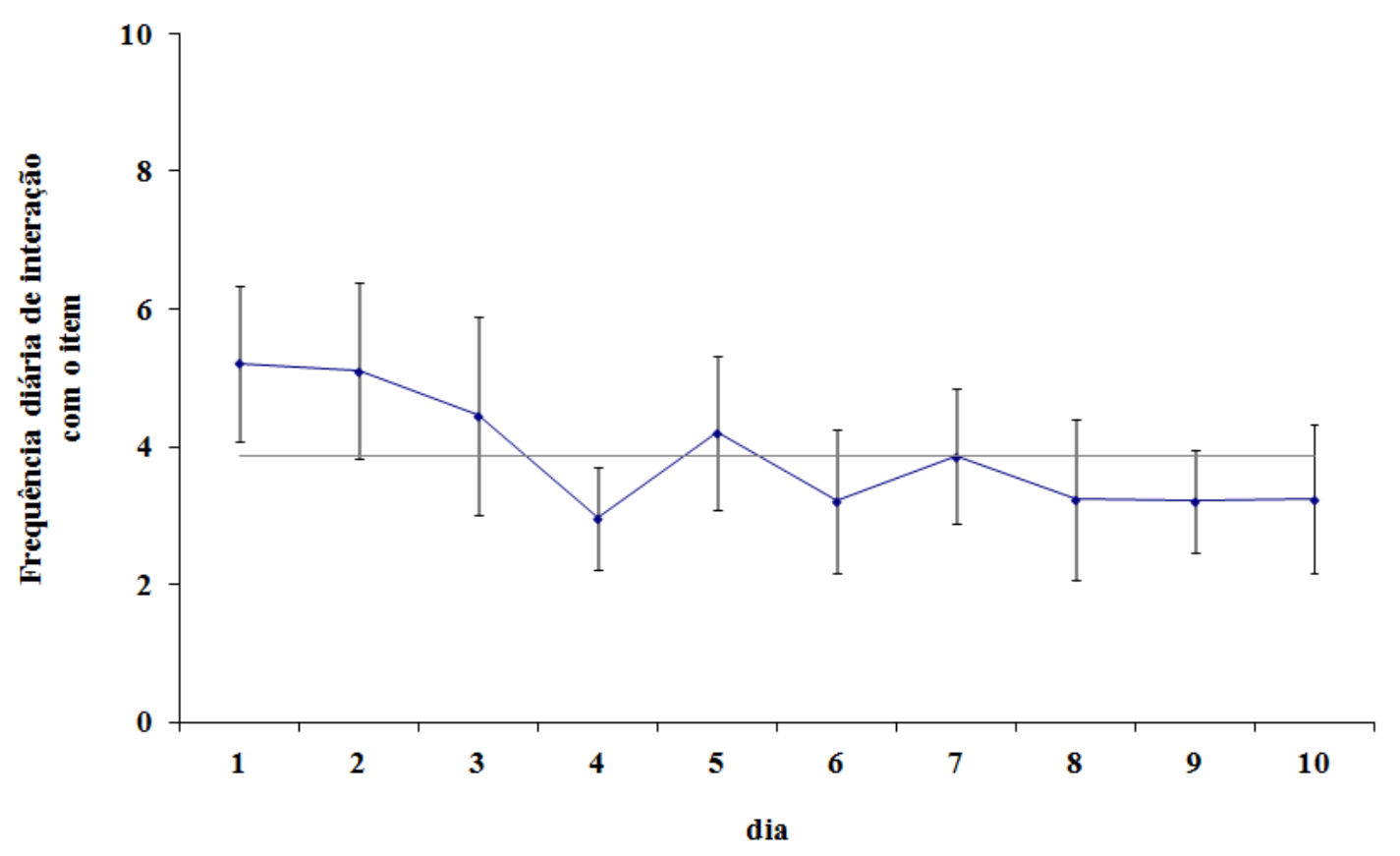

Figura 23: Frequência diária de interação com o item, ao longo dos 10 dias do Teste Enriquecimento Ambiental Físico Temporário de uso Coletivo.

Em relação à latência média de interação com o item, realizada pelos animais, durante os 10 dias de observações, no Teste Enriquecimento Ambiental Físico Temporário de uso Coletivo, os resultados nos mostraram que os animais que interagiram significativamente abaixo da média geral (100,44 minutos), foram: as fêmeas 2.20, 10.4, 4.38, 2.13 e os machos 4.2, 4.15 e 1.7. Dos animais que interagiram significativamente acima da média estão as fêmeas 3.4, 29.1 e 15.1 (Fig. 24). 


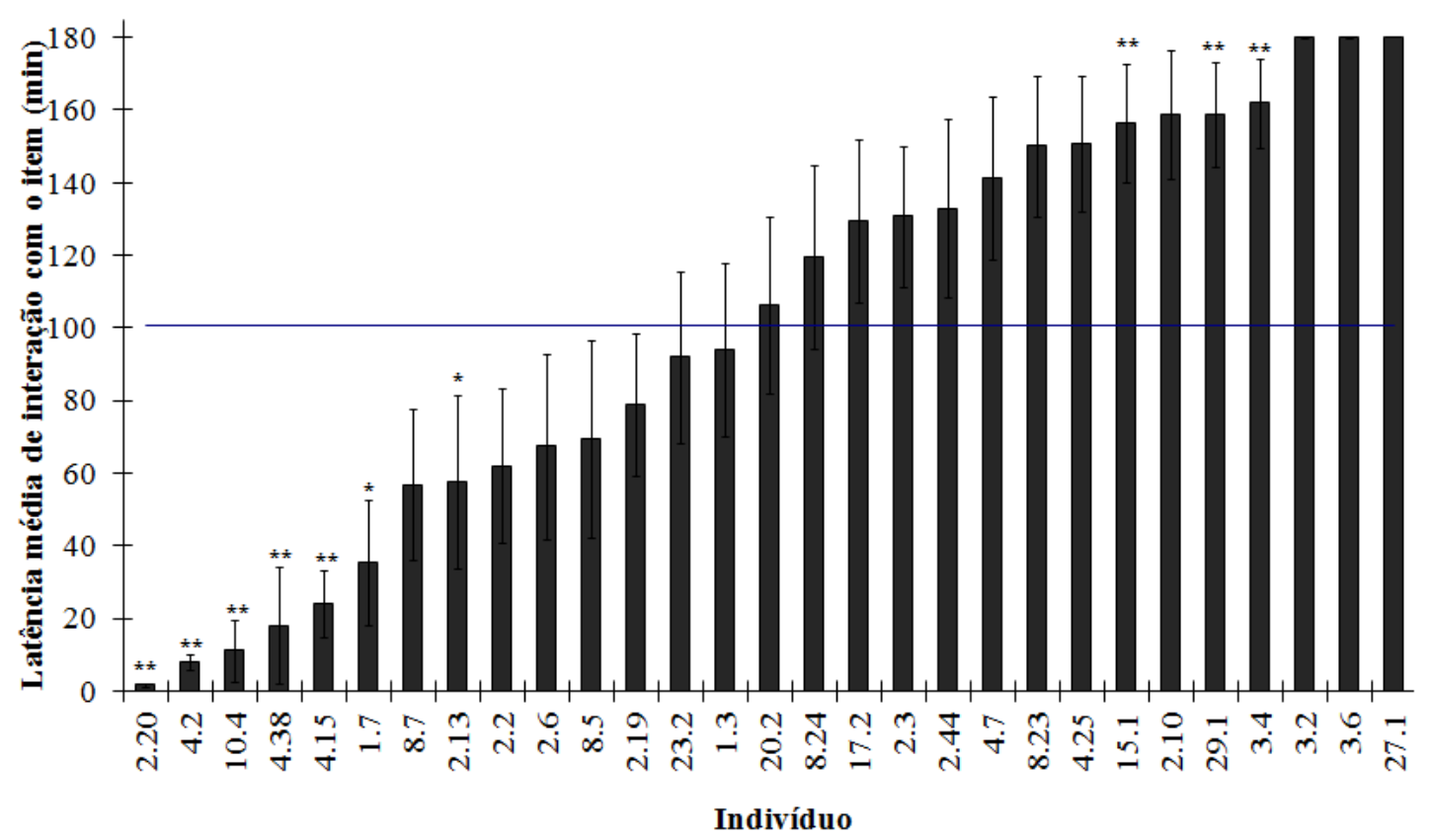

Figura 24: Latência média de interação com o item, realizada pelos animais, durante os 10 dias de observações no Teste de Enriquecimento Ambiental Físico Temporário Coletivo.

Assim, como estão representados na Figura 25, os animais que interagiram com o item temporário de uso coletivo, significativamente acima da média geral $(3,87)$, são: os machos 4.15, 4.2 assim como as fêmeas 2.20, 4.38 e 10.4. Já entre os animais que interagiram abaixo da média, estão: as fêmeas 29.1, 15.1, 4.7, 2.10, 17.2, 4.25, 2.44, 8.24, $8.23,3.4,8.5$, além do macho 8.7. Não houve interação com o item por parte do macho 27.1 e das fêmeas 3.6 e 3.2 .

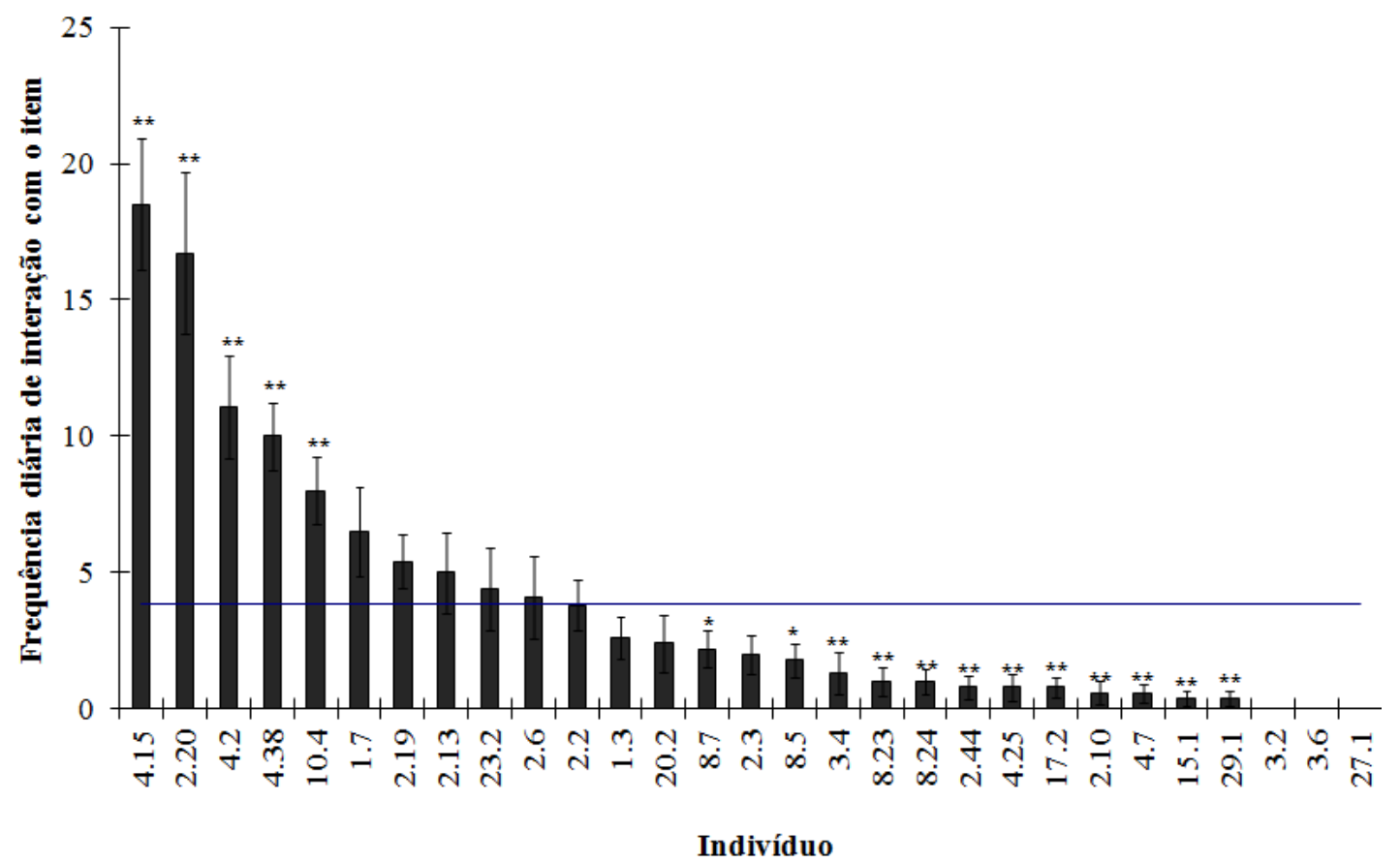

Figura 25: Frequência diária de interação com o item, por indivíduo, durante os 10 dias de observações no Teste de Enriquecimento Ambiental Físico Temporário de Uso Coletivo. 


\subsection{Ocupação de espaços na condição Controle e no Teste Enriquecimento Ambiental Físico Temporá- rio de uso Restrito}

Ao confrontarmos à ocupação de espaços realizada pelos animais, na condição Controle e no Teste Enriquecimento Ambiental Físico Temporário de uso Restrito, constatamos que o número médio de indivíduos por "Scan" ( $\bar{x}=9,84 \pm 0,21)$, ocupando as áreas elevadas foi significativamente maior na presença do item, se comparado ao número médio de indivíduos $(\bar{x}=3,61 \pm 0,18)$ nessa mesma área na condição Controle $(p<0,001)$. Já em relação ao uso do piso, no Teste Enriquecimento Ambiental Físico Temporário de uso Restrito, houve uma diminuição significativa na ocupação dessa área pelos animais, cujo número médio de indivíduos por "Scan" foi de $\bar{x}=0,60 \pm 0,06$, quando comparado à condição Controle, onde o número médio de indivíduos por "Scan" na área de piso foi de $\bar{x}=3,10 \pm 0,13(p<0,001)$ (Fig. 26).

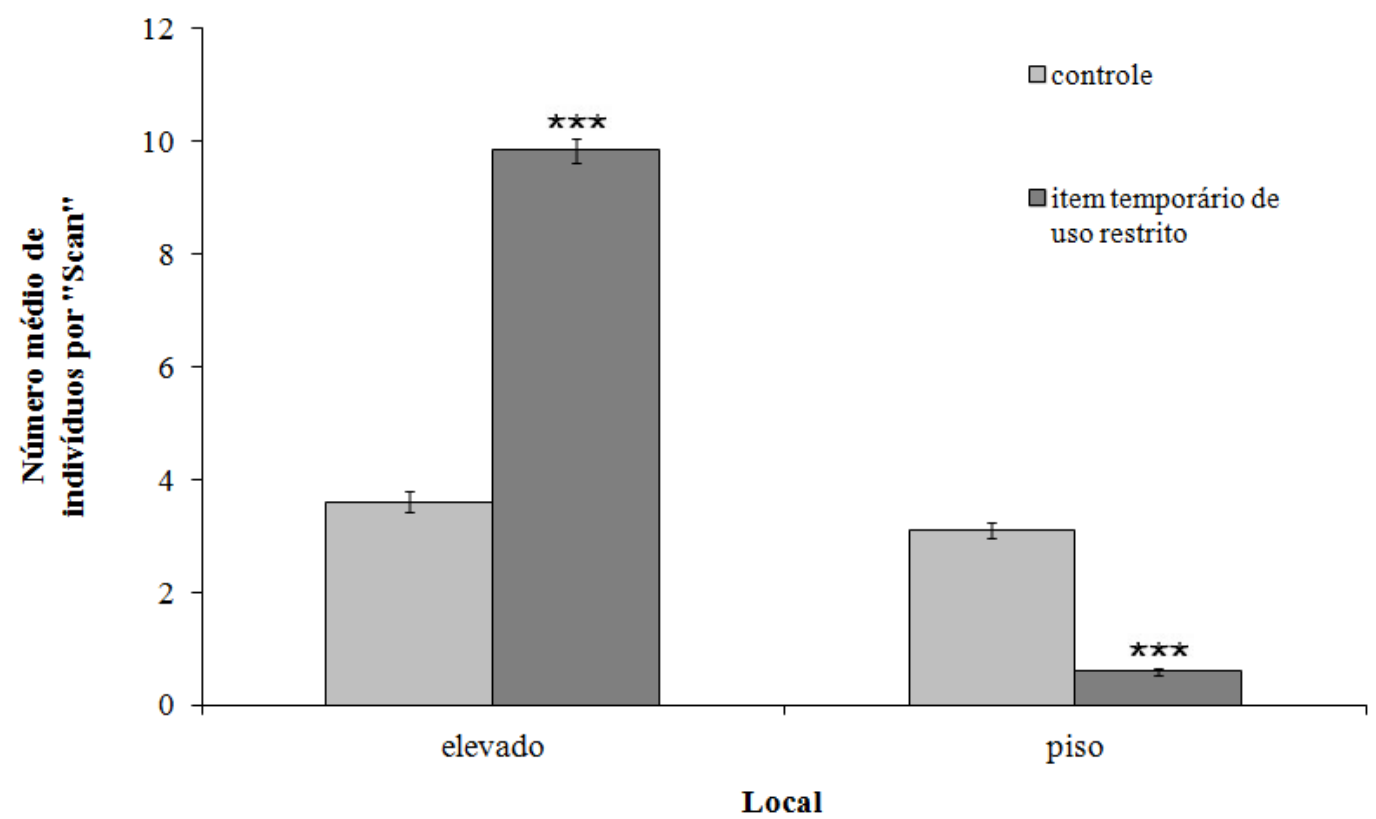

Figura 26: Número médio de indivíduos por "Scan", ocupando as áreas elevadas e de piso, durante os 10 dias de observações na condição Controle e após a introdução do item no Teste Enriquecimento Ambiental Físico Temporário de uso Restrito.

Dentre os comportamentos executados pelos animais em relação ao item temporário de uso restrito, o comportamento "Cheirar" foi o mais realizado, apresentando a frequência diária de $\bar{x}=51,30 \pm 7,04$ interações, significativamente acima da média geral de $(8,61)$ interações $(p<0,01)$ (Fig. 27a). Sendo este também, o comportamento mais executado na área externa do item, apresentando a frequência diária de $(\bar{x}=43,40 \pm 5,97)$ interações, 
significativamente acima da média geral de (4,59) interações $(p<0,01)$ (Fig. 27b). Já em relação aos comportamentos realizados na área interna do item ao longo dos 10 dias do Teste Enriquecimento Ambiental Agudo de uso Restrito, o comportamento "Autogrooming" foi o mais executado pelo grupo de animais, significativamente acima da média geral $(2,66)$, apresentando a frequência diária de $(\bar{x}=10,60 \pm 1,85)$ interações $(p<0,01)$ (Fig. 27c). Sobre os comportamentos executados na área próxima ao item temporário de uso restrito, o comportamento "Descansar" foi o mais realizado pelo grupo de animais, apresentando a frequência diária de $(\bar{x}=6,60 \pm 1,34)$ interações, significativamente acima da média geral de $(1,36)$ interações $(p<0,01)$ (Fig. 27d).

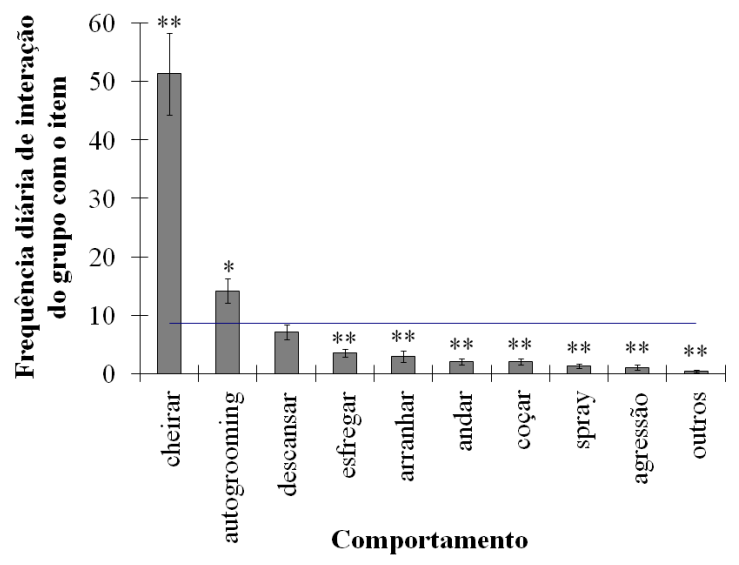

(A)

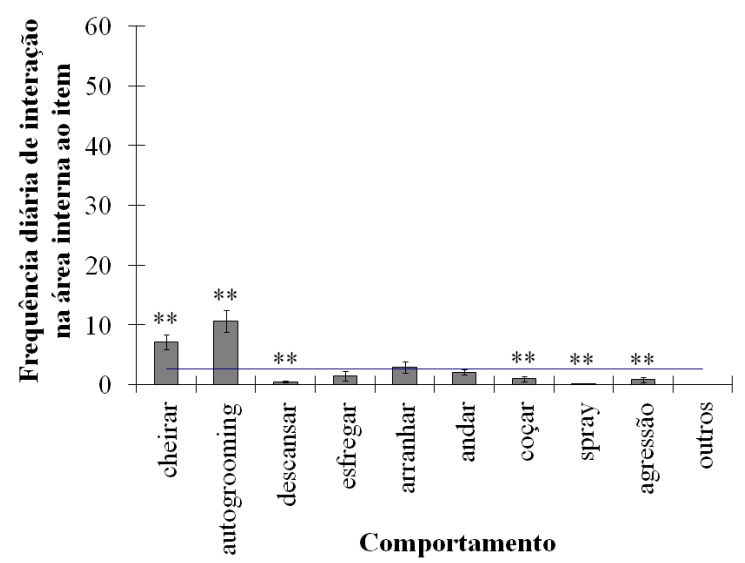

(C)

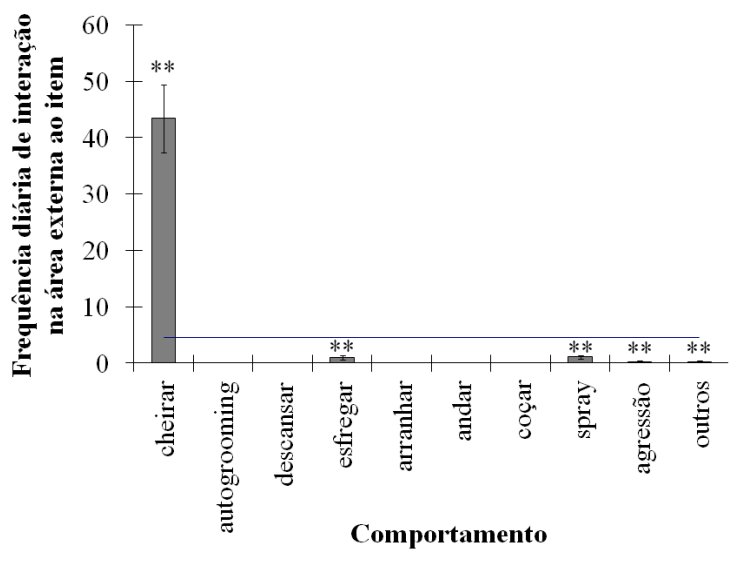

(B)

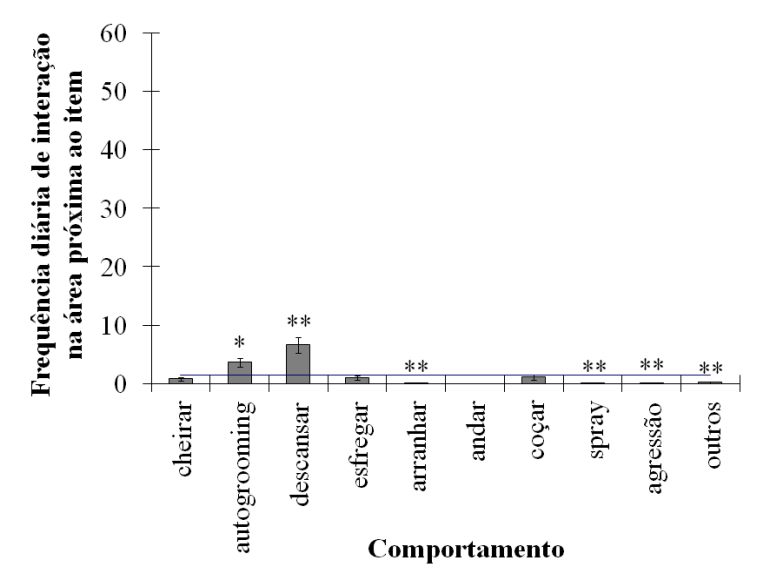

(D)

Figura 27: Frequência diária de comportamentos realizados frente ao item: (A) no total das observações, (B) na área externa ao item, (C) na área interna ao item e (D) na área próxima ao item, ao longo dos 10 dias do Teste Enriquecimento Ambiental Físico Temporário de uso Restrito.

Ao se tratar da interação do grupo de animais frente aos locais/item no Teste Enriquecimento Ambiental Físico Temporário de uso Restrito, a frequência diária de interação na área externa ao item, foi de $(\bar{x}=45,90 \pm 6,04)$, significativamente maior, quando 
comparada à frequência diária de interação do grupo na área próxima ao item, onde a média foi de $(\bar{x}=13,60 \pm 2,10)$ interações $(p<0,001)$ (Fig. 28).

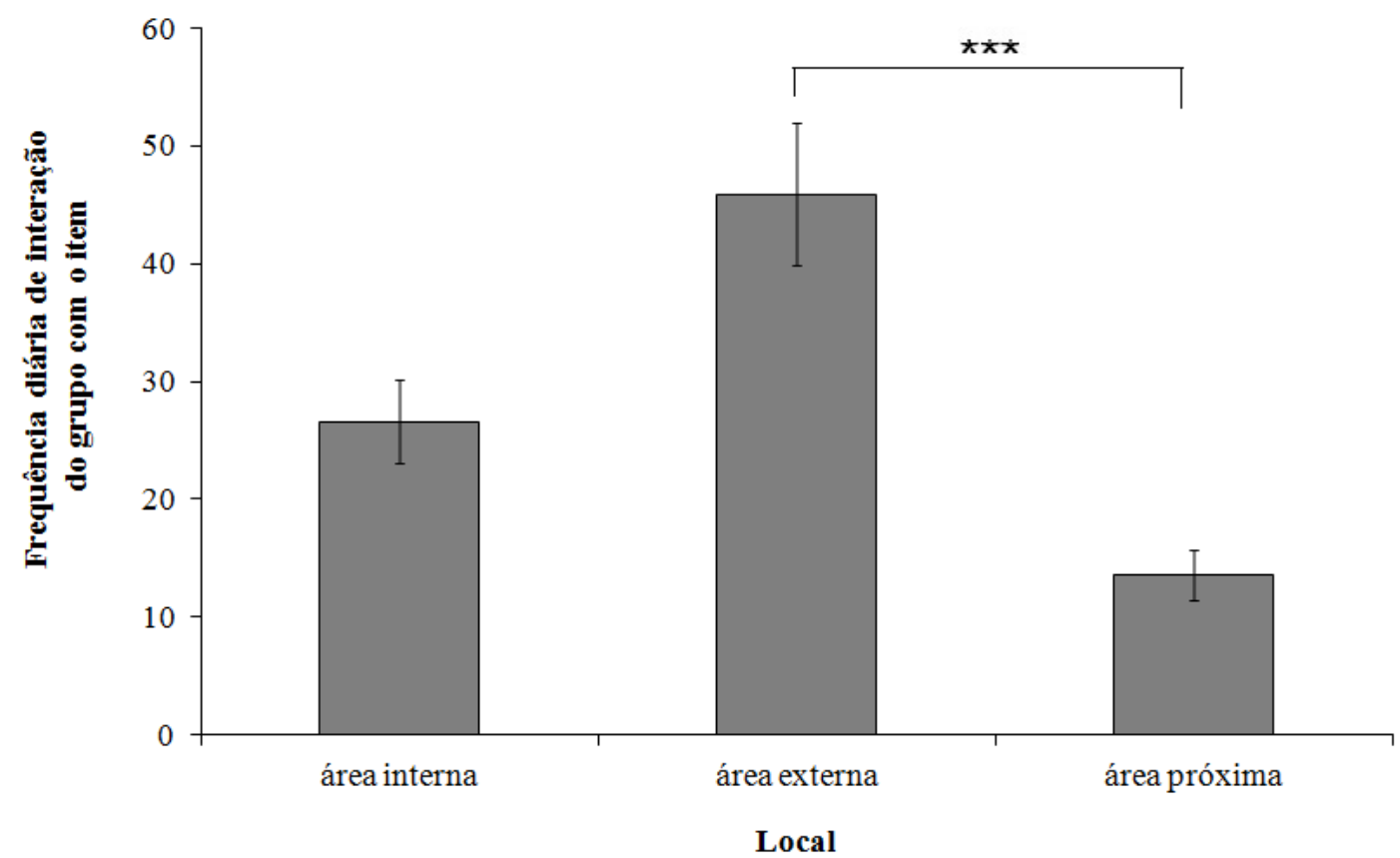

Figura 28: Frequência diária de interação do grupo de animais frente aos locais/item: área interna (animais ocupando internamente o item), área externa (animais interagindo externamente ao item) e área próxima (animais ocupando as proximidades do item) no Teste Enriquecimento Ambiental Físico Temporário de uso Restrito, ao longo dos 10 dias de observações.

Os resultados obtidos em relação ao tempo médio de permanência interagindo (na área interna ou próxima) ao item, realizado durante as três horas de observações, no Teste Enriquecimento Ambiental Agudo de uso Restrito, nos revelaram que os animais, no geral, permaneceram significativamente mais tempo interagindo na área interna do item, ficando em média $\bar{x}=6,50 \pm 1,40$ minutos, em relação ao tempo médio de interação dos indivíduos na área próxima ao item, no total de $\bar{x}=2,69 \pm 0,98(p<0,05)$ (Fig. 29). 


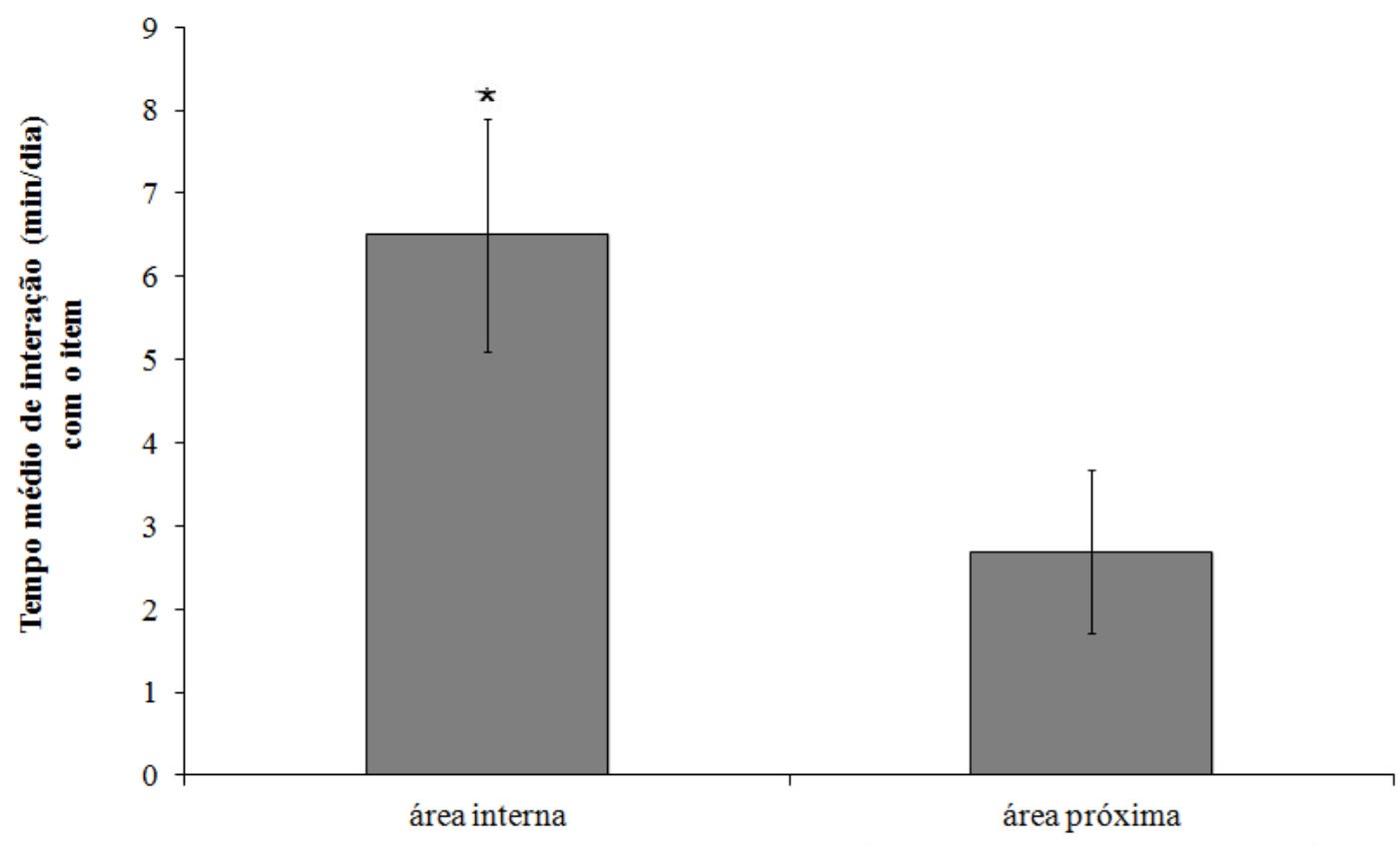

Figura 29: Tempo médio de interação com o item (área interna ou próxima), por indivíduo, durante as três horas de observações no Teste Enriquecimento Ambiental Físico Temporário de uso Restrito, ao longo dos 10 dias.

Assim como nos mostra a Figura 30, não houve diferença significativa na frequência diária de interação por indivíduo com o item, entre as horas de observações, no Teste Enriquecimento Ambiental Físico Agudo de uso Restrito. Onde na primeira hora, à frequência diária de interação com o item foi de $\bar{x}=33,90 \pm 7,07$ minutos, na segunda hora $\bar{x}=21,90 \pm 3,18$ e na terceira hora a frequência diária de interação com o item foi de $\bar{x}=30,30 \pm 3,78$ minutos $(p>0,05)$.

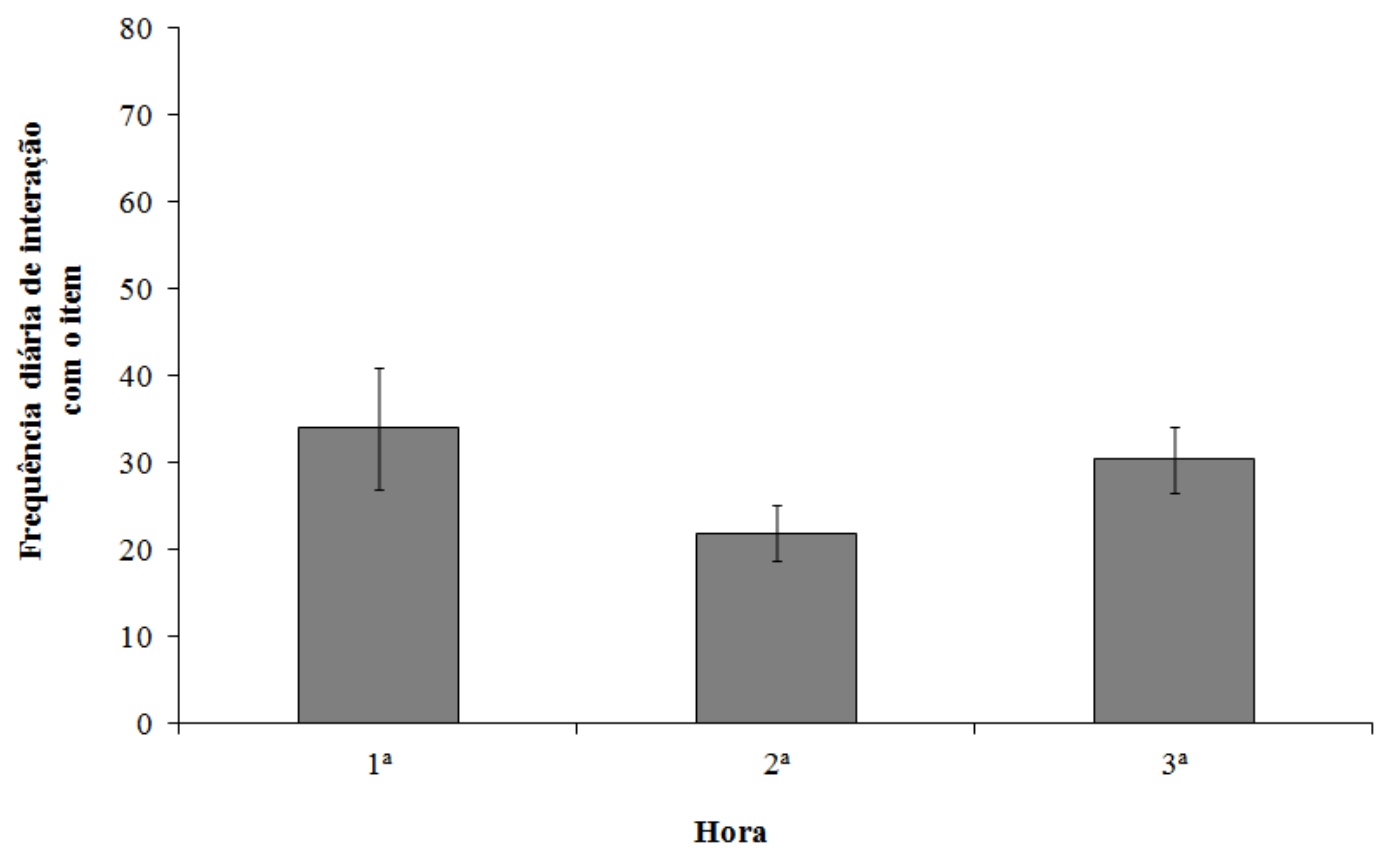

Figura 30: Frequência diária de interação por indivíduo com o item, ao longo das três horas de observações, durante os 10 dias do Teste Enriquecimento Ambiental Físico Temporário de uso Restrito. 
A Figura 31 ilustra que ao longo dos 10 dias do Teste Enriquecimento Ambiental Físico Agudo de uso Restrito, a média geral de interação dos indivíduos com o item foi de $(2,97)$. Onde no primeiro dia a frequência foi de $\bar{x}=5,38 \pm 1,01$ interações, significativamente acima da média geral $(p<0,05)$, do segundo ao sétimo dia, as interações permaneceram dentro da média geral, e a partir do oitavo dia, houve uma queda na frequência de interação com o item, chegando a $\bar{x}=1,34 \pm 0,45$ interações por indivíduo, significativamente abaixo da média geral $(p<0,001)$.

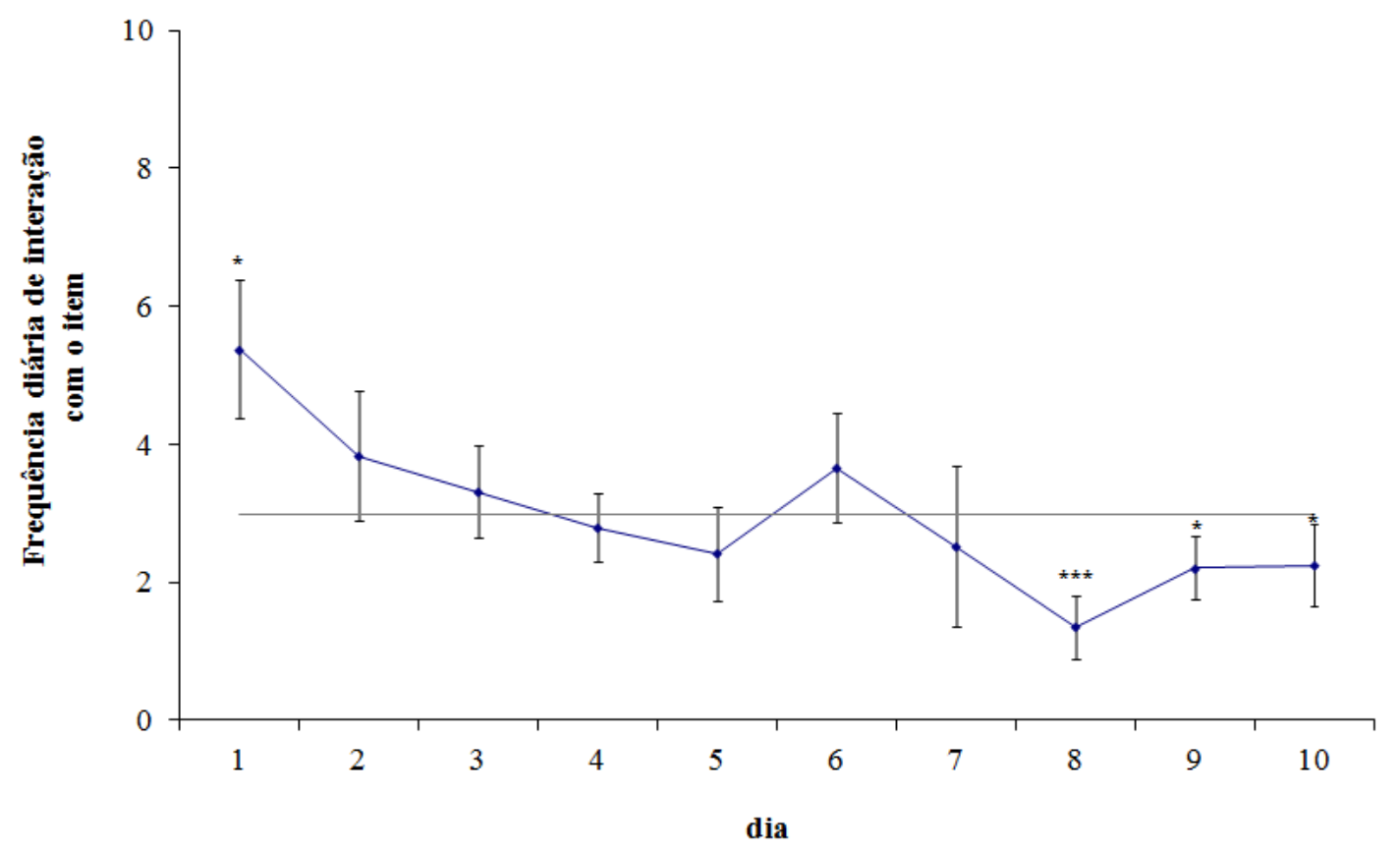

Figura 31: Frequência diária de interação com o item, ao longo dos 10 dias do Teste Enriquecimento Ambiental Físico Temporário de uso Restrito.

Em relação à latência média de interação com o item temporário de uso restrito, realizada pelos animais, os resultados nos mostraram que dentre os animais que interagiram significativamente abaixo da média geral (95,29 minutos), estão as fêmeas 2.20, 8.5, 8.24 e os machos 8.7, 4.2 e 2.19. Já entre os animais que interagiram acima da média, estão: as fêmeas 2.10, 3.6, 4.25, 8.23 e 2.44, assim como o macho 23.2 (Fig. 32). 


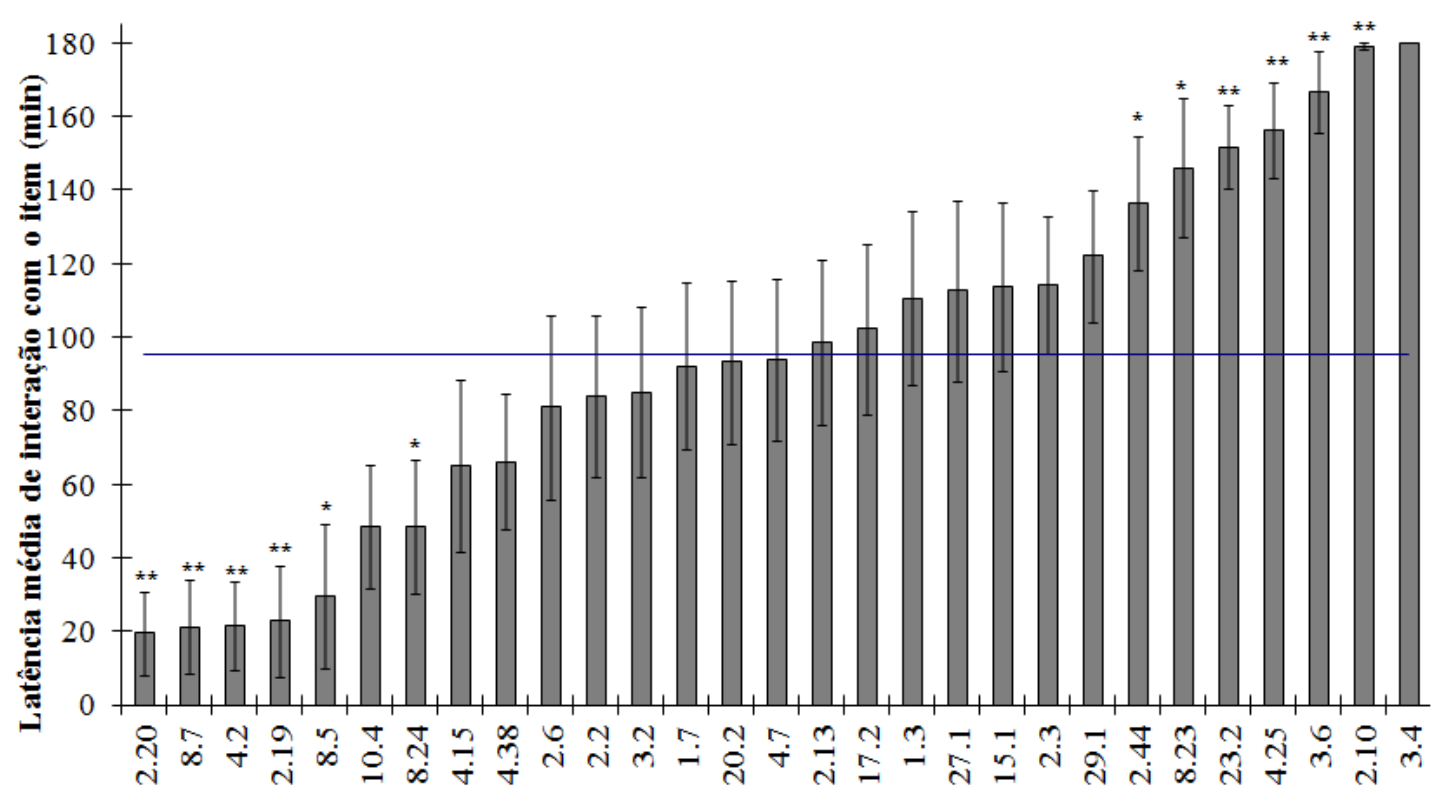

Indivíduo

Figura 32: Latência média de interação com o item, por indivíduo, durante os 10 dias de observações no Teste de Enriquecimento Ambiental Físico Temporário de uso Restrito.

Conforme representado na Figura 33, entre os animais que interagiram significativamente acima da média geral $(2,97)$ estão: o macho 4.2 assim como a fêmea 2.20. Já entre os animais que interagiram abaixo da média, estão as fêmeas 2.10, 3.6, 4.25, 2.44, 15.1 e os machos 27.1 e o 2.3. Não houve interação com o item por parte da fêmea 3.4.

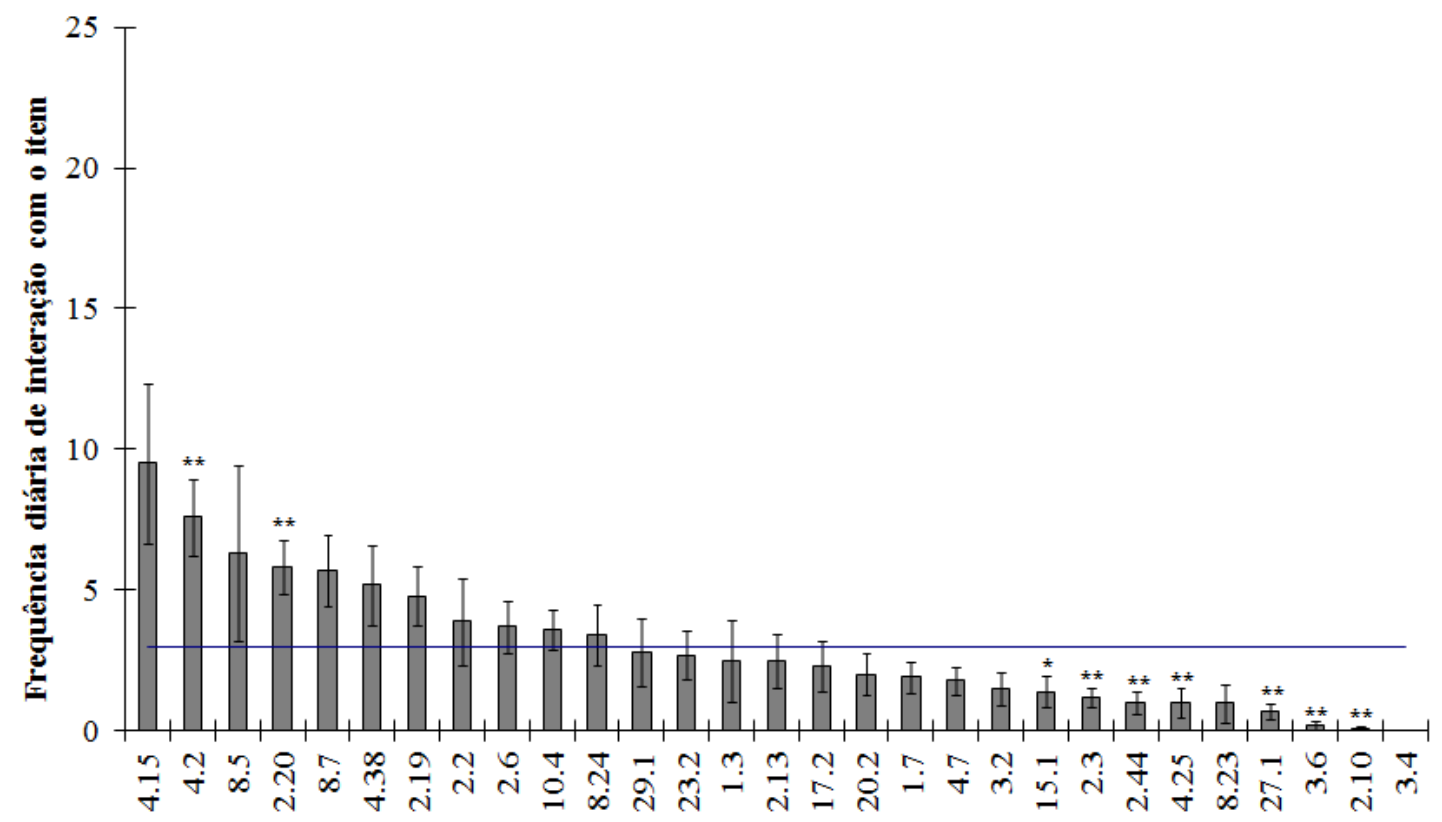

Indivíduo

Figura 33: Frequência diária de interação com o item, por indivíduo, durante os 10 dias de observações no Teste de Enriquecimento Ambiental Físico Temporário de uso Restrito. 
Os resultados nos revelaram que ao longo do Teste Enriquecimento Ambiental Físico Temporário de uso Restrito, houve compartilhamento do item, por alguns indivíduos, que permaneceram em duplas, na área interna ou próxima ao item. Dos animais que compartilharam a área interna do item, estão: a fêmea 8.5 que compartilhou o item por mais de uma hora com a fêmea 3.2, além do macho 8.7, que também compartilhou o item com os machos 4.2 e 4.15, por mais de uma hora, já com as fêmeas 4.7, 2.20 e 8.5 o compartilhamento na área interna ao item foi de até 30 minutos, e com o macho 27.1 e a fêmea 2.2, compartilhou o item por menos de um minuto (Fig. 34).

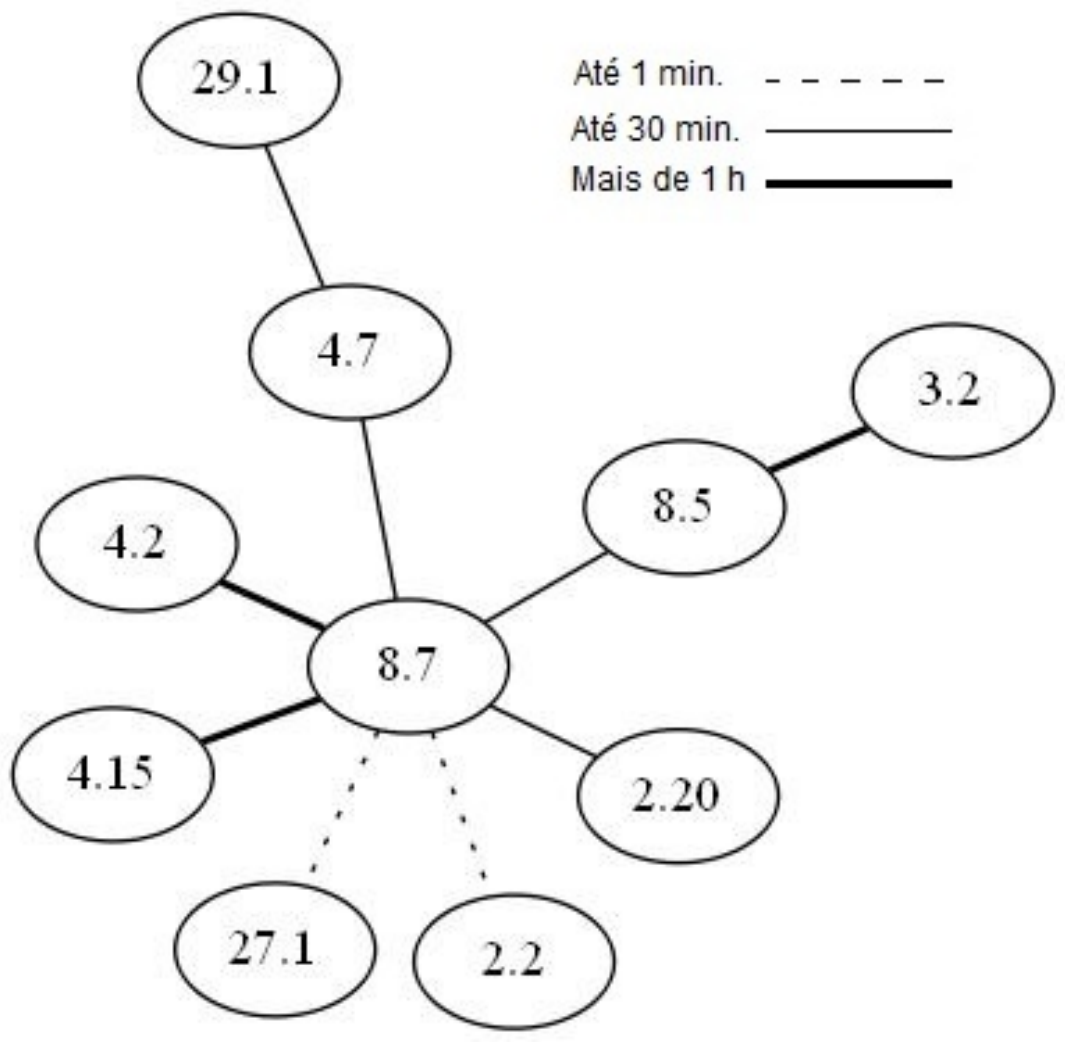

Figura 34: Compartilhamento entre os indivíduos na área interna ao item, durante os 10 dias de observações, no Teste Enriquecimento Ambiental Físico Temporário de uso Restrito. 
Dentre os animais que compartilharam a área próxima ao item temporário de uso restrito, estão a fêmea 2.20, que compartilhou o item com o macho 4.15, por mais de uma hora, com a fêmea 1.3, o compartilhamento foi de até 30 minutos, e com as fêmeas 8.5, 2.13, 10.4, 2.6 e 15.1 compartilhou na área próxima ao item por menos de um minuto (Fig. 35).

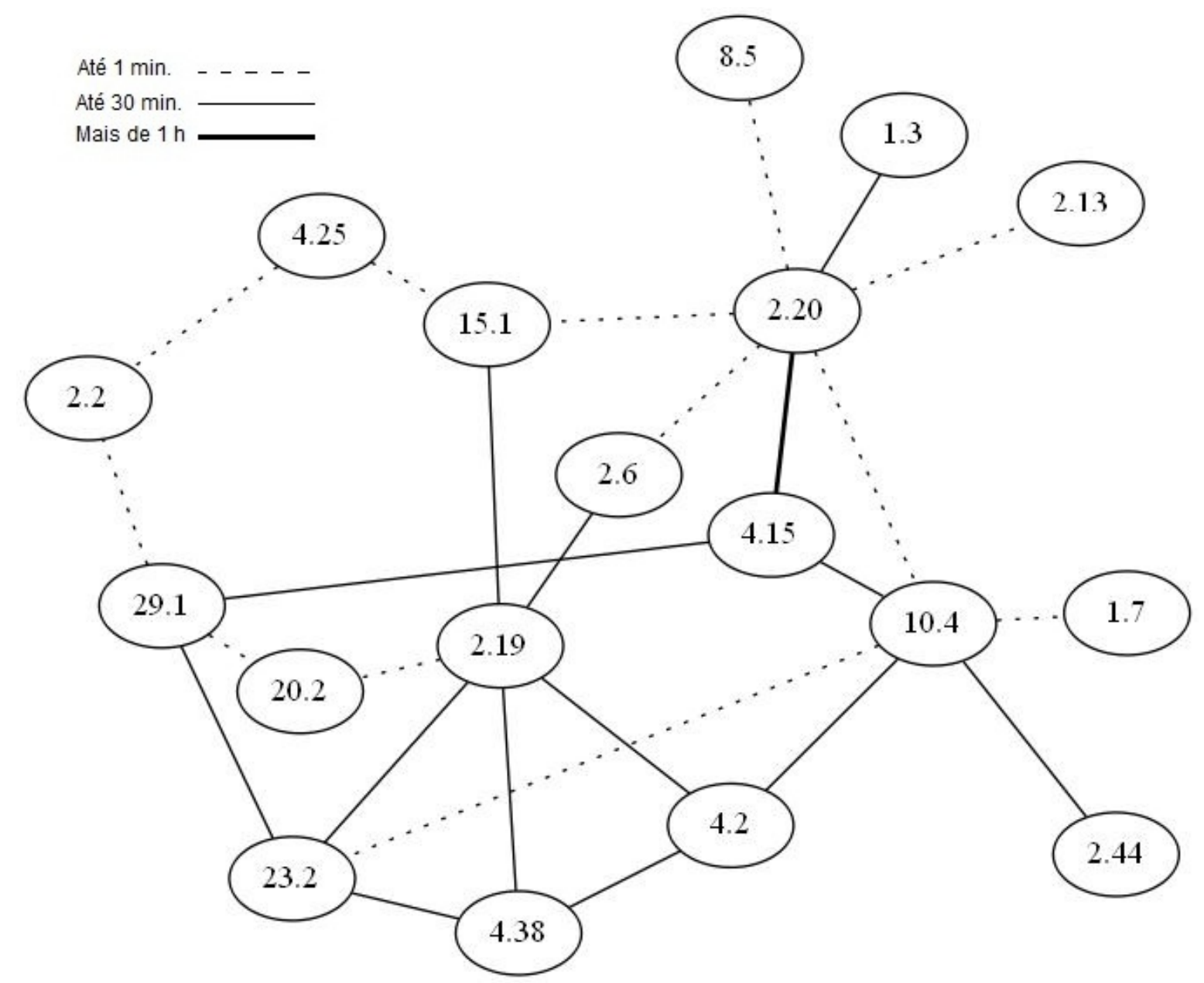

Figura 35: Compartilhamento entre os indivíduos na área próxima ao item, durante os 10 dias de observações, no Teste Enriquecimento Ambiental Físico Temporário de uso Restrito. 
Ao reunir todos os dados que obtivemos sobre a frequência de interação dos indivíduos com os itens de enriquecimento (permanente de uso coletivo, temporário de uso coletivo e temporário de uso restrito) a partir da análise da média de interação dos animais para cada item e a média geral, propusemos uma ordenação dos animais no que se refere ao uso dos enriquecimentos ambientais. Resultando desta forma, em um "Ranking" dos indivíduos para a interação com os itens de enriquecimento propostos nos três testes (Tabela 2).

Tabela 2: Classificação de cada indivíduo em relação à média da frequência de interação com os itens de enriquecimento ambiental (permanente de uso coletivo, temporário de uso coletivo e temporário de uso restrito).

\begin{tabular}{|c|c|c|c|c|c|c|}
\hline \multicolumn{7}{|c|}{$\begin{array}{c}\bar{x} \text { da frequência de interação } \\
\text { com os itens de enriquecimento }\end{array}$} \\
\hline$\Delta$ & Gênero & $\begin{array}{c}\text { Permanente } \\
\text { de uso } \\
\text { Coletivo }\end{array}$ & $\begin{array}{c}\text { Temporário } \\
\text { de uso } \\
\text { Coletivo }\end{array}$ & $\begin{array}{c}\text { Temporário } \\
\text { de uso } \\
\text { Restrito }\end{array}$ & Geral & Ranking \\
\hline 2.20 & $\mathrm{~F}$ & 0,9 & 16,7 & 5,8 & 7,8 & $1^{\underline{O}}$ \\
\hline 4.2 & M & 2,6 & 11,1 & 7,6 & 7,1 & $2^{\underline{O}}$ \\
\hline 4.38 & $\mathrm{~F}$ & 0,4 & 10,0 & 5,2 & 5,2 & $3^{\mathrm{O}}$ \\
\hline 29.1 & $\mathrm{~F}$ & 11,2 & 0,4 & 2,8 & 4,8 & $4^{\mathrm{O}}$ \\
\hline 10.4 & $\mathrm{~F}$ & 0,8 & 8,0 & 3,6 & 4,1 & $5^{\mathrm{O}}$ \\
\hline 8.7 & M & 3,7 & 2,2 & 5,7 & 3,9 & $6^{\mathbf{O}}$ \\
\hline 8.5 & $\mathrm{~F}$ & 3,3 & 1,8 & 6,3 & 3,8 & $7^{\underline{0}}$ \\
\hline 4.15 & M & 0 & 1,0 & 9,5 & 3,5 & $8^{0}$ \\
\hline 2.19 & M & 0 & 5,4 & 4,8 & 3,4 & $9^{\underline{O}}$ \\
\hline 20.2 & M & 5,7 & 2,4 & 2,0 & 3,4 & $10^{\mathrm{O}}$ \\
\hline 1.7 & M & 1,0 & 6,5 & 1,9 & 3,1 & $11^{\mathrm{O}}$ \\
\hline 2.6 & $\mathrm{~F}$ & 0 & 4,1 & 3,7 & 2,6 & $12^{\mathrm{O}}$ \\
\hline 2.2 & $\mathrm{~F}$ & 0 & 3,8 & 3,9 & 2,6 & $13^{\mathrm{O}}$ \\
\hline 4.7 & $\mathrm{~F}$ & 5,2 & 0,6 & 1,8 & 2,5 & $14^{\mathrm{O}}$ \\
\hline 2.13 & $\mathrm{~F}$ & 0 & 5,0 & 2,5 & 2,5 & $15^{\mathrm{O}}$ \\
\hline 23.2 & M & 0 & 4,4 & 2,7 & 2,4 & $16^{\mathrm{o}}$ \\
\hline 1.3 & $\mathrm{~F}$ & 1,8 & 2,6 & 2,5 & 2,3 & $17^{\mathrm{O}}$ \\
\hline 27.1 & M & 5,0 & 0 & 0,7 & 1,9 & $18^{\circ}$ \\
\hline 3.2 & $\mathrm{~F}$ & 3,8 & 0 & 1,5 & 1,8 & $19^{\mathrm{o}}$ \\
\hline 2.44 & $\mathrm{~F}$ & 3,0 & 0,8 & 1,0 & 1,6 & $20^{\mathrm{O}}$ \\
\hline 8.24 & $\mathrm{~F}$ & 0 & 1,0 & 3,4 & 1,5 & $21^{\mathrm{O}}$ \\
\hline 2.3 & M & 0 & 2,0 & 1,2 & 1,1 & $22^{\mathrm{O}}$ \\
\hline 17.2 & $\mathrm{~F}$ & 0 & 0,8 & 2,3 & 1,0 & $23^{\mathrm{O}}$ \\
\hline 2.10 & $\mathrm{~F}$ & 1,9 & 0,6 & 0,1 & 0,9 & $24^{\mathrm{O}}$ \\
\hline 3.4 & $\mathrm{~F}$ & 1,1 & 1,3 & 0 & 0,8 & $25^{\mathrm{O}}$ \\
\hline 4.25 & $\mathrm{~F}$ & 0,3 & 0,8 & 1,0 & 0,7 & $26^{\mathrm{O}}$ \\
\hline 8.23 & $\mathrm{~F}$ & 0 & 1,0 & 1,0 & 0,7 & $27^{\mathrm{O}}$ \\
\hline 15.1 & $\mathrm{~F}$ & 0 & 0,4 & 1,4 & 0,6 & $28^{\mathrm{o}}$ \\
\hline 3.6 & $\mathrm{~F}$ & 1,4 & 0 & 0,2 & 0,5 & $29^{\mathrm{O}}$ \\
\hline
\end{tabular}

$\Delta$ (indivíduos) e Gênero (M: macho e F: fêmea). 


\section{Discussão}

Nossos resultados mostraram que em relação ao padrão de ocupação dos indivíduos na condição Controle, houve uma preferência pelos animais na utilização das áreas elevadas, quando comparado à ocupação desses animais em áreas de piso, corroborando os trabalhos de Carlstead (1993) [23] e Barry (1999) [97], que afirmam sobre a importância de inserir áreas elevadas nos recintos de gatos domésticos, onde a possibilidade de exploração bidimensional do ambiente, resulta no aumento dos comportamentos normais da espécie, além de servir como pontos de observação para os animais, permitindo que os mesmos, possam se manter distantes de outros gatos, caso seja necessário. Garantindo assim, um maior controle do ambiente em que estão sendo mantidos, favorecendo o aumento dos níveis de bem-estar desses animais [24].

A confirmação da preferência dos animais em utilizarem áreas elevadas se deu quando esse padrão de ocupação de espaço se manteve ao longo dos Testes de Enriquecimento Ambiental Físico Permanente de uso Coletivo, Temporário de uso Coletivo e de uso Restrito, ao serem introduzidos no recinto, itens de enriquecimento ambiental.

Ao compararmos a ocupação de espaços realizada pelos animais, na condição Controle e no Teste Enriquecimento Ambiental Físico Permanente de uso Coletivo, com a presença do item de enriquecimento, renovando os locais já conhecidos pelos indivíduos, notou-se que houve uma alteração na distribuição espacial dos animais. Onde os resultados obtidos mostraram que o número médio de indivíduos por "Scan" ocupando as áreas elevadas foi significativamente maior no Teste Enriquecimento Ambiental Físico Permanente de uso Coletivo, cujas áreas estavam enriquecidas, se comparado ao número médio de indivíduos nessa mesma área na condição Controle, que não apresentava o item $(p<0,001)$ (Fig. 13). Ressaltando assim, a efetividade do item de enriquecimento ambiental, que se apresentou como um atrativo e fez com que um maior número de animais utilizasse e explorasse mais as áreas em que estavam inseridos.

Ao avaliarmos a ocupação do espaço, por meio da densidade (número de animais/ $\mathrm{m}^{2}$ ) 
foi visto uma queda na utilização da área de piso, mesmo esta estando disposta em maior dimensão e um aumento na densidade de animais nos locais elevados, disponíveis em menor área no recinto e representados pelas plataformas que estavam enriquecidas, o que também corrobora a literatura atual onde se afirma que o ambiente físico é um fator essencial para o bem-estar animal [98], cuja estrutura adequada do ambiente não se baseia somente em fornecer uma grande área de piso [16], mas sim, o ideal é que seja oferecido aos gatos, a complexidade ambiental, por meio da introdução de áreas elevadas, que irão atuar na diminuição de eventos aversivos entre os membros do grupo [97, 99], proporcionando pontos que viabilizam a identificação de outros co-específicos [35]. E que estas áreas, sejam enriquecidas, oferecendo aos animais, a possibilidade de realizarem comportamentos ativos, típicos à espécie [73, 24].

Ambientes de cativeiro, apresentam limitações no espaço e raramente conseguem ter suas áreas ampliadas. No entanto, afim de melhorar as condições desse ambiente, técnicas de enriquecimento ambiental devem ser incorporadas de diversas maneiras, com a alteração na estrutura física do recinto, mudando a localização de objetos já conhecidos pelos animais, ou através da apresentação de novos estímulos (olfativos, auditivos, visuais) ou ainda, por meio da introdução de novos itens [100]. Garantindo desse modo à manutenção da novidade dentro de um ambiente conhecido, simulando a variabilidade de experiências em vida livre e estimulando os comportamentos espécie-específicos, principalmente o comportamento exploratório [71, 101].

Comportamento este, que não tem sido avaliado de forma significativa em gatos domésticos. Onde os trabalhos que relatam sucintamente a respeito deste tema, possuem como foco assuntos sobre comportamento alimentar [102], relações de dominância [103, 104], e em sua maioria abordam o enriquecimento ambiental para felinos em cativeiro, utilizando o comportamento exploratório como um dos indicadores do nível de bem estar desses animais [23, 72, 105].

Outro aspecto da pesquisa em bem-estar animal, de acordo com Duncan e Fraser (1997) [15], envolve o estudo das preferências de um animal por diferentes ambientes e a força da motivação destes, para obter ou evitar, certos fatores. Os chamados testes de preferência constituem a forma mais comum de testar escolhas e frequentemente identificam fatores ambientais que promoverão bem-estar [106, 107].

A fim de verificar se a preferência dos animais em utilizar as áreas elevadas no Teste Enriquecimento Ambiental Físico Permanente de uso Coletivo, se deu pelo fato destas, estarem localizadas em uma posição acima do solo, ou se foi devido a introdução do item 
permanente de uso coletivo, mudamos a disposição desses itens, em função da altura das plataformas. Os resultados revelaram que na "Disposição 1" (plataformas "f1- superior" e "f4-inferior" com o item de enriquecimento, e plataformas "f2- inferior" e "f3-superior" sem o item) houve uma preferência primordial na ocupação das plataformas enriquecidas, seguidas da preferência de ocupar as plataformas localizadas em uma posição superior (Fig. 16a), revelando que o item permanente de uso coletivo, foi o que surtiu o efeito de novidade e atraiu os animais para as plataformas, independentemente da posição que estas se encontravam.

Já na Figura 16b que mostra o uso das plataformas com o item permanente de uso coletivo na "Disposição 2" (plataformas "f2- inferior" e "f3-superior" com o item de enriquecimento, e plataformas "f1- superior" e "f4-inferior" sem o item), os resultados indicaram que os indivíduos optaram em ocupar primeiro as plataformas dispostas em uma posição superior, seguindo na preferência em ocupar as plataformas que estavam enriquecidas. Mostrando que o efeito da novidade do item permanente de uso coletivo, já havia diminuído, e o que prevaleceu foi a preferência em ocupar os locais elevados.

Em testes de preferência, o recurso que o animal interage em maior número de vezes, escolhe frequentemente ou consome em uma grande quantidade, pode ser dito como preferido [108, 109, 110]. Mostrando que de fato, os animais optam em utilizar as áreas que os satisfaçam com maior contentamento, menores níveis de estresse ou medo, de acordo com as necessidades da espécie [15].

A ocupação preferencial dos animais por locais elevados, nos remete novamente, a importância na adequação dos recintos, que devem ser estruturados de forma que possam ser completamente utilizados pelos gatos, por meio da introdução de áreas em um segundo nível e se possível, em diferentes alturas. Nenhum estudo até hoje mensurou ao certo qual seria a altura ideal para a exploração do espaço vertical por esses animais, apesar de Rochlitz (2000) [24] já ter disseminado que gatos domésticos preferem permanecer em locais elevados que no piso.

Essa afirmação vem de encontro com o que observamos no Teste Enriquecimento Ambiental Físico Temporário de uso Coletivo, que mesmo na presença do item de enriquecimento, subdividindo a área de piso e proporcionando aos animais barreiras visuais, houve um aumento no número de indivíduos ocupando as áreas elevadas, como mostra a Figura 20. O que pode ser explicado pelo fato de que enquanto alguns animais interagiam com o item nas áreas de piso, supostamente os dominantes para com o item de enriquecimento; o restante dos indivíduos continuava em sua maioria, ocupando as áreas 
elevadas.

Assim como acontece na maior parte dos mamíferos, são formados laços entre os indivíduos, resultando geralmente em uma hierarquia não linear dentro do grupo [111]. Os gatos não são exceção, embora alguns pequenos grupos apresentem uma estrutura social simples e linear, a maioria dos grupos de gatos domésticos alojados em um mesmo recinto são susceptíveis a uma hierarquia não linear. Onde a principal função de dominância, se concentra na prioridade de acesso aos recursos como alimentos, água, locais de repouso, parceiros reprodutivos bem como itens de enriquecimento ambiental [104]. O mesmo ocorreu no Teste Enriquecimento Ambiental Físico Temporário de uso Restrito, como mostra a Figura 26, por se tratar de um item de enriquecimento restrito, nem todos os animais conseguiam interagir com o mesmo, alguns indivíduos monopolizaram o item, que se encontrava na área de piso, enquanto os outros animais permaneceram em sua maioria, ocupando as áreas elevadas.

A preferência na ocupação dos animais por áreas elevadas faz salientar novamente a importância em oferecer aos gatos domésticos a oportunidade de explorarem locais elevados, e que ao enriquecer o ambiente, os itens sejam inseridos, preferencialmente, em áreas elevadas ao invés de serem colocados no piso dos recintos, nos quais esses animais são mantidos.

Tais itens devem ser aplicados a fim de incentivar comportamentos naturais dos gatos domésticos [112], bem como reduzir os comportamentos esteriotipados e os níveis elevados de estresse [113]. Visando especificamente melhorar a "qualidade de vida" e o bem-estar dos indivíduos mantidos em cativeiro e/ou utilizados em experimentos. Onde sua eficácia pode ser avaliada através de dados baseados nos índices fisiológicos e comportamentais desses indivíduos [114].

Dentre os comportamentos exibidos pelos animais no nosso estudo, podemos verificar nas Figuras 18a e 18b, que os animais executaram o comportamento "Descansar" em maior escala nas áreas elevadas, tanto na condição Controle, sem enriquecimento ambiental, como durante o Teste Enriquecimento Ambiental Físico Permanente de uso Coletivo, na presença do item de enriquecimento. Mostrando que esta manifestação compõe a grande parte do repertório comportamental da espécie, e que houve preferência por uma localidade, específica, acima do piso, para executar tal comportamento, fato que normalmente é inviabilizado nos locais de manutenção desses indivíduos.

Já nos Testes Enriquecimento Ambiental Físico Temporário de uso Coletivo e de uso Restrito, os resultados exibidos nas Figuras 21 e 27a nos mostraram que o comportamento 
"Cheirar" foi o mais executado frente aos itens de enriquecimento temporário de uso coletivo e de uso restrito, sendo um ato frequentemente realizado pelos indivíduos, como parâmetro exploratório [115, 116, 117]. Para os gatos domésticos, cujo sentido de olfação possui alto significado, o comportamento "Cheirar", auxilia na investigação de ambientes e objetos novos de forma a obter informações sobre suas características [118].

Ainda em relação ao Teste Enriquecimento Ambiental Físico Temporário de uso Coletivo, o comportamento "Descansar", também foi realizado de forma significativa pelos indivíduos na presença do item de enriquecimento. O comportamento descansar é de grande importância para todos os animais, tendo um impacto sobre o crescimento, conservação de energia, restauração dos tecidos, além de outros processos anabólicos [119, 120].

Em um estudo com galinhas, o uso de itens que exerciam função de barreiras visuais, função esta, também utilizada em nosso estudo, pelo item temporário de uso coletivo, aumentou o tempo gasto em descanso pelos animais, ao serem colocadas no recinto [34, $121,122]$.

É imprecindível que locais que ofereçam cobertura ou barreiras visuais, sejam inseridos nos recintos de animais mantidos em confinamento. Já que em ambientes naturais essa cobertura é dada por meio da vegetação, do solo, da sombra das árvores; itens, que muitas vezes estão ausentes em recintos de cativeiro. A introdução de barreiras visuais no ambiente de confinamento, além de oferecer esconderijos, pode ser usada para reduzir a comunicação inter-específica, o contato visual e possíveis agressões entre os indivíduos que estão alojados em grupo [123], minimizando situações de conflitos e/ou estressantes.

Pesquisas sobre os efeitos da introdução de itens que promovam barreiras visuais nos recintos de mamíferos e aves, revelaram muitos benefícios, como a significativa redução de ferimentos em criação de veados [124], aumento na taxa de crescimento e no ganho de peso em porcos recém-desmamados [68], diminuição de comportamentos esteriotipados em guepardos (Acinonyx jubatus) [100] redução no arranque de penas em perus domésticos [125], além de refletir maior complexidade do ambiente e uma distribuição espacial mais homogênea em galinhas de granja (Gallus gallus domesticus) dentro do espaço disponível [34].

Já no trabalho de Buijs et. al. (2011) [67], foi visto que ao fornecer a coelhos, estruturas de enriquecimento que dividiam a gaiola em diferentes áreas funcionais, houve uma diminuição das necessidades espaciais, e a utilização mais eficaz do espaço. Cujo efeito positivo no bem-estar desses animais, foi comprovado por níveis mais baixos de metabólitos de glicocorticosteróides fecais, encontrados nas gaiolas em que foram acrescentadas bar- 
reiras visuais. Assim como citado no trabalho acima, também se faz necessário inserir nos recintos dos gatos domésticos, uma variedade de estruturas, que proporcionem barreiras visuais (painéis verticais ou cortinas), além de itens parcialmente fechados (como por exemplo, caixas de papelão), de modo que possam oferecer refúgios para os animais que estejam confinados no mesmo ambiente [27].

Foi o que evidenciamos através dos resultados exibidos na Figura 29, onde o item temporário de uso restrito, além de enriquecer o ambiente, também foi utilizado como refúgio pelos animais do estudo, cuja permanência na área interna ao item foi de $\bar{x}=6,50 \pm 1,40$ minutos, tempo significativamente maior, quando comparado a permanência na área próxima ao item, que foi de $\bar{x}=2,69 \pm 0,98(p<0,05)$. Vindo de encontro a literatura, que relata a necessidade que os gatos apresentam de se esconderem, principalmente em situações estressantes, que incluem barulhos altos, movimentos bruscos, introdução de objetos novos no recinto, bem como a abordagem de estranhos (seres humanos, gatos ou outros animais) dentro do seu espaço pessoal [126].

Kry e Casey (2007) [127] mostraram que o comportamento de alerta em gatos domésticos é frequentemente associado com níveis elevados de ansiedade e estresse, e que a redução desses níveis se deu, na presença do item de enriquecimento baseado em "caixas abrigos". Geret (2011) [27], também relatou que caixas de papelão, poderiam atuar como itens de enriquecimento ambiental eficazes, funcionando como refúgios e barreiras verticais, que são itens importantes na adequação de ambientes para felinos.

Entretanto, é de fundamental importância, refletir sobre a viabilidade da apresentação de um objeto novo ou qualquer outro item de enriquecimento ambiental, atentando para os riscos oferecidos aos animais, o investimento financeiro [128] e a efetividade do mesmo, baseada por exemplo, pela frequência de interação e o tempo de habituação dos animais para com os itens, fatores estes, também relatados em nosso trabalho.

As observações mostraram que ao longo das três horas de filmagens do Teste Enriquecimento Ambiental Físico Temporário de uso Coletivo, houve uma queda significativa na frequência diária de interação dos indivíduos com o item entre a primeira com a segunda e terceira hora de observação $(p<0,001)$ (Fig. 22). O mesmo foi visto no trabalho de Ellis e Wells (2010) [112] com gatos domésticos, onde houve um maior número de interações dos indivíduos com o item de enriquecimento ambiental (flanelas com odores) na primeira hora do experimento $\bar{x}=0,99 \pm 0,11$, comparado com a segunda $\bar{x}=0,61 \pm 0,12$ e com a terceira hora, que apresentou o número médio de $\bar{x}=0,68 \pm 0,12$ interações com as flanelas, sugerindo um certo grau de habituação com o item de enriquecimento. 
Nos trabalhos de Hall (2002) [129] e Wells (2009) [130], também foi visto que gatos domésticos habituam-se rapidamente à objetos novos inseridos no ambiente e à estímulos visuais em movimento, como imagens de televisão. Portanto, para evitar a possível habituação, o ideal é que haja estratégias e uma rotatividade na apresentação dos itens de enriquecimento ambiental, a fim de manter a novidade e o efeito enriquecedor no ambiente para os animais [131].

Em relação aos dias de observações, não houve diferença significativa na frequência de interação dos indivíduos com o item temporário de uso coletivo, ao longo dos 10 dias de teste $(p>0,05)$, o que pode ser explicado pelo fato de ser considerado, um item de enriquecimento ambiental de uso mais abrangente, seria necessário um maior número de dias de observações, para que houvesse habituação por parte dos indivíduos, tema este, que continuará sendo abordado em trabalhos futuros, desenvolvidos por nosso laboratório.

Estudos com suínos (Sus scrofa domesticus) [132], leopardos (Felis bengalensis) [23], ratos (Rattus novergicus) [133] e bovinos [134] demonstram que animais mantidos em ambientes restritos, são altamente responsivos à estímulos novos, porém necessitaram de um longo tempo para aprender, interagir e se habituar com o objeto novo ou com outras alterações do ambiente.

Fato este, também evidenciado no Teste Enriquecimento Ambiental Físico Temporário de uso Restrito, onde não foi possível observar diferença significativa na frequência de interação dos indivíduos com o item entre as três horas de teste. Em relação aos 10 dias de filmagem, os resultados apresentados na Figura 31 indicam uma ligeira queda na frequência diária de interação com o item temporário de uso restrito, começando no segundo dia de teste e se mantendo estável até o sétimo dia. A partir do oitavo dia, houve uma queda significativa na frequência de interação, sugerindo ser o início da habituação ao item.

A habituação varia de acordo com a intensidade da motivação dos indivíduos em explorar o item [101], ou seja, aqueles com maior motivação exploratória irão demorar mais tempo para habituar-se ao item de enriquecimento. Características individuais também são importantes fazendo com que a exploração possa ocorrer de forma diferenciada entre os indivíduos [135].

Dentre os 31 animais observados no Teste Enriquecimento Ambiental Físico Permanente de uso Coletivo, alguns animais, como as fêmeas 29.1, 4.7, 1.3, 3.6 e o macho 20.2, exploraram em maior frequência o item, que outros indivíduos. Estudos com várias espécies sugerem que diferenças sociais e relações de dominância na exploração de ob- 
jetos [116], podem ter influenciado a configuração dos animais nos diferentes graus de exploração com o item permanente de enriquecimento.

No Teste Enriquecimento Ambiental Físico Temporário de uso Coletivo, foi visto que os animais que apresentaram menor latência para a interação, como as fêmeas 2.20, 10.4, 4.38, e os machos 4.2 e 4.15, também foram os que interagiram em maior frequência com o item, porém tratou-se de outros indivíduos do grupo, diferente daqueles que demonstraram interesse em explorar o item permanente de uso coletivo. Vindo de encontro a literatura, cujos relatos dizem que diferenças na personalidade dos gatos podem levar a respostas distintas em relação aos estímulos, com alguns animais exibindo preferência sobre um tipo de intervenção em relação a outras [112].

Durr e Smith (1997) [103] realizaram um dos raros trabalhos que enfocam a resposta de gatos domésticos a estímulos de novidade, e ao avaliar a latência de interação para com o objeto, os autores concluíram que os animais demonstraram diferenças individuais na reação ao estímulo que foi independente do grau de dominância que esses apresentavam no grupo, ou seja, o animal dominante nem sempre o é em todas as situações, ou tipos de atividade.

Em relação ao Teste Enriquecimento Ambiental Físico Temporário de uso Restrito, a fêmea 2.20 e o macho 4.2, estavam entre os indivíduos que apresentaram a menor latência de interação com o item temporário de uso restrito, sendo também os animais que mais interagiram com o mesmo. Porém, por se tratar de um único item de enriquecimento ambiental que foi inserido no recinto, houve um menor número de animais interagindo, se comparado a quantidade de animais que entraram em contato com os outros itens dispostos de uma forma mais abrangente no recinto. Refletindo assim, em um dos propósitos do trabalho, que foi averiguar a maneira como os animais interagiam a diferentes formas e técnicas de aplicação dos itens de enriquecimento ambiental.

Desta forma, é importante analisar a quantidade de itens de enriquecimento a ser oferecida para um grupo de animais, para que estes possam ser utilizados pelo maior número de indivíduos mantidos no mesmo recinto [74]. Também deve ser considerado, o tempo em que os itens ficarão expostos, além da possibilidade natural de cada item de enriquecimento ser usado conjuntamente ou não, pelos animais.

A utilização do item de enriquecimento ambiental por apenas um grupo de animais faz com que a eficácia do mesmo seja diminuída, além de atuar potencialmente como um fator frustrante e até estressante para os que não conseguem interagir com os itens, podendo causar prejuízos no bem-estar dos indivíduos em questão. 
Deste modo, estabelecemos um ranking dos animais em relação à frequência de interação com os itens de enriquecimento ambiental, com a finalidade de identificarmos, de que modo, a colônia se organiza para o acesso a um item novo. Os resultados revelaram que há uma ordenação entre os indivíduos para interação com esse item, representados no ranking de maneira decrescente à prioridade de acesso ao enriquecimento (Tabela 2). A partir disso, podemos considerar que os indivíduos do topo do ranking, como a fêmea 2.20 (1ํㅡㄹ lugar) e o macho 4.2 ( $2^{\mathrm{O}}$ lugar), são dominantes aos demais, especificamente em relação à utilização dos itens de enriquecimento ambiental, apresentados neste estudo.

De acordo com Ramos (2012) [136], quanto mais limitado o espaço para um grupo de gatos, mais rigorosa será a hierarquia social. Sugerindo que estes formam hierarquias de dominância, como um mecanismo social que ajuda a lidar com a impossibilidade de se organizar espacialmente quando confinados. A compreensão das relações sociais entre os gatos e como essas relações afetam o acesso aos recursos tais como comida, água, lugares de repouso e itens de enriquecimento ambiental é de fundamental importância para a adequada manutenção desses animais em cativeiro [104].

Gatos domésticos apresentam grande plasticidade em comportamentos sociais, adaptando-se a uma variedade de condições ambientais, quer em completo isolamento ou como parte de colônias de animais [137], situação esta, semelhante ao nosso grupo de estudo. No entanto, apesar dos diversos estilos de vida, é claramente notável, que nem todos os gatos são capazes de se adaptar igualmente bem, a um determinado ambiente. O que pode ser evidenciado pela alta incidência de problemas comportamentais em grupo de animais em confinamento [138]. Porém, comportamentos afiliativos, como por exemplo, dormir ou permanecer sentado próximo a outro coespecífico, também são exibidos por gatos domésticos mantidos em grupos [139].

No nosso estudo, tais comportamentos também foram executados, onde os resultados nos revelaram que ao longo do Teste Enriquecimento Ambiental Físico Temporário de uso Restrito, houve um compartilhamento do item de enriquecimento, por alguns indivíduos, que permaneceram em contato com outros coespecíficos, interagindo simultaneamente na área interna ou próxima ao item. Dos animais que compartilharam na área interna ao item, o macho 8.7,um dos indivíduos que reside a mais tempo no recinto, foi o indivíduo que compartilhou o item com um maior número de animais, e juntamente com os machos 4.2 e 4.15, foram os que apresentaram um maior tempo de compartilhamento na área interna ao item (Fig. 34). Tais evidências de relações estruturadas e preferências para um dos parceiros do grupo, também foram observadas por Smith (1994) [140] e Crowell- 
Davis (2004) [104] entre gatos que residiam juntos no mesmo local por um longo período de tempo. Dentre os animais que compartilharam na área próxima ao item temporário de uso restrito, a fêmea 2.20, foi quem compartilhou o item com um maior número de animais, sendo ela também, junto com o macho 4.15, os indivíduos que apresentaram o maior tempo de compartilhamento na área externa ao item (Fig. 35). Fato, que também foi relatado no trabalho Barry e Crowell-Davis (1999) [97], onde fêmeas de gatos domésticos, apresentaram uma maior frequência de comportamentos afiliativos, além de passarem por longos períodos em proximidade com outras fêmeas, vindo de encontro com os dados obtidos no nosso estudo.

Colônias de gatos que residem em ambientes restritos sofrem com as limitações no uso do espaço, não só pelo tamanho do recinto, mas também pelas características estruturais e a complexidade do ambiente.

Assim como proposto no nosso trabalho, afim de melhorar as condições desses locais de manutenção, técnicas de enriquecimento ambiental devem ser aplicadas com a alteração na estrutura física do recinto, mudando a localização de objetos já conhecidos pelos animais, ou através da apresentação de novos estímulos, ou ainda, por meio da introdução de novos itens. Garantindo desse modo à manutenção da novidade dentro de um ambiente conhecido, simulando a variabilidade de experiências em vida livre e estimulando os comportamentos naturais da espécie.

As observações e os resultados provindos desse estudo, demonstraram como os animais ocupam os espaços disponíveis no recinto e/ou utilizam e escolhem diferentes itens em seu ambiente, podendo ser considerados um valioso meio de determinar aspectos positivos e negativos do cativeiro, além de ser uma forma de avaliar a adequação do ambiente, maximizando o bem-estar da espécie em questão. 


\section{Conclusão}

O estudo da ocupação do espaço, bem como o modo de utilização dos itens de enriquecimento ambiental, são ferramentas fundamentais para um adequado delineamento de recintos e/ou gaiolas de manutenção, resultando no aumento do bem-estar de gatos domésticos mantidos em confinamento.

Este trabalho possuiu o intuito de acrescentar informações relevantes para a manutenção de colônias de gatos mediante a observação da distribuição dos animais nos locais disponíveis do recinto, frente à aplicação de diferentes itens de enriquecimento ambiental.

Através dos nossos resultados, podemos concluir que o padrão de ocupação dos animais no recinto se deu por uma maior utilização das áreas elevadas em relação às áreas de piso, tanto na condição Controle, como após a introdução de itens de enriquecimento ambiental.

A ocupação preferencial dos animais por locais elevados, faz salientar a importância na adequação dos recintos, que devem ser estruturados de forma que possam ser completamente utilizados pelos gatos, por meio da introdução de áreas acima do solo, e que ao inserir itens de enriquecimento ambiental, estes sejam colocados, primordialmente, em áreas elevadas.

Dentre os itens de enriquecimento utilizados no nosso estudo, e suas diferentes formas de aplicação, nossos resultados revelaram que houve uma maior interação por parte dos indivíduos com o item temporário de uso coletivo, que além de enriquecer o ambiente de forma mais abrangente, atuou como barreira visual, promovendo a subdivisão das áreas do recinto e resultando em uma ocupação mais homogênea dos animais no espaço disponível.

Foi visto que a colônia estudada possui uma organização para interação com os itens, onde alguns indivíduos exploraram os itens de enriquecimento de forma mais acentuada, já outros animais nem sequer entraram em contato com os itens, o que pode ter sido influenciado pela impossibilidade de acesso ao recurso pelos outros indivíduos. Estudos relacionados ao aprimoramento da metodologia para aplicação das técnicas de enriquecimento ambiental são fundamentais e continuarão sendo realizados por nosso laboratório, 
em projetos futuros, para que tais técnicas sejam satisfatórias e possam beneficiar o maior número de indivíduos mantidos no mesmo recinto.

Concluímos que por meio de observações da ocupação do espaço, assim como, através do modo de utilização dos itens de enriquecimento ambiental pelos indivíduos, podemos acessar informações relevantes sobre as preferências e as necessidades biológicas dos animais, adequando o seu habitat e aumentando os níveis de bem-estar da espécie em questão. 


\section{Referências}

[1] Genaro, G.; GAVIOLli, A. E. Posse responsável de animais domésticos, alternativa educativa: Poder público e privado. Rev.CRMV-PR, v. 5, p. 21, 2006.

[2] BROOM, D. M.; FRASER, A. F. (Eds.). Domestic animal behavior and welfare. Oxfordshire: CAB, 2007.

[3] SWAiSGOOD, R. R.; ELLIS, S.; FORTHMAN, D. L.; SHEPHERDSON, D. J. Commentary: Improving well-being for captive giant pandas: Theoretical and practical issues. Zoo Biology, v. 22, p. 347-354, 2003.

[4] MCPHEE, M. E. Intact carcasses as enrichment for large felids: Effects on and off exhibit behaviors. Zoo Biology, v. 21, p. 37-47, 2002.

[5] KESSLER, M. R.; TURNER, D. C. Effects of density and cage size on stress in domestic cats (felis silvestris catus) housed in animal shelters and boarding catteries. Animal Welfare, v. 8, p. 259-267, 1999.

[6] GOUVEIA, K.; MAGALHÃES, A.; DE SOUSA, L. The behaviour of domestic cats in a shelter: Residence time, density and sex ratio. Applied Animal Behaviour Science, v. 130, n. 1-2, p. 53-59, 2011.

[7] BOERE, V. Environmental enrichment for neotropical primates in captivity: a review. Ciência Rural, v. 31, p. 451-460, 2001.

[8] MARKOWITZ, H. (Ed.). Behavioural enrichment in the zoo. New York: Van Nostrand Rein- hold, 1982.

[9] WILSON, S. F. Environmental influences on the activity of captive apes. Zoo Biology, v. 1, p. 201-209, 1982.

[10] RESENDE, S. L.; GOMES, P. C. K.; ANDRIOLO, A.; GENARO, G.; REMY, L. G.; JUNIOR, R. A. V. Influence of cinammon and catnip on the steriotipcal pacing on oncilla cats (leopardus tigrinus) in captivity. Journal of Applied Animal Welfare Science, p. 247-254, 2011.

[11] BROOM, D. M.; JOHNSON, K. G. (Eds.). Stress and animal welfare. London: London: Chapman \& Hall, 1993.

[12] SHEPHERDSON, D. J. (Ed.). Improving animal's lives in captivity through environmental enrichment. London: Humane Education Centre, 1989.

[13] ROCHLITZ, I. Recommendations for the housing of ats in the home, in catteries and animal shelters, in laboratories and in veterinary surgeries. Journal of Feline Medicine and Surgery, p. 181-191, 1999. 
[14] GENARO, G. O conhecimento do comportamento felino como ferramenta para a clínica médica veterinária. MedVep-Revista Científica de Medicina Veterinária- Pequenos Animais e Animais de Estimação, v. 4, p. 8-9, 2006.

[15] DUNCAN, I. J. H.; FRASER, D. (Eds.). Understanding animal welfare. Cab International, 1997.

[16] BAUMANS, V. Science-based assessment of animal welfare: laboratory animals. Rev. sci. tech. off. int. Epiz., v. 24, p. 503-514, 2005.

[17] TERlouW, E. M. C.; SCHOUTEn, W. G. P.; LADEWIG, J. (Eds.). Physiology. UK: CABI: Oxon, 1997.

[18] Guidelines for housing cats. Animal Behaviour, 2002.

[19] JONGMAN, E. C. Adaptation of domestic cats to confinement. Journal of Veterinary Behaviour, v. 2, p. 193-196, 2007.

[20] ASCHWANDEN, J. Loose housing of small goat groups: Influence of visual cover and elevated levels on feeding, resting and agonistic behaviour. Applied Animal Behaviour Science, v. 119, p. 171-179, 2009.

[21] GENARO, G. Comportamento felino: organização social e especial, comunicação intraespecífica e conflitos com a vida doméstica. MedVep-Revista Científica de Medicina Veterinária- Pequenos Animais e Animais de Estimação, v. 2, p. 61-66, 2004.

[22] ROCHLITZ, I. (Ed.). The welfare of cats. Cambridge: Springer, 2005b. v. 3.

[23] CARLSTEAD, K.; BROWN, J.; SEIDENSTICKER, J. Behavioral and adrenocortical responses to environmental changes in leopard cats (felis bengalensis). Zoo Biology, v. 12, p. 321-331, 1993.

[24] ROCHLITZ, I. Recommendations for the housing and care of domestic cats in laboratories. Laboratory Animals, v. 34, p. 1-9, 2000.

[25] ROCHLITZ, I. (Ed.). Comfortable quarters for cats in research institutions. Washington: Animal Welfare Institute, 2002.

[26] ELLIS, S. Environmental enrichment practical strategies for improving feline welfare. Journal of Feline Medicine and Surgery, v. 11, p. 901-912, 2009.

[27] GERET, C. P.; RIOND, B.; CATTORI, V.; MELI, L. M.; HOFMANN-LEHMANN, R.; LUTZ, H. Housing and care of laboratory cats: from requirements to practice. Schweiz. Arch. Tierheilk, v. 153, n. 4, p. 157-164, 2011.

[28] LAW, G.; GRAHAM, D.; MCGOWAN, P. Environmental enrichment for zoo and domestic cats. Animal Tecnology, v. 52, n. 2, 2001.

[29] TILSON, R. L.; SEAL, S. U. (Eds.). Tigers of the world: the biology, biopolitics, management and conservation. New Jersey: Park Riedge, 1987.

[30] GENARO, G.; SCHMIDEK, W. R. Exploratory activity of rats in three diferent environments. Ethology, v. 106, p. 849-859, 2000. 
[31] MENCH, J. A. (Ed.). Environment enrichment and the importance of exploratory bahaviour. Washington: Smithsoniam Institution Press, 1998.

[32] LEWIS, N. J.; HURNIK, J. F. Locomotion of broiler chickens in floor pens. Poultry Sci., v. 69, p. 1087-1093, 1990.

[33] NEWBERRY, R. C.; HALL, J. W. Use of space by broiler chickens: Effects of age and pen size. Applied Animal Behaviour Science, v. 25, p. 125-136, 1990.

[34] CORNETTO, T. L.; ESTEVEZ, I. Influence of vertical panels on use of space by domestic fowl. Applied Animal Behaviour Science, v. 71, p. 141-153, 2001.

[35] JENSEN, S. P.; GRAY, S. J.; HURST, J. L. How does habitat structure affect activity and use of space among house mice? Animal Behaviour, v. 66, p. 239-250, 2003.

[36] ODEnDAAL, J. S. J. Animal welfare in practice. Applied Animal Behaviour Science, v. 59, p. 93-99, 1998.

[37] ROSS, S. R.; SCHAPIRO, S. J.; HAU, J.; LUKAS, K. E. Space use as indicator of enclosure appropriateness: a novel measure of captive animal welfare. Applied Animal Behaviour Science, v. 121, p. 42-50, 2009.

[38] ESTEVEZ, I.; CHRISTMAN, C. M. Analisys of the movement and use of space of animals in confinament: The effect of sampling effort. Applied Animal Behaviour Science, v. 97, p. 221-240, 2006.

[39] BEnSON, J. F.; CHAMBERLAin, M. J.; LEOPOLD, B. D. Regulation of space use in a solitary felid: population density or prey availability? Animal Behaviour, v. 71, p. 685-693, 2006.

[40] LEONE, E. H.; ESTEVEZ, I.; CHRISTMAN, M. C. Environmental complexity and group size: immediate effects on use of space by domestic fowl. Applied Animal Behaviour Science, v. 102, n. 2, p. 39-52, 2007.

[41] NIELSEN, H. L.; MOGENSEN, L.; KROHN, C.; HINDHEDE, J.; SORENSEN, J. T. Resting and social behaviour of dairy heifers housed in slatted floor pens with different sized bedded lying areas. Applied Animal Behaviour Science, v. 54, p. 307-316, 1997.

[42] FREGONESI, J. A.; LEAVER, J. D. Influence of space allowance and milk yield level on behaviour, performance and health of dairy cows housed in straw yard and cubicle systems. Livest. Prod. Sci., v. 78, p. 245-257, 2004.

[43] BOE, K. E.; BERG, S.; ANDERSEN, I. L. Resting behaviour and displacements in ewes effects of reduced lying space and pen shape. Applied Animal Behaviour Science, v. 98, p. 249-259, 2006.

[44] BERLYNE, D. E. Curiosity and exploration. Science, , n. 153, p. 25-33, 1966.

[45] HUGHES, R. N. Intrinsic exploration in animals motives and measurement. Behavioural Process, v. 41, p. 213-226, 1997. 
[46] BOISSY, A. Assessment of positive emotions in animals to improve their welfare. Physiology Behavior, v. 92, p. 375-397, 2007.

[47] NOLAN, V.; THOMPSON, C. F. (Eds.). Current ornithology. New York: Plenum Press, 2001.

[48] GENARO, G.; SCHMIDEK, W. R.; FRANCI, C. R. Social condition affects hormone secretion and exploratory behavior in rats. Brazilian Journal of Medical and Biological Research, v. 37, n. 6, p. 833-840, 2004a.

[49] MATZEL, L. D. Exploration in outbreed mice covaries with general learning abilities irrespective of stress reactivity, emotionality, and physical attributes. neurobiology of learning and memory. Neurobiology of Learning and Memory, v. 86, n. 2, p. $228-240,2006$.

[50] MARIN, M. T.; CRUZ, F. C.; PLANETA, C. S. Chronic restraint or variable stresses differently affect the behavior, corticosterone secretion and body weight in rats. Physiology and Behaviour, v. 90, n. 1, p. 29-35, 2007.

[51] MORATO, S.; BRANDÃO, M. L. Paradoxical increase of exploratory behavior in the elevated plus-maze by rats exposed to two kinds of aversive stimulus. Brazilian Journal of Medical and Biological Research, v. 30, n. 9, p. 1113-1120, 1997.

[52] BASSETT, L.; BUCHANAN-SMITH, H. M. Effects of predictability on the welfare of captive animals. Applied Animal Behaviour Science, v. 102, p. 223-245, 2007.

[53] MACHADO, C. J.; GENARO, G. Comportamento exploratório em gatos domésticos (felis silvestris catus linnaeus, 1758): uma revisão. Archives of Veterinary Science, v. 15, n. 2, p. 107-117, 2010.

[54] ROSS, S. R.; LUKAS, K. E. Use of space in a non-naturalistic environment by chimpanzees (pan troglodytes) and lowland gorillas (gorilla gorilla gorilla). Applied Animal Behaviour Science, v. 96, p. 143-152, 2006.

[55] BROOM, D. M. Cognitive ability and awareness in domestic animals and decisions about obligations to animals. Applied Animal Behaviour Science, v. 126, p. $1-11,2010$.

[56] OlSSON, I. A. S.; NEVISOn, C. M.; PATTERSON-KANE, E. G.; SHERWIN, C. M.; VAN DE WEERD, H. A.; WÜRBEL, H. Understanding behaviour: the relevance of ethological approaches in laboratory animal science. Applied Animal Behaviour Science, v. 81, p. 245-264, 2003.

[57] MASON, G. J. Why and how should we use environmental enrichment to tackle stereotypic behavior? Applied Animal Behaviour Science, v. 102, p. 163-188, 2007.

[58] HOLM, L.; LADEWIG, J. The effect of housing rats in a stimulus rich versus stimulus poor environment on preference measured by sigmoid double demand curves. Applied Animal Behaviour Science, v. 107, p. 342-354, 2007. 
[59] MELLEN, J. D.; SHEPHERDSON, D. J. Environmental enrichment for felids: na integrated approach. Int. Zoo Yb, v. 35, p. 191-197, 1997.

[60] GenARO, G. Gato doméstico: comportamento \& clínica veterinária. MedVepRevista Científica de Medicina Veterinária- Pequenos Animais e Animais de Estimação, v. 3, p. 16-22, 2005.

[61] BALCOMBE, J. P. Laboratory environments and rodents behavioural needs: a review. Laboratory Animals, v. 40, p. 217-235, 2006.

[62] SOFFIE, M.; HAHN, K.; TERAO, E. Behavioural and glial changes in old rats following environmental enrichment. Behavioural Brain Research, v. 101, n. 1, p. 37-49, 1999 .

[63] KAZLAUCKAS, V.; PAGNUSSAT, N.; MIORANZZA, S. Enriched environment effects on behaviour, memory and bdnf in low and high exploratory mice. Phisiology and Behavior, v. 102, n. 5, p. 475-480, 2011.

[64] PIETROPAOLO, S. Utilisation of a physically-enriched environment by laboratory mice: age and gender differences. Applied Animal Behaviour Science, v. 88, p. 149-162, 2004.

[65] FONSECA, S.; GENARO, G. Bem-estar felino: Ocupação de espaços. Relatório Final do Estágio Curricular do Curso de Medicina Veterinária, Centro Universitário Barão de Mauá, Ribeirão Preto, São Paulo, 2009.

[66] ROCHLITZ, I. The welfare of cats in a quarantine cattery. Veterinary Record, v. 143, p. 35-39, 1998.

[67] BUIJS, S.; KEELING, J. L.; TUYTTENSA, M. A. F. Behaviour and use of space in fattening rabbits as influenced by cage size and enrichment. Applied Animal Behaviour Science, v. 134, p. 229-238, 2011.

[68] WARAN, K. N.; BROOM, M. D. The influence of a barrier on the behaviour and growth of early-weaned piglets. Animal Production, v. 56, n. 1, p. 115-119, 1993.

[69] MELlEN, J. D.; HAYES, M. P.; SHEPHERDSON, D. J. (Eds.). Captive environments for small felids. Washington: Smithsonian Institution Press, 1998.

[70] ROCHLITZ, I. A review of the housing requirements of domestic cats (felis silvestris catus ) kept in home. Applied Animal Behaviour Science, v. 93, p. 97-109, 2005.

[71] NEWBERRY, R. C. Environmental enrichment: Increasing the biological relevance of captive environments. Applied Animal Behaviour Science, v. 44, p. 229-243, 1995.

[72] SHEPHERDSON, D. J.; MELlEN, J. D.; HUTCHINS, M. (Eds.). Second nature: environmental enrichment for captive animals. London: Smithsonian Institution Press, 1998.

[73] MCCUNE, S. Enriching the environment of the laboratory cat. , Washington, p. 27-42, 1995. 
[74] DANTAS-DIVERS, S. M. L.; CROWELL-DAVIS, L. S.; ALFORD, K.; GENARO, G.; D'ALMEIDA, M. J.; PAIXAO, L. R. Agonistic behavior and environmental enrichment of cats communally housed in a shelter. Journal of the American Veterinary Medical Association, v. 239, n. 6, p. 796-802, 2011.

[75] AMAT, M. Potential risk factors associated with feline behaviour problems. Applied Animal Behaviour Science, v. 121, p. 134-139, 2009.

[76] TRONCON, K. E. Comunicação química por meio das fezes e da urina em felinos e comportamento social em gatos domésticos (felis silvestris catus ). Dissertação de Mestrado, Universidade de São Paulo,Faculdade de Filosofia,Ciências e Letras, Departamento de Psicologia e Educação, Programa de Pós-Graduação em Psicobiologia, Ribeirão Preto, 2006.

[77] SWANSON, W. F.; WILDT, D. E. Estrategies and progress in reproductive research involving small cat species. International Zoo Yearbook, v. 35, p. 152-159, 1997.

[78] FELDMAN, H. N. Methods of scent marking in the domestic cat. Canadian Journal of Zoology, v. 72, p. 1093-1099, 1994.

[79] MACDONALD, D. W.; YAMAGUCHI, N.; KERBI, G. (Eds.). Group living in the domestic cat: its sociobiology and epidemiology. Cambridge: University Press, 2000.

[80] SAY, L.; PONTIER, D. Spacing pattern in a social group of stray cats: effects on male reproductive success. Animal Behaviour, v. 68, p. 175-180, 2004.

[81] GENARO, G. Gato doméstico: futuro desafio para controle da raiva em áreas urbanas? Pesquisa Veterinária Brasileira, v. 30, n. 2, p. 186-189, 2010.

[82] HOENIG, M.; JORDAN, E. T.; GLUSHKA, J.; KLEY, S.; PATIL, A.; WALDRON, M.; PRESTEGARD, J. H.; FERGUSON, D.; WU, S.; OLSON, D. E. Effect of macronutrients,age, and obesity on 6- and 24-h postprandial glucose metabolism in cats. American journal of physiology-regulatory integrative and comparative physiology, v. 301, n. 6, p. R1798-R1807, 2011.

[83] DEVILlARD, S.; SANTIN-JANIN, H.; SAY, L.; PONTIER, D. Linking genetic diversity and temporal fluctuations in population abundance of the introduced feral cat (felis silvestris catus) on the kerguelen archipelago. Molecular Ecology, v. 20, n. 24, p. 5141-5153, 2011.

[84] ESSEN, V.; VIVIAN, J.; UILENRRIF, J. J.; SZATMARI, V. Ultrasound-guided serial transabdominal cardiac biopsies in cats. Veterinary Journal, v. 191, n. 3, p. 341-346, 2012.

[85] QUOC, E. B.; RIBOT, J.; QUENECH'DU, N.; DOUTREMER, S.; LEBAS, N.; GRANTYN, A.; AUSHANA, Y.; MILLERET, C. Asymmetrical interhemispheric connections develop in cat visual cortex after early unilateral convergent strabismus: anatomy, physiology, and mechanisms. Frontiers in neuroanatomy, v. 5, 2012.

[86] KONERDING, W. S.; HEDRICH, H. J.; BLEICH, E.; ZIMMERMANN, E. Paw preference is not affected by postural demand in a nonprimate mammal (felis silvestris catus). Journal of comparative psychology, v. 126, n. 1, p. 15-22, 2012 . 
[87] WELLS, D. L.; MILLSOPP, S. The ontogenesis of lateralized behavior in the domestic cat (felis silvestris catus). Journal of comparative psychology, v. 126, n. 1, p. 23-30, 2012.

[88] GERRIKAGOITIA, X.; GIL, H.; GARCIA-ESTEBAN, C. Presence of bartonella species in wild carnivores of northern spain. Applied and environmental microbiology, v. 78, n. 3, p. 885-888, 2012.

[89] BURKHARD, M. J.; DEAN, G. A. Transmission and immunopathogenesis of fiv in cats as a model for hiv. Curr. HIV Res., v. 1, p. 15-29, 2003.

[90] MEnOtTI-RAYMOND, M.; O'BRIEN, S. J. (Eds.). The domestic cat, felis catus, as a model of hereditary and infectious disease. Totowa: P. M. Conn Humana Press, 2008.

[91] HUPPERT, F.; WILCOCK, G. Ageing, cognition and dementia. Age Ageing S4, p. 20-23, 1997.

[92] ADAMS, B.; CHAN, A.; CALlAHAN, H.; MILGRAM, N. W. The canine as a model of human cognitive aging: recent developments. Biol. Psychiat., v. 24, p. 675-692, 2000.

[93] ERICKSON, C. A.; BARNES, C. A. The neurobiology of memory changes in normal aging. Exp. Gerontol, v. 38, p. 61-69, 2003.

[94] GUNn-MOORE, D. A.; MCVEE, J.; BRADSHAW, J. M.; PEARSON, G. R.; HEAD, E.; GUNN-MOORE, F. J. Ageing changes in cat brains demonstrated by B-amyloid and at8-immunoreactive phosphorylated tau deposits. J. Feline Med. Surg., v. 8, p. 234-242, 2006.

[95] ELLIS, S.; WELLS, D. L. The influence of visual stimulation on the behavior of cats housed in a rescue shelter. Applied Animal Behaviour Science, v. 113, p. 166-174, 2008.

[96] MARTIN, P.; BATESON, P. (Eds.). Measuring behaviour an introductory guide. Cambridge: Cambridge University Press, 1986.

[97] BARRY, K. J.; CROWELL-DAVIS, S. L. Gender differences in the social behavior of the neutered indoor-only domestic cat. Applied Animal Behaviour Science, v. 64, p. 193-211, 1999.

[98] APPLEBY, M.; WARAN, N. (Eds.). Physical conditions. Cab International, 1997.

[99] CAWS, C. E.; WEHNELT, S.; AURELI, F. The effect of a new vertical structure in mitigating aggressive behaviour in a large group of chimpanzees (pan troglodytes ) .

[100] QUIRKE, T.; ORIORDAN, M. R.; ZUUR, A. Factors influencing the prevalence of stereotypical behaviour in captive cheetahs (acinonyx jubatus). Applied Animal Behaviour Science, v. 142, p. 189-197, 2012. 
[101] VAN DE WEERD, H. A.; DAY, J. E. L. A review of environmental enrichment for pigs housed in intensive housing systems. Appl. Anim. Behav. Sci., v. 116, p. 1-20, 2009.

[102] FITZGERALD, M. B.; TURNER, D. (Eds.). Hunting behaviour of domestic cats and their impact on prey populations. Cambridge: Cambridge University Press, 2000 .

[103] DURR, R.; SMITH, C. Individual differences and their relation to social structure in domestic cats. Journal of Comparative Psychology, v. 111, n. 4, p. 412-418, 1997.

[104] CROWELL-DAVIS, S. L.; CURTIS, T. M.; KNOWLES, R. J. Social organization in the cat: A modern understanding. Journal of Feline Medicine Surgery, v. 6, n. 1, p. 19-28, 2004.

[105] BASHAW, M. J. To hunt or not to hunt? a feeding enrichment experiment with captive large felids. Zoo Biology, v. 22, n. 2, p. 189-198, 2003.

[106] DAWKINS, M. S. Battery hens name their price: consumer demand theory and the measurement of ethological needs. Animal Behaviour, v. 31, p. 1195-1205, 1983.

[107] DAWKINS, M. S. From an animal's point of view: motivation, fitness and animal welfare (with commentaries). Behavioural Brain Science, v. 13, p. 1-61, 1990.

[108] FRASER, D.; MATTHEWS, L. R. (Eds.). Preference and motivation testing. Wallingford, UK: CAB International, 1997.

[109] GalHaRDO, L.; ALMEIDA, O.; OLIVEIRA, R. F. Preference for the presence of substrate in male cichlid fish: effects of social dominance and context. Appl. Anim. Behav., v. 120, p. 224-230, 2009.

[110] KIRKDEN, R. D.; PAJOR, E. A. Using preference, motivation and aversion tests to ask scientific questions about animals feelings. Appl. Anim. Behav. Sci., v. 100, p. 29-47, 2006.

[111] LEHNER, P. N. (Ed.). Handbook of ethological methods. Cambridge: Cambridge University Press, 1996.

[112] ELLIS, S.; WELLS, D. L. The influence of olfactory stimulation on the behavior of cats housed in a rescue shelter. Appl. Anim. Behav. Sci., v. 123, p. 56-62, 2010.

[113] MASON, G. J. Stereotypes: a critical review. Anim. Behav., v. 41, p. 1015, 1991.

[114] ROSIER, L. R.; LANGKILDE, T. Does environmental enrichment really matter? a case study using the eastern fence lizard (sceloporus undulatus). Applied Animal Behaviour Science, v. 131, p. 71-76, 2011.

[115] WELLS, D. L.; EGLI, J. M. The influence of olfactory enrichment on the behaviour of blackfooted cats (felis nigripes). Applied Animal Behaviour Science, v. 85, n. 1, p. 107-119, 2004. 
[116] BERGMAN, T. J.; KITCHEN, D. M. Comparing responses to novel objects in wild baboons (papio ursinus) and geladas (theropithecus gelada). Animal Cognition, v. 12 , p. $63-73,2009$.

[117] MOTA, M. C.; REIS, N. R. Elaboração de um catálogo comportamental de gatodo-matopequeno, (leopardus tigrinus) (schreber, 1775) (carnivora: Felidae) em cativeiro. Biota Neotropica, v. 9, n. 3, p. 165-171, 2009.

[118] BEAVER, B. V. (Ed.). Feline behavior: A guide for veterinarians. Philadelphia: Saunders, 1992.

[119] BLOKHUIS, H. J. Rest in poultry. Applied Animal Behaviour Science, v. 12, p. 289-303, 1984.

[120] MALlEAU, A. E.; DUNCAN, I. J. H.; WIDOWSKI, T. M.; ATKINSON, J. L. The importance of rest in young domestic fowl. Appl. Anim. Behav. Sci., v. 106, p. 52-69, 2007.

[121] CORnetto, T. L.; ESTEVEZ, I.; DOUGLASS, L. W. Using artificial cover to reduce aggression and disturbances in domestic fowl. Applied Animal Behaviour Science, v. 75, p. 325-336, 2002.

[122] NEWBERRY, R. C.; SHACKLETON, D. M. Use of visual cover by domestic fowl: a venetian blind effect? Animal Behaviour, v. 54, p. 387-395, 1997.

[123] ESTEP, D. Q.; BAKER, S. C. The effects of temporary cover on the behavior of socially housed stump-tailed macaques (macaca arctoides). Zoo Biol., v. 10, p. 465-472, 1991.

[124] WhitTingtON, C. J.; CHAMOVE, A. S. Effects of visual cover on farmed red deer behavior. Applied Animal Behaviour Science, v. 45, p. 309-314, 1995.

[125] SHERWIN, C. M.; LEWIS, P. D.; PERRY, G. C. Effects of environmental enrichment, fluorescent and intermittent lighting on injurious pecking amongst male turkey poults. Appl. Anim. Behav. Sci., v. 62, p. 319-333, 1999.

[126] STELLA, J.; CRONEYA, C.; BUFFINGTON, T. Effects of stressors on the behavior and physiology of domestic cats. Applied Animal Behaviour Science, v. 143, p. 157-163, 2013.

[127] KRY, K.; CASEY, R. The effect of hiding enrichment on stress levels and behaviour of domestic cats (felis silvestris catus).

[128] NICOL, C. J.; CAPLEN, G.; EDGAR, J.; BROWNE, W. J. Associations between welfare indicators and environmental choice in laying hens. Animal Behaviour, v. 78, n. 2, p. 413-424, 2009.

[129] HALL, S. L.; BRADSHAW, J. W. S.; ROBINSON, I. H. Object play in adult domestic cats: the roles of habituation and disinhibition. Applied Animal Behaviour Science, v. 79, n. 3, p. 236-271, 2002.

[130] WELLS, D. L. Sensory stimulation as environmental enrichment for captive animals: A review. Applied Animal Behaviour Science, v. 118, n. 1-2, p. 1-11, 2009. 
[131] GUY, H.; MEADS, A. Z.; SHIEL, S. R.; EDWARDS, A. S. The effect of combining different environmental enrichment materials on enrichment use by growing pigs. Applied Animal Behaviour Science, v. 144, p. 102-107, 2013.

[132] BRACKE, M. B. M.; SPOOLDER, H. A. M. Novel object test can detect marginal differences in environmental enrichment in pigs. Applied Animal Behaviour Science, v. 109, n. 1, p. 39-48, 2007.

[133] ZIMMERMANN, M.; STAUFFACHER, W.; LANGHANS, W. Enrichmentdependent differences in novelty exploration in rats can be explained by habituation. Behavioral Brain Research, v. 121, n. 1-2, p. 11-20, 2001.

[134] WESTERATH, H. S.; LAISTER, S.; WINCKLER, C. Exploration as an indicator of good welfare in beef bulls: An attempt to develop a test for on-farm assessment. Applied Animal Behaviour Science, v. 116, n. 2, p. 126-133, 2009.

[135] VERBEEK, M. E. M.; DRENT, P. J.; WIEPKEMA, P. R. Consistent individual differences in early exploratory behaviour of male great tits. Animal Behaviour, v. 48, n. 5, p. 1113-1121, 1994.

[136] RAMOS, D.; ARENA, N. M.; RECHE-JUNIOR, A.; DANIEL, T. G. A.; ALBINO, C. V. M.; VASCONCELLOS, S. A.; VIAU, P.; OLIVEIRA, A. C. Factors affecting faecal glucocorticoid levels in domestic cats (felis catus): a pilot study with single and large multi-cat households. Animal Welfare, v. 21, p. 285-291, 2012.

[137] KERBY, G.; MACDONALD, D. W. (Eds.). Cat society and the consequences of colony size. Cambridge: Cambridge University Press, 1988.

[138] PRYOR, P. A.; HART, B. L.; BAIN, M. J.; CLIFF, K. D. Causes of urine marking in cats and effects of environmental management on frequency of marking. Journal of the American Veterinary Medical Association, v. 219, n. 12, p. 1709-1713, 2001.

[139] MACDONALD, D. W.; APPS, P. J. The social behaviour of a group of semidependent farm cats, felis catus: a progress report. Carniv. Genet. Newsl., v. 3, p. 256-268, 1978.

[140] SMITH, D. F. E.; DURMAN, K. J.; ROY, D. B.; BRADSHAW, J. W. S. Behavioural aspects of the welfare of rescued cats. J. Fel. Advis. Bur., v. 28, p. 31-25, 1994. 